\author{
UNIVERSIDADE DE SÃO PAULO \\ FACULDADE DE CIÊNCIAS FARMACÊUTICAS \\ Programa de Pós-Graduação em Ciências dos Alimentos \\ Área de Nutrição Experimental
}

\begin{abstract}
Influência dos polimorfismos Pro198Leu, -602A/G e Arg5Pro na atividade da enzima glutationa peroxidase e no estado nutricional de indivíduos adultos com relação ao selênio
\end{abstract}

Kaluce Gonçalves de Sousa Almondes

São Paulo 


\author{
UNIVERSIDADE DE SÃO PAULO \\ FACULDADE DE CIÊNCIAS FARMACÊUTICAS \\ Programa de Pós-Graduação em Ciências dos Alimentos \\ Área de Nutrição Experimental
}

\begin{abstract}
Influência dos polimorfismos Pro198Leu, -602A/G e Arg5Pro na atividade da enzima glutationa peroxidase e no estado nutricional de indivíduos adultos com relação ao selênio
\end{abstract}

\author{
Kaluce Gonçalves de Sousa Almondes \\ Versão corrigida da Dissertação/Tese conforme resolução CoPGr 6018. \\ O original encontra-se disponível no Serviço de Pós Graduação da FCF/USP. \\ Tese para obtenção do grau de \\ DOUTOR \\ Orientadora: \\ Profa Titular Silvia Maria Franciscato Cozzolino
}

São Paulo 
Ficha Catalográfica

Elaborada pela Divisão de Biblioteca e Documentação do Conjunto das Químicas da USP.

Almondes, Kaluce Gonçalves de Sousa

A452i Influência dos polimorfismos Pro198Leu,-602A/G e Arg5Pro na atividade da enzima glutationa peroxidase e no estado nutricional de indivíduos adultos com relação ao selênio / Kaluce Gonçalves de Sousa Almondes. -- São Paulo, 2015.

$121 \mathrm{p}$.

Tese (doutorado) - Faculdade de Ciências Farmacêuticas da Universidade de São Paulo. Departamento de Alimentos e Nutrição Experimental

Orientador: Cozzolino, Silvia Maria Franciscato

1. Nutrição experimental : Ciência dos alimentos 2. Selênio 3. Polimorfismo 4. Estresse oxidativo I. T. II. Cozzolino, Silvia Maria Franciscato, orientador.

$641.1 \quad$ CDD 


\title{
Influência dos polimorfismos Pro198Leu, -602A/G e Arg5Pro na atividade da enzima glutationa peroxidase e no estado nutricional de indivíduos adultos com relação ao selênio
}

\author{
Comissão Julgadora \\ da \\ Tese para obtenção do Título de Doutor
}

Profa Titular Silvia Maria Franciscato Cozzolino

Orientadora/Presidente

$1^{\circ}$ Examinador

$2^{\circ}$ Examinador

$3^{\circ}$ Examinador

$4^{\circ}$ Examinador

São Paulo, de de 2015. 


\section{DEDICATÓRIA}

Aos meus pais Francisco e Francisca Almondes, ao meu irmão Jardel Almondes e ao meu marido Flávio Sousa por todo amor, carinho, dedicação e incentivo em todos os momentos da minha vida. 


\section{AGRADECIMENTOS}

À Deus por ter me guiado pelos melhores caminhos ajudando-me a conquistar os meus sonhos, iluminado meus pensamentos em cada momento de dificuldades e me dado coragem para seguir sempre em frente.

À professora Silvia Maria Franciscato Cozzolino, minha orientadora, que me recebeu de braços abertos para a realização deste doutorado, compartilhou comigo suas experiências e sempre acreditou que ia dar tudo certo.

À professora Nadir do Nascimento Nogueira que guiou os meus primeiros passos na pesquisa científica, me incentivando a ir cada vez mais longe, e deu todo o suporte necessário para as etapas da pesquisa realizadas no Laboratório de Nutrição Experimental da UFPI.

À professora Dilina Marreiro pelo profissionalismo exemplar, motivo de grande admiração, e também pelo suporte necessário às etapas da pesquisa realizadas no Laboratório de Nutrição Experimental da UFPI.

Ao corpo docente do Programa de Pós-graduação em Ciências dos Alimentos da FCF/USP, pelos conhecimentos transmitidos.

Aos participantes da pesquisa que realizaram cada etapa com muita disponibilidade, possibilitando a realização deste trabalho.

Aos meus pais Francisco e Francisca Almondes, e irmão, Jardel Almondes, por serem meu suporte, apoiarem minhas decisões, torcer pelos meus sonhos e serem meus exemplos de caráter, humildade e amor.

Ao meu marido Flávio Sousa, pelo amor, carinho, dedicação, paciência, palavras de conforto, conversas científicas de grande valor, por me fazer sentir confiança em mim mesma e estar sempre o meu lado.

À minha amiga irmã e exemplo de determinação, Vivianne Rocha, que foi uma grande parceira da vida em SP, tornando os meus dias mais felizes.

À minha família, tios, primos, avós por toda a força, incentivos, carinho e confiança.

Às amigas Heila Dias, Sueli Teixeira e Kyria Jayanne que foram além de parceiras de coleta de dados, pois construímos ou reforçamos uma linda amizade no período inicial da pesquisa.

Às amigas do laboratório de Nutrição-Minerais - FCF/USP: Graziela Biude, Bruna Zavarize, Kátia Callou, Bárbara Cardoso, Ariana Rocha, Janaína Lombello, Larissa Bezerra, Isabela Saraiva, Liliani Pires, Leila Hashimoto, Verônica Bandeira e Luciane Alencar pelo apoio nos momentos dos experimentos ou coletas, pelas trocas de experiências, revisões de textos, diversões "extra-laboratório" e convivência tão agradável que tornaram as atividades do laboratório menos cansativas e cada vez mais divertidas e prazerosas. 
Um agradecimento especial à Kátia Callou e Graziela Biude, por serem minhas irmazinhas de coração e se fazerem sempre presentes com muita alegria.

À José Alexandre Coelho Pimentel, técnico do Laboratório de Nutrição-Minerais da FCF/USP, pelo apoio durante as análises, pelo entusiasmo na transmissão do seu conhecimento e por ter se mostrado sempre disponível para ajudar no que precisasse.

Aos amigos Ernesto Vargas e Leandro Garcia pelas trocas de experiências e ajudas com a estatística.

Aos alunos de iniciação científica da USP - Vanessa e Rafael, e da UFPI Ana Karoline, Ágata Carvalho, Vanessa Brito, Lívia França, Jordana Rayane, Karine Fernandes, Larisse Monteiro, Larissa Fontenele, Ianamara Borges, Lana Lima, Denise Pinto e Elise Saffnauer pelo apoio durante o período de coletas e análises, pelo prazer de me deixarem ensiná-los o que já aprendi e por tornar o ambiente do laboratório muito mais alegre.

Aos amigos da pós-graduação: Cristiane Hermes, Fabiana Araújo, Ana Raquel Oliveira, Fernanda Santana, Fernanda Shinagawa, Ana Mara Silva, Ana Lina, Lucília Rabelo, Leonardo Torres, Emídio Matos, Roberto Yamamoto, Jaqueline Leite, Pryscila Teixeira, Eduardo De Carli, Alexandre Lobo, Kelly Silva, Vanessa Lima, Kelcylene Gomes, Luciana Nishimura, Mayara, Aline, Raquel, Luiza Guido, Juliana Ortega e Ilana Louise por compartilharem dos mesmos sonhos.

Aos amigos da pensão que morei em SP: Vivianne Rocha, Marcelo Victor, Kátia Callou, Tamires Bizarro, Tiago Cerqueira, Dayves Augusto, Isa dos Anjos, Cristiane Vieira, Othon Campos, Diane Rossetto, Jorge Torrejón, Leandro Montalvão, Normando Peres e Tatiane Moreira, por terem se tornado minha família de SP, compartilhado alegrias e dificuldades do dia-a-dia e aprendizados de uma pós-graduação.

Aos técnicos e funcionários do bloco 14 - FCF/USP, em especial à Lurdes Pedrosa, Rosângela Paiva, Ivanir Pires, Edilson Feitosa, Mônica Perussi, Cleonice Estrela, Roberta Uerara, Elaine Midori, Jorge de Lima, Irineu e Miriam.

À equipe técnica administrativa e professoras do Departamento de Nutrição da UFPI, especialmente às professoras Socorro Alencar, Apolônia Nogueira e Regilda MoreiraAraújo pelo auxílio durante as coletas de dados.

Aos professores Regina Célia, do Departamento de Bioquímica da UFPI, pelo apoio com as análises de perfil lipídico, e Francisco Teixeira, do Departamento de Fiologia da UFPI, pelo auxílio com a coleta de dados de bioimpedância.

À professora Ana Paula Loureiro e Tiago Oliveira do Departamento de Análises Clínicas e Toxicológicas da FCF/USP pela colaboração nas análises de malondialdeído.

Ao Hospital Universitário da UFPI pelo apoio com as análises de perfil lipídico.

Ao CNPq pela bolsa de doutorado e taxa de bancada concedidas. 


\section{EPÍGRAFE}

Talvez não tenha conseguido fazer o melhor, mas lutei para que o melhor fosse feito. Não sou o que deveria ser, mas Graças a Deus, não sou o que era antes”.

(Marthin Luther King) 
ALMONDES, K. G. S. Influência dos polimorfismos Pro198Leu, -602A/G e Arg5Pro na atividade da enzima glutationa peroxidase e no estado nutricional de indivíduos adultos com relação ao selênio. 2015. 121p. Tese (Doutorado em Ciências dos Alimentos) - Faculdade de Ciências Farmacêuticas, Universidade de São Paulo, São Paulo. 2015.

\section{RESUMO}

O objetivo deste estudo foi avaliar o estado nutricional relativo ao selênio em indivíduos adultos relacionando-o com polimorfismos no gene da enzima GPx e sua influência sobre a enzima e o balanço redox. Foram selecionados 343 estudantes da Universidade Federal do Piauí entre 20 e 50 anos, de ambos os sexos, selecionados de acordo com critérios de inclusão adotados, como ausência de doenças crônicas não transmissíveis (DCNT) dentre outros. Sangue venoso foi coletado para análise de Se, genotipagem dos SNP da GPx1 (Pro198Leu, -602A/G e Arg5Pro), da atividade das enzimas antioxidantes (GSH-Px e SOD) eritrocitárias, malondialdeído (MDA) e capacidade de absorção de radicais de oxigênio (ORAC) plasmáticas. A análise de Se foi realizada por meio de espectrometria de absorção atômica por geração de hidretos, a genotipagem por PCR em tempo real em Step One Plus, as enzimas em analisador bioquímico automático utilizando kits comerciais, o MDA em cromatografia líquida de alta eficiência e ORAC em um leitor de microplaca. A análise estatística foi realizada por meio do software R 3.0.2. Foram realizados testes de comparação de duas e de mais que três médias entre as variáveis genéticas e os parâmetros de avaliação do Se e do balanço redox. Análises de regressão linear e linear generalizada foram realizadas para identificar a influência das variáveis genéticas, antropométricas, do perfil lipídico e estilo de vida sobre o Se sanguíneo e as variáveis do balanço redox. Os dados foram considerados significativos com p menor que 5\%. A idade média dos participantes foi de 24,4 45,0 anos sendo $57,7 \%$ do sexo feminino. Entre os participantes, 95,7\% eram carreadores do alelo Leu do SNP Pro198Leu e G do -602A/G e não possuíam quantidades mínimas de Se plasmático para otimizar a atividade da GPx. A atividade da GPx foi significativamente mais baixa e de ORAC mais alta nos indivíduos com o genótipo Leu/Leu em relação ao Pro/Pro do SNP Pro198Leu. Os indivíduos com o genótipo Arg/Pro apresentaram atividade da GPx significativamente maior que aqueles com o genótipo Arg/Arg do SNP Arg5Pro. Não houve diferença significativa entre as médias de MDA e SOD e os genótipos dos três SNP. As variáveis genéticas, de avaliação antropométrica, do perfil lipídico e estilo de vida mostraram influência sobre os marcadores do balanço redox, alterando o perfil antioxidante dos participantes. Os indivíduos são deficientes em Se e aqueles com o alelo Leu do SNP Pro198Leu apresentam em seu organismo maior concentração de ORAC, provavelmente para proteção contra radicais livres. O alelo variante do SNP Arg5Pro mostrou-se benéfico para o estado nutricional relativo ao Se.

Palavras-chave: selênio, glutationa peroxidase, Pro198Leu, -602A/G, Arg5Pro, estresse oxidativo 
ALMONDES, K. G. S. Influence of polymorphisms Pro198Leu, -602A/G and Arg5Pro in the glutathione peroxidase enzyme activity and at the nutritional status of adult individuals with respect to selenium. 2015. 121p. Thesis ( $\mathrm{PhD}$ in Food Sciences) Faculty of Pharmaceutical Science, University of São Paulo, São Paulo, 2015.

\begin{abstract}
The aim of this study was to evaluate the nutritional status relative to Se of adult individuals relating it to polymorphisms in the GPx enzyme gene and its influence on the enzyme and the redox balance. We selected 343 students of the Federal University of Piauí between 20 and 50 years, of both genders, selected according to inclusion criteria, such as the absence of chronic noncommunicable diseases (NCD) among others. Venous blood was collected for analysis of Se, genotyping of SNP of GPx1 (Pro198Leu, -602A / G and Arg5Pro), the activity of antioxidant enzymes (GSH-Px and SOD) erythrocyte, malondialdehyde (MDA) and absorption capacity of plasma oxygen radicals (ORAC). The analysis of Se was performed by atomic absorption spectrometry through hydride generation, genotyping by real time PCR in Step One Plus, enzymes in automatic biochemical analyzer by the use of commercial kits, MDA analysis was conducted in high-performance liquid chromatography and ORAC in a microplate reader. Statistical analysis was obtained using the software $\mathrm{R}$ version 3.0.2. Comparison tests were performed with two and more than three averages between the genetic variables and the evaluation parameters from $\mathrm{Se}$ and redox balance. Linear regression analysis and generalized linear were carried out to identify the influence of genetic variables, anthropometric, lipid profile and lifestyle on the sanguine Se and the variables of the redox balance. Data were considered significant for $\mathrm{p}$ less than $5 \%$. The average age of participants was $24.4 \pm 5.0$ years and $57.7 \%$ were female. Among the participants, $95.7 \%$ were allele carriers Leu of SNP Pro198Leu and G of $-602 \mathrm{~A} / \mathrm{G}$, and they did not have minimal amounts of Se plasma to optimize the activity of GPx. The GPx activity was significantly lower and that of ORAC was higher in subjects with the Leu/Leu genotype compared to Pro/Pro of SNP Pro198Leu. Individuals with the Arg/Pro genotype had GPx activity significantly higher than those with genotype Arg/Arg of SNP Arg5Pro. There was no significant difference between the means of MDA and SOD of the genotypes of the three SNP. The genetic variables, anthropometric measurements, lipid profile and lifestyle showed influence on markers of redox balance by changing the antioxidant profile of the participants. Individuals are deficient in Se, and those with the Leu allele of SNP Pro198Leu present in their bodies highest concentration of ORAC, probably to protect against free radicals. The variant allele of the SNP Arg5Pro proved to be beneficial to the nutritional status of the Se.
\end{abstract}

Keywords: selenium, glutathione peroxidase, Pro198Leu, -602A / G, Arg5Pro, oxidative stress 


\section{LISTA DE FIGURAS}

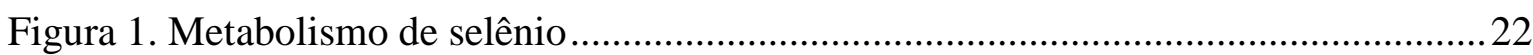

Figura 2. Mecanismo da biossíntese de selenocisteína....................................................23

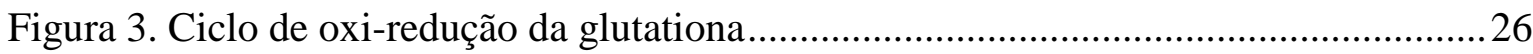

Figura 4. Concentrações plasmáticas e eritrocitárias de $\mathrm{Se}(\mu \mathrm{g} / \mathrm{L})$ de indivíduos adultos nos Estados do Ceará, São Paulo, Amazonas e Rondônia ........................................................... 31

Figura 5. Distribuição dos indivíduos adultos segundo a adequação da ingestão dos macronutrientes de acordo com a recomendação da distribuição em percentual da energia

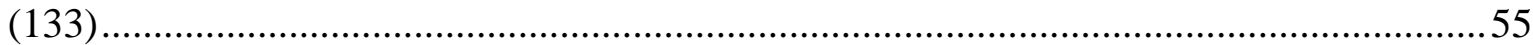




\section{LISTA DE TABELAS}

Tabela 1. Distribuição dos indivíduos adultos do estado do Piauí segundo os aspectos socioeconômicos e clínicos

Tabela 2. Medidas de tendência central e dispersão das variáveis idade, antropometria e perfil lipídico de indivíduos adultos do estado do Piauí

Tabela 3. Ingestão alimentar de selênio ( $\mu \mathrm{g} /$ dia) dos indivíduos adultos do estado do Piauí segundo o sexo.

Tabela 4. Distribuição dos indivíduos adultos do estado do Piauí de acordo com os genótipos dos polimorfismos Pro198Leu, -602A/G e Arg5Pro da GPx1....

Tabela 5. Medidas de tendência central e dispersão das concentrações de Se plasmático, eritrocitário e urinário dos indivíduos adultos do estado do Piauí de acordo com os genótipos dos SNP Pro198Leu, -602A/G e Arg5Pro

Tabela 6. Modelos de regressão linear múltiplo para as variáveis dependentes Se plasmático e Se eritrocitário dos indivíduos adultos do estado do Piauí .....

Tabela 7. Medidas de tendência central e dispersão dos marcadores do balanço redox de indivíduos saudáveis adultos do estado do Piauí de acordo a presença dos polimorfismos Pro198Leu, -602A/G e Arg5Pro da GPx1 60

Tabela 8. Modelos de regressão linear univariado para a variável dependente GPx dos indivíduos adultos do estado do Piauí.

Tabela 9. Modelos de regressão linear múltiplo para a variável dependente GPx dos indivíduos adultos do estado do Piauí.

Tabela 10. Modelos de regressão linear generalizado para a variável dependente SOD dos indivíduos adultos do estado do Piauí.

Tabela 11. Modelos de regressão linear múltiplo para a variável dependente ORAC dos indivíduos adultos do estado do Piauí.

Tabela 12. Modelos de regressão linear múltiplo para a variável dependente MDA dos indivíduos adultos do estado do Piauí. 


\section{LISTA DE QUADROS}

Quadro 1. Classificação das medidas antropométricas.

Quadro 2. Classificação das medidas de perfil lipídico de acordo com a Sociedade

46

Quadro 3. Frequência dos alelos e genótipos do polimorfismo Pro198Leu da GPx1 observados em diversas populações 


\section{LISTA DE SIGLAS E ABREVIATURAS}

\begin{tabular}{|c|c|}
\hline A & Adenina \\
\hline AAPH & 2,2'-azobis (2-methylpropionamidine) dihydrocloride \\
\hline ADP & Adenosina Difosfato \\
\hline AMP & Adenosina Monofosfato \\
\hline Arg & Arginina \\
\hline ATP & Adenosina trifosfato \\
\hline AUG & Códon para metionina \\
\hline CEP & Comitê de Ética e Pesquisa \\
\hline $\mathrm{C}$ & Citosina \\
\hline $\mathrm{CC}$ & Circunferência da cintura \\
\hline $\mathrm{CT}$ & Colesterol Total \\
\hline DCNT & Doença crônica não transmissível \\
\hline $\mathrm{DIO}$ & Iodotironina deiodinase \\
\hline DMS & Dimetilselenido \\
\hline DNA & Ácido desoxiribonucléico \\
\hline DNPH & Dinitrofenilhidrazina \\
\hline DRI & Ingestão dietética de referência \\
\hline EAR & Necessidade média estimada \\
\hline EDTA & Ácido etilenodiamino tetra-acético \\
\hline eEFSec & Fator de elongação de tradução para inserção de selenocisteína \\
\hline EER & Necessidade estimada de energia \\
\hline ERN & Espécie Reativa de Nitrogênio \\
\hline ERO & Espécie Reativa de Oxigênio \\
\hline FCF & Faculdade de Ciências Farmacêuticas \\
\hline FNB & Food and Nutrition Board \\
\hline $\mathrm{Fe}^{2+}$ & Forma ferrosa do ferro \\
\hline $\mathrm{Fe}^{3+}$ & Forma férrica do ferro \\
\hline G & Guanina \\
\hline GC & Gordura corporal \\
\hline GGSeMSec & Metilselenocisteína \\
\hline GG-Se-SG & Selenodiglutationa \\
\hline GPx & Glutationa peroxidase \\
\hline GSH & Glutationa reduzida \\
\hline GSSG & Glutationa oxidada \\
\hline $\mathrm{Hb}$ & Hemoglobina \\
\hline HCL & Cloreto de hidrogênio \\
\hline HDL & Lipoproteína de alta densidade \\
\hline HGQTAAS & $\begin{array}{l}\text { Espectrometria de absorção atômica por geração de hidretos acoplada à cela de } \\
\text { quartzo }\end{array}$ \\
\hline
\end{tabular}




\begin{tabular}{|c|c|}
\hline HPLC & Cromatografia líquida de alta eficiência \\
\hline $\mathrm{HSe}^{-}$ & Selenido \\
\hline $\mathrm{H}_{2} \mathrm{SePO}_{3}^{-}$ & Selenofosfato \\
\hline $\mathrm{H}_{2} \mathrm{O}_{2}$ & Peróxido de hidrogênio \\
\hline IMC & Índice de massa corporal \\
\hline IME & Instituto de Matemática e Estatística \\
\hline IOM & Institute of Medicine \\
\hline LDL & Lipoproteína de baixa densidade \\
\hline Leu & Leucina \\
\hline MDA & Malondialdeído \\
\hline Met & Metionina \\
\hline MSe & Monometilselenido \\
\hline mRNA & Ácidos ribonucléicos mensageiros \\
\hline $\mathrm{NADH}^{+}$ & Nicotinamida adenina dinucleotídeo \\
\hline NADPH & Nicotinamida adenina dinucleotídeo fosfato \\
\hline NF-kB & Fator nuclear kappa B \\
\hline OMS & Organização Mundial de Saúde \\
\hline ORAC & Capacidade de absorção de radicais de oxigênio \\
\hline PA & Pureza analítica \\
\hline POF & Pesquisa de Orçamentos Familiares \\
\hline Pro & Prolina \\
\hline PSTK & Fosfoseril tRNA quinase \\
\hline RDA & Ingestão dietética recomendada \\
\hline $\mathrm{rpm}$ & Rotações por minuto \\
\hline RT-PCR & Reação em cadeia da Polimerase em Tempo Real \\
\hline SBP2 & Proteína de ligação ao SECIS 2 \\
\hline SECIS & Sequência de inserção de selenocisteína \\
\hline $\mathrm{Se}$ & Selênio \\
\hline $\mathrm{Se}^{0}$ & Selênio metálico \\
\hline SeAlb & Selenoalbumina \\
\hline $\mathrm{Sec}$ & Selenocisteína \\
\hline $\mathrm{SecS}$ & Selenocisteína sintetase \\
\hline SeMet & Selenometionina \\
\hline SeMSec & Selenometilselenocisteína \\
\hline SelP & Selenoproteína P \\
\hline Se-PAPS & 3-fosfoadenosina 5-fosfossulfato \\
\hline Se-Php & Selenofosfato \\
\hline $\mathrm{SeO}_{3}{ }^{2-}$ & Selenito \\
\hline $\mathrm{SeO}_{4}{ }^{2-}$ & Selenato \\
\hline Ser & Serina \\
\hline SerS & Seril-tRNA sintetase \\
\hline SOD & Superóxido dismutase \\
\hline SPS2 & Selenofosfato sintetase 2 \\
\hline
\end{tabular}




$\begin{array}{ll}\text { SNP } & \text { Polimorfismo de um único nucleotídeo } \\ \text { T } & \text { Timina } \\ \text { TACO } & \text { Tabela de Composição de Alimentos } \\ \text { TCLE } & \text { Termo de Consentimento Livre e Esclarecido } \\ \text { TG } & \text { Triglicerídeos } \\ \text { TMSe } & \text { Trimetilselenido } \\ \text { tRNA } & \text { Ácido ribonucléico transportador } \\ \text { TrxR } & \text { Tioredoxina redutase } \\ \text { UGA } & \text { stop codon ou códon de parada } \\ \text { UFPI } & \text { Universidade Federal do Piauí } \\ \text { UNICAMP } & \text { Universidade Estadual de Campinas } \\ \text { USP } & \text { Universidade de São Paulo }\end{array}$




\section{SUMÁRIO}

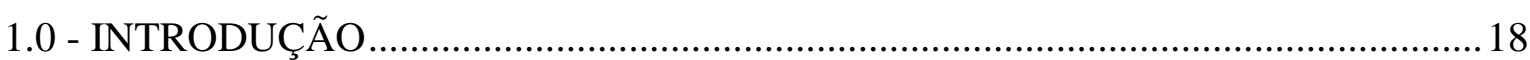

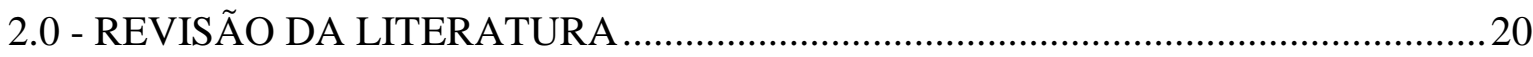

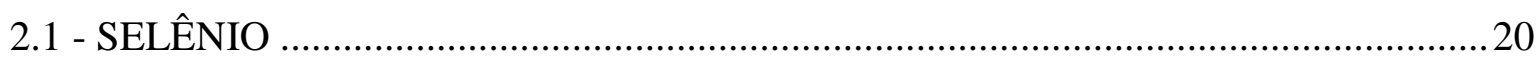

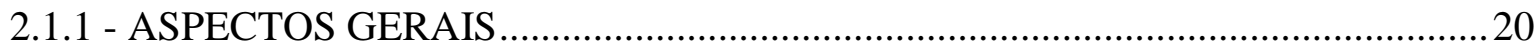

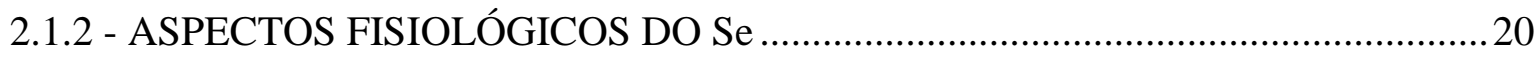

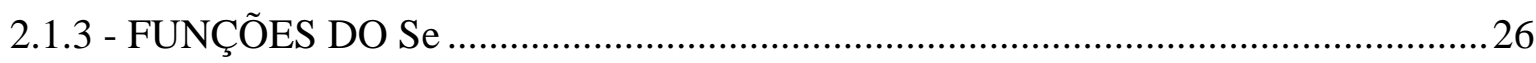

2.1.4 - FONTES, RECOMENDAÇÕES, DEFICIÊNCIA E EXCESSO ............................2 28

2.1.5 AVALIAÇÃO DA CONCENTRAÇÃO DE Se SANGUÍNEO …….........................29

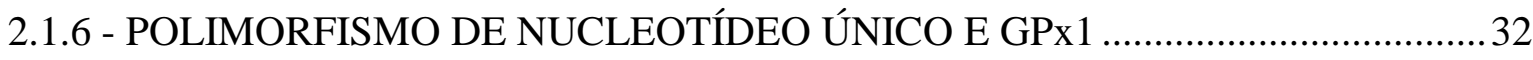

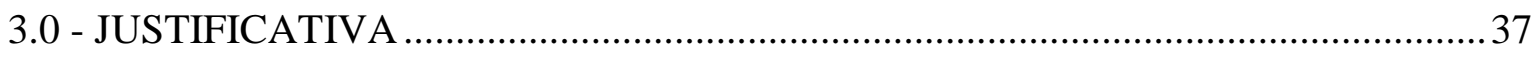

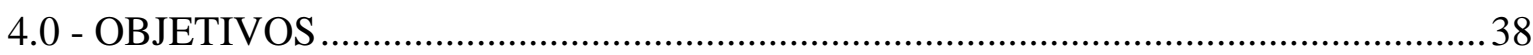

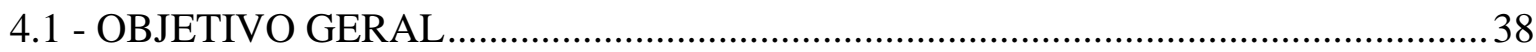

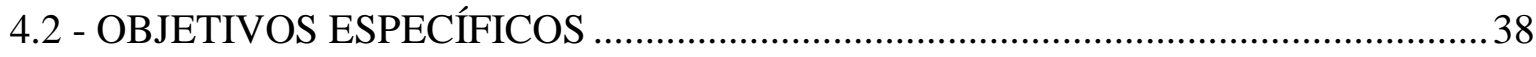

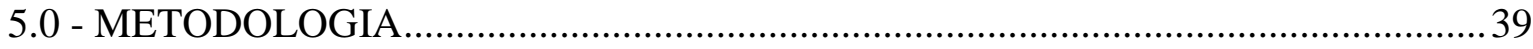

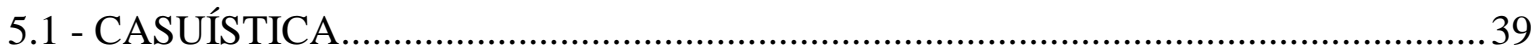

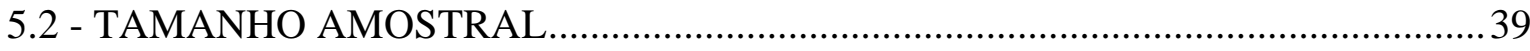

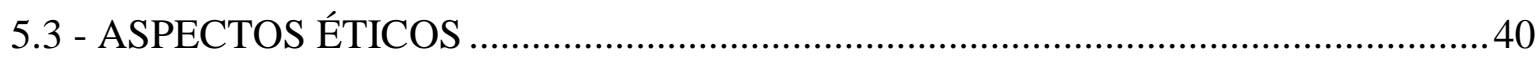

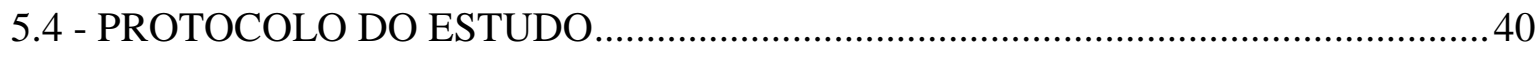

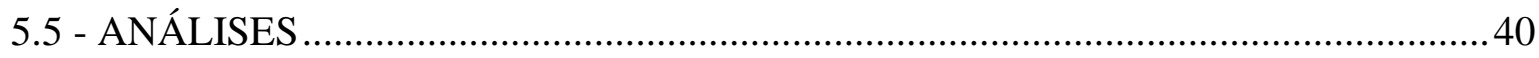

5.5.1 - AVALIAÇÃO DO CONSUMO ALIMENTAR ................................................ 40

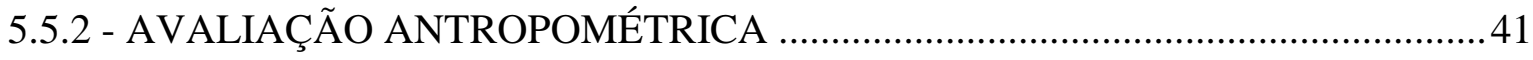

5.5.3 - COLETA E PROCESSAMENTO DE SANGUE E URINA ................................... 43

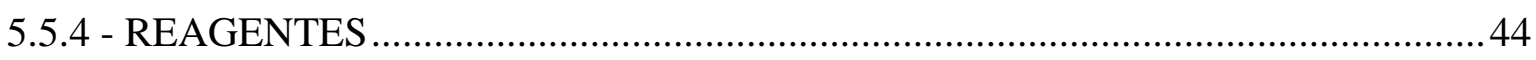

5.5.5 - CONTROLE DE CONTAMINAÇÃO ............................................................. 44

5.5.6 - DETERMINAÇÃO DA CONCENTRAÇÃO Se SANGUÍNEO E URINÁRIO .... 44 
5.5.8 - DETERMINAÇÃO DOS POLIMORFISMOS Pro198Leu, -602A/G e Arg5Pro DA ENZIMA GPx1.

5.5.9 - DETERMINAÇÕES DOS PARÂMETROS LIPÍDICOS 46

5.5.10 - AVALIAÇÃO DO BALANÇO REDOX 46

5.5.10.1 - DETERMINAÇÃO DA CONCENTRAÇÃO PLASMÁTICA DE MDA 46

5.5.10.2 - DETERMINAÇÃO DA ATIVIDADE DA ENZIMA GPX 47

5.5.10.3 - DETERMINAÇÃO DA ATIVIDADE DA ENZIMA SOD 48

5.5.10.4 - DETERMINAÇÃO DA CAPACIDADE DE ABSORÇÃO DE RADICAIS DE

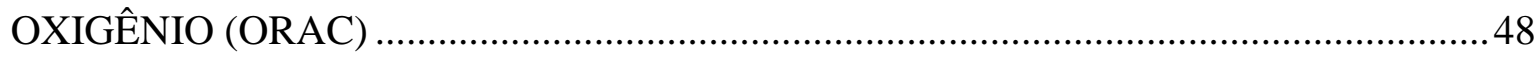

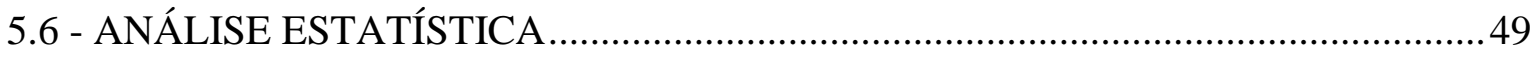

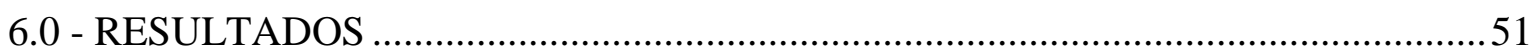

6.1 - CARACTERIZAÇÃO DA POPULAÇÃO ............................................................... 51

6.1.1 - DADOS SOCIOECONÔMICOS E CLÍNICOS .................................................. 51

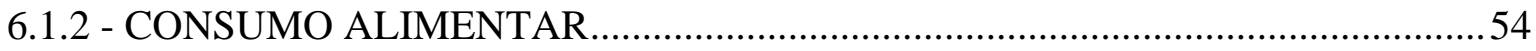

6.1.3 - GENOTIPAGEM DOS POLIMORFISMOS Pro198Leu, -602A/G e Arg5Pro DA

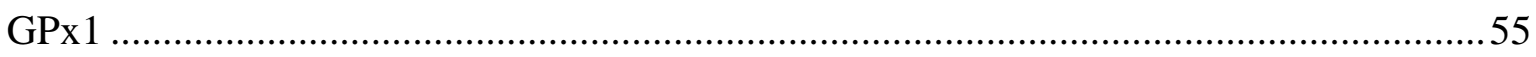

6.3 - MARCADORES BIOQUÍMICOS DO ESTADO NUTRICIONAL DE Se ...............57

6.4 - PARÂMETROS DE AVALIAÇÃO DO BALANÇO REDOX ……...........................59

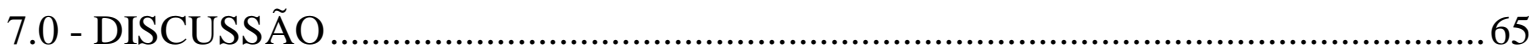

7.1 - GENOTIPAGEM DOS POLIMORFISMOS Pro198Leu, -602A/G e Arg5Pro DA

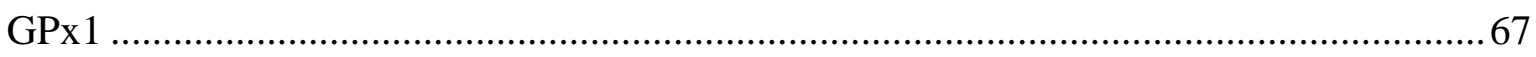

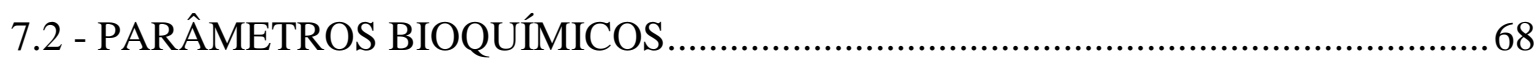

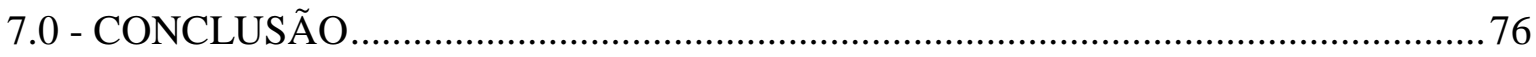

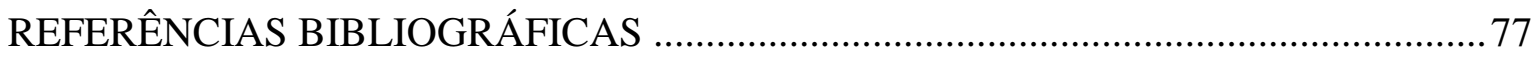

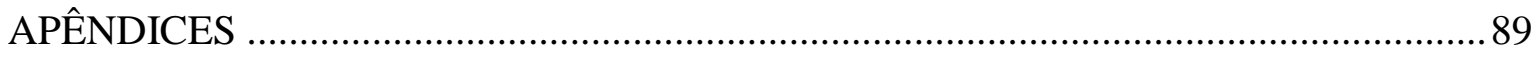

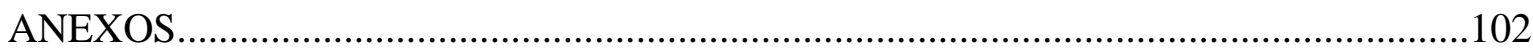




\section{0 - INTRODUÇÃO}

O selênio ( $\mathrm{Se}$ ) é um mineral essencial para o organismo humano. Seu nome vem do grego selene, que significa lua. Atribuiu-se este nome ao elemento porque tem características químicas semelhantes ao telúrio, que em grego significa terra (1). O Se é um metalóide pertencente ao mesmo grupo da tabela periódica dos elementos oxigênio, enxofre e telúrio, e é similar ao enxofre em propriedades químicas, diferindo deste durante o metabolismo corporal (2).

A concentração do Se presente no solo é influenciada por fatores relacionados ao $\mathrm{pH}$, ao tipo de rocha, à pluviosidade e ao uso de fertilizantes. O mineral tende a ser mais concentrado em solos de regiões secas, os quais são geralmente mais alcalinos. Já em regiões mais úmidas, a lixiviação pelas chuvas costuma influenciar na retirada de Se do solo. Em regiões de solos ácidos mais arejados, o mineral costuma encontrar-se indisponível para captação pelas plantas, por estar presente em forma de complexos de selenito insolúveis $(3,4)$.

Alimentos que contêm Se podem apresentar diferenças da ordem de dez vezes no seu teor, que depende do conteúdo do mineral no solo onde o animal é criado ou o vegetal cresce. Isso acontece devido a diferente forma de metabolização do mineral por vegetais ou animais. Os vegetais não necessariamente exigem Se em seu metabolismo, sendo que este ocorre por meio das vias de enxofre na qual o Se pode substitui-lo. As formas mais comuns de Se nos vegetais são selenometionina, selenocisteína ou metabólitos. Ao contrário dos vegetais, os animais necessitam deste mineral. Carnes e frutos do mar contêm o elemento na sua forma funcional como selenoproteínas. Praticamente todas as proteínas animais contêm selenometionina obtida quando o animal consome Se a partir de plantas. Isto significa que o conteúdo de Se da carne depende em grande parte, do consumo de selenometionina do animal (5).

O Se tem importante papel na formação de hormônios da tireoide, síntese de DNA, funções musculares, fertilidade, reprodução (6), proteção ao DNA, do estresse oxidativo, da inflamação, destoxificação, melhora da resposta imune, aumento da expressão da proteína supressora de tumor p53, inativação da proteína $\mathrm{C}$ quinase, modulação na metilação do DNA, controle do ciclo celular, indução da apoptose de células cancerígenas e inibição da angiogênese (7). 
As doenças crônicas não transmissíveis (DCNT) têm como fatores de risco, além de características não modificáveis como idade, sexo e predisposição genética, alguns aspectos modificáveis relacionados à transição nutricional, caracterizada pelo excesso na oferta de alimentos ricos em açúcar, sódio e lipídios, e a diminuição da atividade física. A adoção do estilo de vida ocidental, com hábitos como redução do consumo de frutas, verduras e legumes, tabagismo e consumo crônico de álcool tendem a aumentar o risco de DCNT. Nesse contexto, a alimentação destaca-se como o fator ambiental ao qual as pessoas estão continuamente expostas e, dessa forma, caracteriza-se como um dos mais importantes pontos de intervenção com vistas à redução do risco do desenvolvimento de DCNTs $(8,9)$.

O estado nutricional deficiente de Se está relacionado ao aumento do risco de DCNT, uma vez que a manutenção da atividade ótima de selenoproteínas é importante para a prevenção destas doenças (10). Dentre as DCNT destacam-se o diabetes mellitus, em que uma das principais ações deste mineral se dá pela sua função antioxidante (11); as doenças cardiovasculares, concentrações adequadas de Se e atividade normal da glutationa peroxidase fosfolipídio hidroperóxido protegem as células endoteliais dos vasos sanguíneos contra o dano causado pelas lipoproteínas de baixa densidade oxidadas (12); e o câncer, no qual o Se funciona como um agente antimutagênico, prevenindo transformações malignas de células normais (7).

O consumo inadequado de Se e a presença de polimorfismos no gene da GPx1, estão relacionados com redução na atividade dessa enzima, podendo prejudicar o sistema de defesa antioxidante do organismo (13). Alguns estudos tem destacado a relação entre SNP em genes da GPx com o aumento do risco de câncer $(14,15,16,17,18,19,20)$, diabetes, doença cardiovascular (21) e síndrome metabólica (22).

Diante do exposto, este trabalho visa avaliar o estado nutricional relativo ao $\mathrm{Se} \mathrm{em}$ indivíduos adultos relacionando-o com polimorfismos no gene da enzima GPx e sua influência sobre a enzima e o balanço redox. 


\section{0 - REVISÃO DA LITERATURA}

\section{1 - SELÊNIO}

\subsection{1 - ASPECTOS GERAIS}

O selênio (Se) é um mineral essencial para o organismo humano. Foi descoberto em 1817 (1), mas só teve sua essencialidade reconhecida para a nutrição humana em 1979, junto ao diagnóstico da doença de Keshan, uma cardiomiopatia descoberta por pesquisadores chineses em uma área da China deficitária em Se (23).

Esse mineral possui alta toxicidade com uma estreita faixa de adequação entre as doses que levam à deficiência ou ao excesso. Em experimentos com animais, na dieta ou água para beber, sua faixa de adequação está na ordem de 0,1 a 1,0 $\mu \mathrm{g} / \mathrm{g}$ (2).

\subsection{2 - ASPECTOS FISIOLÓGICOS DO Se}

O Se pode apresentar-se na forma inorgânica, metálica $\left(\mathrm{Se}^{0}\right)$ ou em oxiânions como selenito $\left(\mathrm{SeO}_{3}{ }^{2-}\right)$ e selenato $\left(\mathrm{SeO}_{4}{ }^{2-}\right)$, e também na forma orgânica, como selenocisteína (Sec), selenometionina (SeMet), selenometilselenocisteína (SeMSec) e $\gamma$-glutamil-Semetilselenocisteína (GGSeMSec) $(2,24)$.

O Se participa do centro ativo de selenoproteínas, que são proteínas que contêm Sec como parte integral da sua cadeia de polipeptídeos. O selenoproteoma humano consiste de 17 famílias de selenoproteínas, sendo que as melhores caracterizadas funcionalmente são as glutationa peroxidases (GPx), tioredoxina redutase (TrxR), iodotironina deiodinase (DIO), selenoproteína P e selenofosfato sintetase 2 (SPS2) (25).

A absorção das espécies de Se ocorre principalmente na parte inferior do intestino delgado por diferentes vias e mecanismos. Entre os nutrientes que facilitam a absorção de Se destacam-se a presença de metionina/proteína e vitaminas E, A e C; enquanto que altas doses de enxofre e metais pesados reduzem a sua absorção (26). Tanto as formas orgânicas quanto inorgânicas são facilmente absorvidas (70-90\%) sob condições fisiológicas e de ingestão normais, com exceção de $\mathrm{SeO}_{3}{ }^{2-}$, com absorção direta não excedendo $60 \%$. 
A absorção do $\mathrm{SeO}_{3}{ }^{2-}$ pode ser aumentada na presença de glutationa reduzida (GSH) nos fluídos gastrointestinais, pois reagem não enzimaticamente formando selenodiglutationa (GS-Se-SG) (Figura 1, parte a), que é subsequentemente decomposta pela glutationa redutase em $\mathrm{HSe}^{-}$(Figura 1, parte b). A fração de $\mathrm{SeO}_{3}{ }^{2-}$ absorvida diretamente é capturada pelos eritrócitos, reduzida a $\mathrm{HSe}^{-}$e transferida para o fígado ligada à albumina. As proteínas de transporte envolvidas na absorção direta ou indireta de $\mathrm{SeO}_{3}{ }^{2-}$ ainda não são bem conhecidas.

A outra forma inorgânica, o $\mathrm{SeO}_{4}{ }^{2-}$, tem elevada eficiência de absorção paracelular, por meio de um processo de difusão passiva. Após absorvido, ele é capturado pelos hepatócitos por meio de um sistema de transporte usando fosfato e é reduzido a selenito (Figura 1, parte d) pela ATP sulfurilase, por um processo semelhante à redução do sulfato, utilizando uma via ainda não bem identificada do isólogo de Se, 3-fosfoadenosina 5fosfossulfato (Se-PAPS). O $\mathrm{HSe}^{-}$proveniente dessas duas formas inorgânicas é utilizado para a síntese de selenoproteínas $(2,27,28,29,30)$.

As formas orgânicas são absorvidas por vias transcelulares mediadas por transportadores, os quais ainda não possuem identidade e afinidade bem estabelecidas. A absorção de SeMSec utiliza o dipeptídeo de Se GGSeMSec como um transportador. Após a ingestão alimentar, a maior parte de GGSeMSec é hidrolisado por $\gamma$-glutamiltranspeptidase no trato gastrointestinal (Figura 1, parte i) liberando SeMSec para absorção e distribuição sistêmica para outros tecidos. SeMSec e GGSeMSec são clivadas pela $\beta$ liase para monometilselenido (MSe) (Figura 1, parte j) que posteriormente será metilado e excretado $(30,31,32)$.

A SeMet é absorvida por um processo dependente de $\mathrm{Na}^{+}$(Figura 1, parte e). As formas orgânicas de Se são transformadas em $\mathrm{HSe}^{-}$por meio da clivagem redutiva da ligação C-Se por uma reação de liase. A Sec é clivada diretamente pela enzima $\beta$-liase (Figura 1, parte g), enquanto que a SeMet pode ser lisada diretamente por $\gamma$-liase para HSe ou pode seguir outra via, sendo transformada em Sec por meio de uma trans-selenação, sendo posteriormente lisada pela $\beta$-liase para $\mathrm{HSe}^{-}$(Figura 1, parte f). O excesso de SeMet pode também sofrer metilação direta por $\gamma$-liase (Figura 1, parte h) $(2,30,31,33,34,35)$

A SeMet está presente na forma de um resíduo de SeMet em proteínas em geral, como a albumina e hemoglobina, sendo incorporada de forma não específica como compostos de Se. Ela é metabolizada de acordo com o turnover protéico da metionina, independente da necessidade de Se do organismo. Dessa forma, quando o aminoácido é catabolizado, o Se torna-se disponível para uso específico (36). Assim, a SeMet pode ser 
utilizada para a síntese de proteínas sem distinção entre SeMet e metionina, não havendo um códon específico correspondente, sendo este o mesmo que codifica a metionina, o AUG (37,38). Portanto, proteínas que contêm Se na forma de SeMet são chamadas simplesmente de proteínas contendo Se $(2,25)$.

Figura 1. Metabolismo de selênio

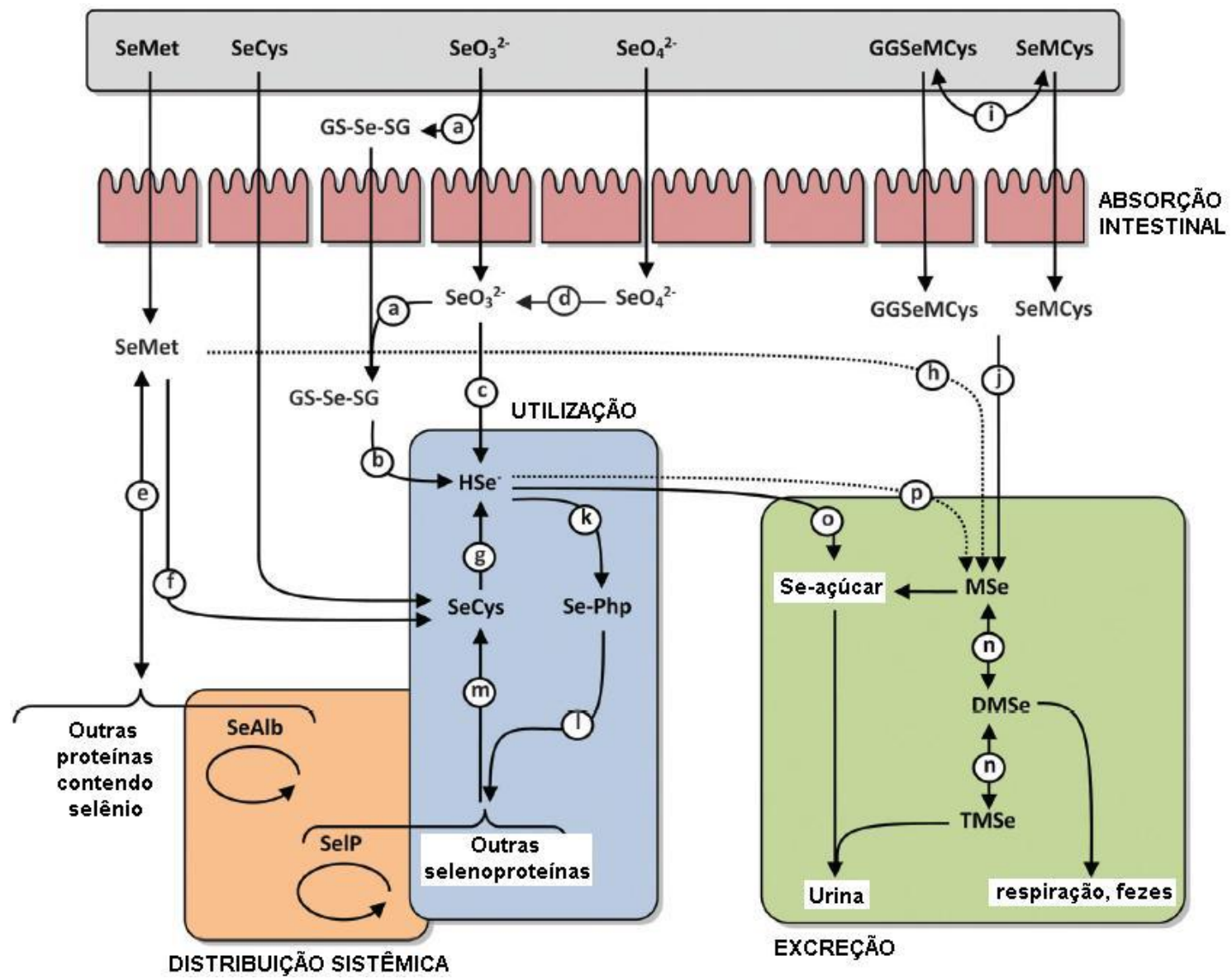

Fonte: Adaptado de Roman et al. (30)

Legenda: SeMet - Selenometionina; SeCys - Selenocisteína; $\mathrm{SeO}_{3}{ }^{2-}$ - Selenito; $\mathrm{SeO}_{4}{ }^{2-}$ - Selenato; GGSeMCys - Metilselenocisteína; SeMCys - Selenometilselenocisteína; GS-Se-SG - Selenodiglutationa; HSe- - Selenido; Se-Php - Selenofosfato; SeAlb - Selenoalbumina; SelP - Selenoproteína P; MSe - Monometilselenido; DMSe - Dimetilselenido; TMSe - Trimetilselenido.

A Sec é incorporada em uma sequência de resíduos de aminoácidos em selenoproteínas de plantas e animais. Para a produção de selenoproteínas, uma das primeiras etapas necessárias é a biosíntese de $\mathrm{Sec}$, a qual ocorre no próprio ácido ribonucléico transportador (tRNA), sendo assim chamado de Sec tRNA ${ }^{[\mathrm{Ser}] \mathrm{Sec}}$. Inicialmente, o tRNA ${ }^{[\mathrm{Ser}] \mathrm{Sec}}$ é aminoacilado com serina pela ação da enzima seril-tRNA sintetase (SerS) formando seryl-tRNA ${ }^{[\mathrm{Ser}] \mathrm{Sec}}$, que fornece a espinha dorsal para biossíntese 
de Sec. Em seguida, a enzima fosfoseril-tRNA quinase (PSTK) fornece o intermediário fosforilado PSer-tRNA ${ }^{[\mathrm{Ser}] \mathrm{Sec}}$, que serve como um substrato para a enzima Sec sintetase $(\mathrm{SecS})$ converter a porção serina no tRNA ${ }^{[\mathrm{Ser}] \mathrm{Sec}}$ para selenocisteil-tRNA ${ }^{[\mathrm{Ser}] \mathrm{Sec}}$. A SecS incorpora selenofosfato $\left(\mathrm{H}_{2} \mathrm{SePO}_{3}^{-}\right)$, a forma ativa de $\mathrm{Se}$, dentro da espinha dorsal do aminoácido, gerado pela SPS2 da reação entre $\mathrm{HSe}^{-}$e ATP (Figura 1, parte k; Figura 2) $(39,40)$.

Figura 2. Mecanismo da biossíntese de selenocisteína.

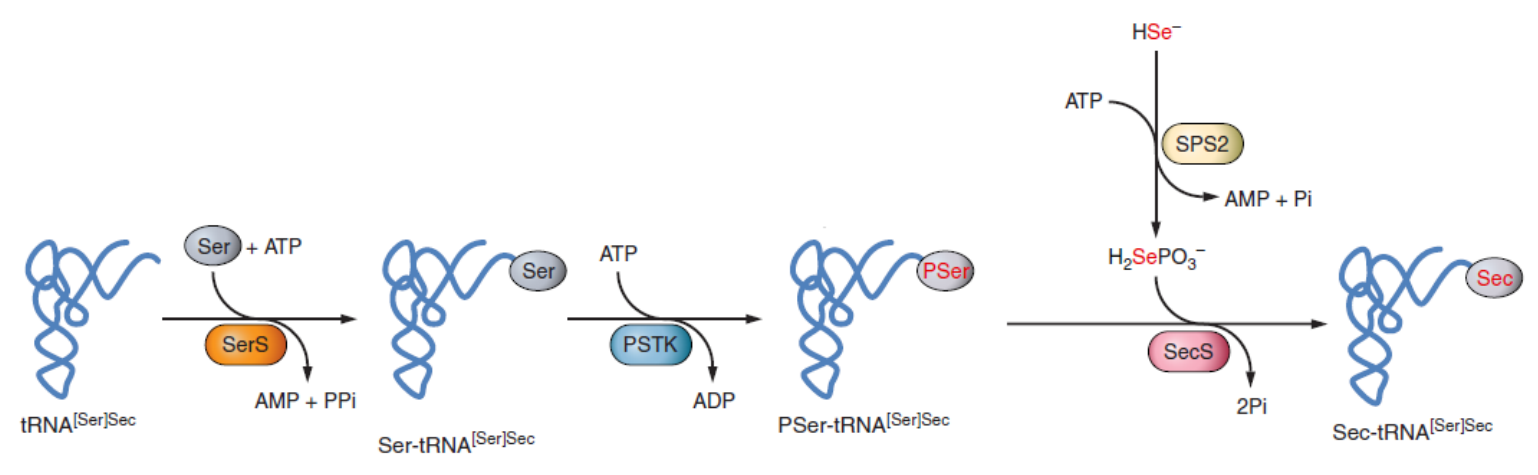

Fonte: Adaptado de Labunsky et al. (40)

Legenda: tRNA - Ácido ribonucleico transportador; Ser - Seril; Sec - Selenocisteína; SerS - seril-tRNA sintetase; ATP - Adenosina trifosfato; ADP - Adenisina difosfato; AMP - adenosina monofosfato; PSTK fosfoseril-tRNA quinase; SPS2 - selenofosfato sintetase 2; SecS - Selenocisteína Sintetase; $\mathrm{H}_{2} \mathrm{SePO}_{3}{ }^{-}$Selenofosfato.

A Sec é incorporada em sequências polipeptídicas de proteínas (Figura 1, parte 1) por códons UGA presentes em ácidos ribonucléicos mensageiros (RNAm) e um complexo mecanismo que envolve proteínas específicas, durante o processo de tradução. Na produção de selenoproteínas, quando um ribossomo encontra o códon UGA, o qual finalizaria a tradução, o mesmo passa a ser recodificado como Sec, por meio de uma maquinaria que envolve o elemento SECIS (sequência de inserção de selenocisteína) - uma estrutura específica dentro do RNAm e próxima da região 3'UTR que dita esta recodificação; a Sec-tRNA ${ }^{[\operatorname{Ser}] \mathrm{Sec}}$ - que tem um anticódon complementar ao UGA; a proteína de ligação ao SECIS 2 (SBP2) - que é ela própria uma selenoproteína, é associada de forma estável aos ribossomos e se liga ao elemento SECIS com alta afinidade e especificidade; e o fator de elongação de tradução para inserção de selenocisteína (eEFSec) - que também interage com SBP2, recruta a Sec-tRNA ${ }^{[\operatorname{Ser}] \operatorname{Sec}}$ e facilita a incorporação de Sec dentro do polipeptídeo crescente $(39,40)$. 
As espécies de Se absorvidas no trato gastro-intestinal são em primeiro lugar transportadas para o fígado, onde são sintetizadas a maior parte das selenoproteínas. $\mathrm{O}$ $\mathrm{SeO}_{4}{ }^{2-}$ e as espécies orgânicas podem ser transportados intactos ou por mecanismos que ainda não foram elucidados, enquanto que a SeMet é normalmente transportada sob a forma de Se-albumina (SeAlb). Além do fígado, as espécies de Se também podem ser armazenadas nos músculos, esqueleto, eritrócitos, pâncreas, rins, estômago, cérebro, pele e mucosa gastrointestinal. O plasma é outro local de armazenamento de Se, onde é encontrado principalmente sob a forma de selenoproteína P (60 a 70\%) - responsável pela distribuição de Se para outros órgãos. Nestes, outras selenoproteínas podem ser sintetizadas com a liberação de Sec que é reconvertida a $\mathrm{HSe}^{-}$(Figura 1, parte m). Ainda no plasma, como GPx (20 a 30\%) e os restantes 10\% ligado a lipoproteínas de baixa densidade e de muito baixa densidade $(5,30,35,41,42,43,44)$.

A distribuição de Se para todo o organismo é regulada pelo fígado, por triagem do Se metabolicamente disponível entre as vias de síntese de selenoproteínas e de metabolitos de excreção. A fração de Se que não pode ser utilizada para a síntese de selenoproteínas é excretada. A regulação dos metabólitos excretados ainda é investigada. Sabe-se que a excreção de Se pode seguir dois caminhos, ambos com produtos metilados. Em casos de suplementação de Se ou toxicidade, o principal metabólito é o trimetilselenido (TMSe), que é excretado na urina. Sua produção inicia a partir de fontes de Se mono-metiladas, como SeMSec, que passam por uma sequência de metilações mediada por metiltransferases, tendo como intermediário o dimetilselenido (DMSE), excretado por meio da respiração (Figura 1, parte n). Nesses casos de excesso de Se, bem como na baixa toxicidade do nutriente, o $\mathrm{HSe}^{-}$pode ser convertido em selenoaçúcares e ser excretado na urina (Figura 1, parte o) $(30,45,46,47,48)$.

Todas essas etapas que incluem a síntese de tRNA-Sec pelo $\mathrm{HSe}^{-}$, a maquinaria de proteínas que incorporam $\mathrm{Sec}$ em selenoproteínas e o transporte de Se do fígado para o tecido alvo formam uma unidade que coordena a síntese de selenoproteínas. Portanto, o padrão da expressão de selenoproteínas e seus alvos direcionados são resultados funcionais da ingestão nutricional, sendo que tanto a ingestão de selênio quanto a presença de fatores genéticos podem influenciar este padrão (39). Como os resíduos de Sec estão presentes em todas as selenoproteínas - com poucas exceções constituindo seu sítio ativo, importante para as reações redox catalíticas - a ausência destes resíduos bem como suas mutações para qualquer outro aminoácido, poderão conduzir à conduzir a inatividade das selenoproteínas (40). 
Algumas evidências sugerem que a baixa ingestão de Se influencia a atividade de várias selenoproteínas e podem causar alterações em RNAm em genes de selenoproteínas. É o que se tem observado, por exemplo, no fígado e outros tecidos de ratos: uma redução na atividade da GPx1 e na expressão de $\operatorname{RNAm}(49,50,51,52)$; maior redução da GPx1 comparada com a redução da atividade da GPx4 e DIO (50); maior redução da TrxR2 comparada à TrxR1 (53). Em linhagens celulares também foi verificada redução na expressão da GPx1, mas não da GPx2, com a redução de Se $(39,54,55)$.

Essas evidências demonstram que a síntese de selenoproteínas é sensível à disponibilidade de Se, mas nem todas as selenoproteínas são afetadas da mesma forma pela deficiência do mineral em questão. Algumas respondem rapidamente à deficiência de Se com diminuição da sua atividade, enquanto outras se mantêm estáveis sob moderada deficiência e apenas reduzem a atividade frente à depleção prolongada. Há, portanto, uma hierarquia para a síntese das selenoproteínas, que é classificada de acordo com a importância de sua função no organismo. Tem-se observado que a DIOI é a selenoproteína menos vulnerável. Entre as GPx a GPx2 e GPx4 têm prioridade em relação à GPx1 e GPx3, e a selenoproteína $\mathrm{P}$, ocupa posição intermediária $(39,56,57)$.

A determinação da hierarquia das selenoproteínas é complexa e envolve alguns fatores, tais como: variações na extensão da região 3'UTR de diferentes RNAm de selenoproteínas e na posição da recodificação da Sec pelo UGA dentro da região codificadora. Como consequência, modifica o número de nucleotídeos entre o UGA e o SECIS; mutações em proteínas necessárias ao complexo de incorporação da Sec, como a SBP2, que podem levar a diferenças na expressão de selenoproteínas com maiores efeitos na desiodase que na GPx (58); mutações no RNAt-Sec, que podem influenciar a incorporação de Sec em algumas selenoproteínas mais que em outras, sendo as GPx1 e GPx3 mais sensíveis à tal mutação que TrxR1 e GPx4 (59); especificidade do tecido, por exemplo, em ratos deficientes, a atividade da DIO reduz mais que $90 \%$ no fígado, mas aumenta na tireoide, a expressão da TrxR1 é afetada mais no fígado que no rim, a atividade da GPx4 reduz no coração e no fígado mas não na tireoide $(60,61)$. Embora seja reconhecida a hierarquia de selenoproteínas, nosso conhecimento ainda é limitado a poucas selenoproteínas, tais como a GPx, TrxR, DIO e P (39). 


\subsection{3 - FUNÇÕES DO Se}

As funções do Se estão intimamente ligadas à associação com selenoproteínas (62), como por exemplo, a GPx, que reduz peróxidos de hidrogênio e hidroperóxidos a partir do metabolismo da glutationa, um dos mecanismos de defesa antioxidante mais importantes do sistema biológico. Para que a atividade de redução de espécies reativas seja mantida, é necessário que haja a regeneração da GSH. Para tanto, uma molécula de peróxido de hidrogênio é reduzida a duas moléculas de água, enquanto duas moléculas de glutationa (GSH) são oxidadas em uma reação catalisada pela GPx. A glutationa oxidada (GSSG) pode ser reduzida pela glutationa redutase, utilizando NADPH como co-fator (Figura 3) $(24,63,64)$.

Figura 3. Ciclo de oxi-redução da glutationa

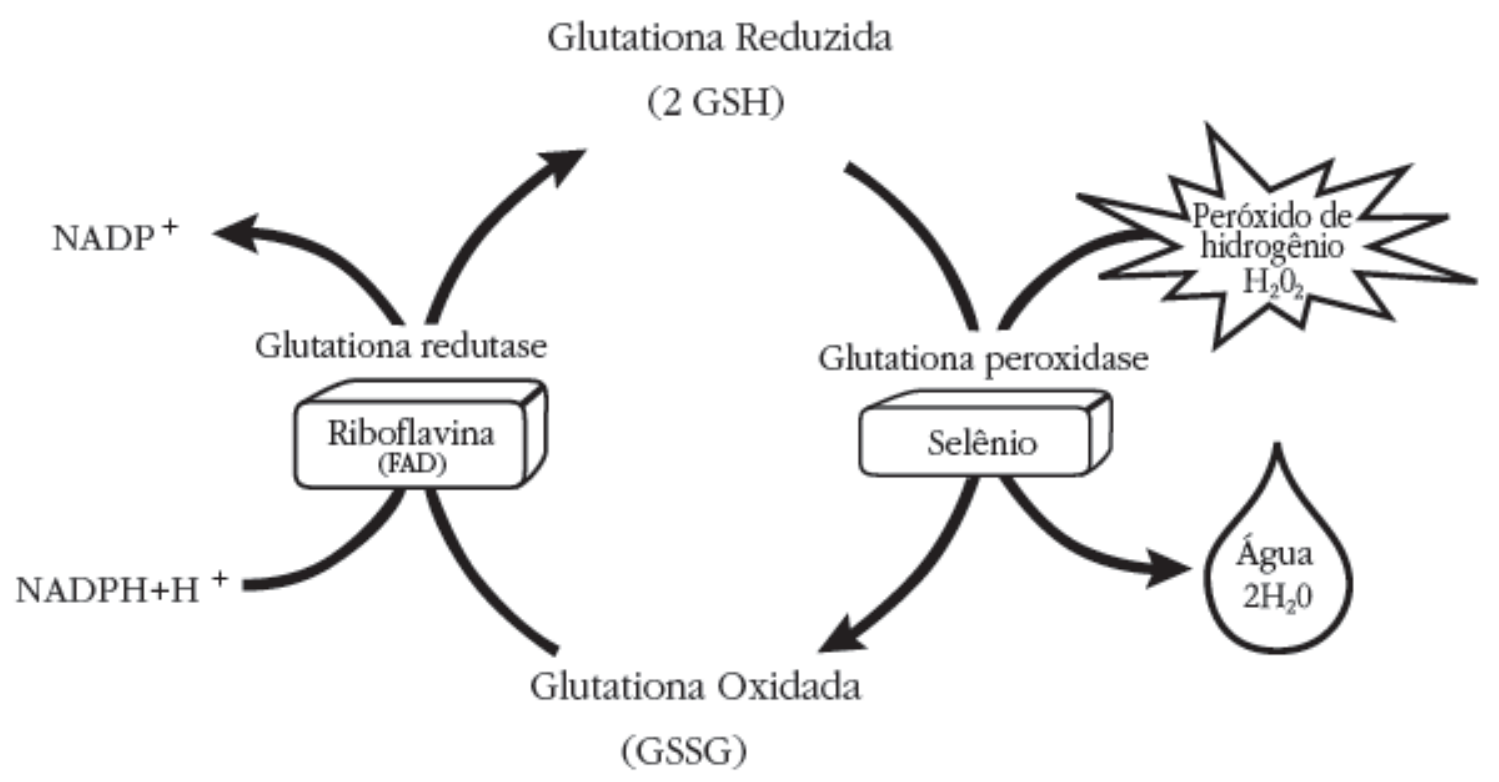

Fonte: Cominetti et al. (64); Higdon, Drake e Whagner (65)

Em mamíferos há oito tipos de GPx, sendo que cinco (GPx1, GPx2, GPx3, GPx4 e GPx6) contém resíduos de Sec em seu sítio ativo e três (GPx5, GPx7 e GPx8) contém cisteína no lugar de Sec no sítio ativo. A GPx1 é uma enzima citosólica ubíqua que é expressada em todos os tipos de tecidos, em maiores concentrações no fígado e rim. As GPx2 e GPx3 são limitadas a certos tecidos, encontradas especialmente no epitélio do trato gastrointestinal e rim, respectivamente. A GPx4 é expressa em vários tipos de células e 
tecidos, e a GPx6 somente no epitélio olfativo e durante o desenvolvimento embrionário (66).

As GPx1, GPx2 e GPx3, e possivelmente a GPx6, tem especificidade por peróxido de hidrogênio $\left(\mathrm{H}_{2} \mathrm{O}_{2}\right)$ e outros hidroperóxidos de baixo peso molecular. A GPx4 está envolvida na redução do complexo hidroperóxido fosfolipídico bem como com hidroperóxido de fosfatidilcolina e hidroperóxido de colesterol que são associados com membranas celulares $(40,67)$.

A GPx1 tem sido considerada uma das principais enzimas antioxidantes implicada na proteção das células contra danos oxidativos e é altamente regulada pela disponibilidade de Se. Estudo com camundongos verificou que na deficiência de Se a atividade da GPx1 no fígado e rim estava significativamente reduzida e com a reintrodução do nutriente na dieta houve aumento em sua atividade. Destaca-se que sua atividade reduzida ou deficiência resulta em elevados concentrações de $\mathrm{H}_{2} \mathrm{O}_{2}$ intracelulares, enquanto que a super expressão da GPx1 pode levar a redução do estresse oxidativo e pode interromper a sinalização de $\mathrm{H}_{2} \mathrm{O}_{2}$. Assim, a GPx1 modula vários processos e vias biológicas regulados pelo $\mathrm{H}_{2} \mathrm{O}_{2}$ incluindo a proliferação celular, apoptose, resposta ao estresse e funções relacionadas às mitocôndrias $(40,68,69,70)$.

A família das selenoproteínas desiodases (DIO I, DIO II e DIO III) tem papel importante sobre os hormônios da tireoide. A DIO I é expressa principalmente no fígado, rins, tireoide e gordura marrom, enquanto a DIO II é abundante no sistema nervoso central, tecido adiposo marrom e músculos esqueléticos. Ambas ativam os hormônios da tireoide convertendo a tiroxina inativa em ativa (3,3'-5'triiodothyronine). E a DIO III, presente na placenta, útero, feto e no sistema nervoso central, tem atividade fetal e na desativação de hormônios da tireoide $(6,27,71)$.

Há três selenoproteínas TrxR: TrxR1 - localizada no meio intracelular (citosólica/nuclear); TrxR2, expressa em altas concentrações na célula, especialmente nas mitocôndrias; e TrxR3, localizada principalmente nos testículos. Elas desempenham um papel antioxidante e no controle do potencial redox intracelular, e também podem atuar como fator de crescimento de células, na síntese de DNA e a inibição da apoptose (6, 27, $71)$.

A selenoproteína $\mathrm{P}$ é uma glicoproteína extracelular que, como comentado anteriormente, é uma das principais reservas plasmáticas de Se e transporta o nutriente para outros tecidos, função esta que se deve à presença de dez Sec em sua estrutura, das quais uma se localiza no domínio $\mathrm{N}$-terminal e nove no resíduo C-terminal. Além do fígado, 
também tem sua expressão aumentada no cérebro e testículos e age também como um antioxidante extracelular, pois elimina peroxinitritos, resultantes da reação de íons superóxido com óxido nitrico, produzidos em situações de inflamação $(6,27,71,72)$.

O Se tem papel importante frente ao sistema imunológico, tais como a manutenção da integridade da membrana das células imunocompetentes; otimização da resposta imune celular e humoral mediante a melhoria dos fenômenos de fagocitose das células natural killer; proliferação dos linfócitos T e síntese de imunoglobulinas; inibição da transcrição mediada pelo fator nuclear kappa B (NF-kB) limitando a resposta inflamatória e regulação do metabolismo de hidroperóxidos que levam à síntese de leucotrienos, tromboxanos, prostaglandinas e lipóxidos (43).

\subsection{4 - FONTES, RECOMENDAÇÕES, DEFICIÊNCIA E EXCESSO}

As principais espécies de $\mathrm{Se}$ encontradas em vegetais são $\mathrm{SeO}_{3}{ }^{2-}, \mathrm{SeO}_{4}{ }^{2-}$ e SeMet, e em menor quantidade Sec, SeMSec e GGSeMSec. Em animais, as principais espécies encontradas são $\mathrm{SeO}_{3}{ }^{2-}, \mathrm{SeO}_{4}{ }^{2-}$, SeMet e $\mathrm{Sec}$, com proporções variáveis dependendo da dieta do animal (73). As melhores fontes alimentares de Se são de origem animal como as carnes, que possuem concentrações variando entre $0,2 \mu \mathrm{g} / \mathrm{g}$ e $0,6 \mu \mathrm{g} / \mathrm{g}$, produtos marinhos, com concentrações chegando até $0,87 \mu \mathrm{g} / \mathrm{g}$ e lácteos, com menos de 0,1 a $0,3 \mu \mathrm{g} / \mathrm{g}$ de Se. Os alimentos de origem vegetal apresentam concentrações variadas de Se. Os cereais e grãos contêm desde concentrações abaixo de 0,1 até $0,8 \mu \mathrm{g} / \mathrm{g}$ de Se; e frutas e vegetais, menos de $0,1 \mu \mathrm{g} / \mathrm{g}$ de Se (74). Apesar de ser de origem vegetal, a castanha-do-brasil é a principal fonte alimentar, apresentando concentração variando de 50,0 a 70,0 $\mu \mathrm{g} / \mathrm{g}$ podendo chegar a $110 \mu \mathrm{g} / \mathrm{g}$, de acordo com análises realizadas no Laboratório de Nutrição Minerais da Faculdade de Ciências Farmacêuticas da Universidade de São Paulo.

O estabelecimento da recomendação dietética de Se baseou-se em dados epidemiológicos da doença de Keshan e na maximização da atividade de selenoproteínas como a GPx plasmática. Segundo a ingestão dietética de referência (DRI) publicada pelo Institute of Medicine (IOM) (5) de 2000, a necessidade média estimada (EAR) e a ingestão dietética recomendada (RDA) para indivíduos com idade a partir de 19 anos de ambos os sexos é de $45 \mu \mathrm{g} /$ dia e $55 \mu \mathrm{g} /$ dia, respectivamente.

Entre as principais formas de apresentação da deficiência de Se em humanos, destaca-se a doença de Keshan, uma cardiomiopatia que pode ocorrer quando a ingestão diária de Se é menor ou igual a $11 \mu \mathrm{g} /$ dia $(5,75)$. Sua forma aguda é caracterizada por uma 
súbita insuficiência da função cardíaca, e, a forma crônica, por crescimento moderado ou excessivo do coração, com diversos graus de insuficiência cardíaca. No aspecto histopatológico, há quadros de necrose multifocal cardíaca, substituição fibrosa do miocárdio e miocitólise (76).

Outra forma de apresentação da deficiência do mineral é a doença de Kashin-Beck, uma osteoartrite endêmica que ocorre durante a pré-adolescência ou adolescência (77), caracterizada por degeneração necrótica dos condrócitos, que resulta em nanismo e deformação de articulações (78).

A intoxicação por Se também pode ser do tipo aguda ou crônica. A primeira pode ocorrer por ingestão acidental ou suicida de altas doses de Se, e pode levar ao surgimento de graves distúrbios gastrointestinais e neurológicos, síndrome do desconforto respiratório agudo, infarto do miocárdio e insuficiência renal. A intoxicação crônica também conhecida como selenose se caracteriza pela perda de cabelos e unhas, distúrbios gastrointestinais, erupções cutâneas, hálito de alho (causada por compostos de selênio), fadiga, irritabilidade e alterações do sistema nervoso. A selenose pode surgir com a ingestão de selênio acima de $850 \mu \mathrm{g} / \mathrm{d}(5)$.

\subsubsection{AVALIAÇÃO DA CONCENTRAÇÃO DE Se SANGUÍNEO}

As diferentes concentrações de Se no solo são as principais determinantes das quantidades de Se nos alimentos, influenciando a ingestão e as concentrações dos biomarcadores nos indivíduos, isso poderia explicar as variações no status do mineral de indivíduos em diferentes países (79). É o caso dos Estados Unidos, Índia, Austrália e Japão que possuem áreas com solos ricos em Se, enquanto que China, Nova Zelândia e República Tcheca possuem áreas com solo pobre em Se (80).

Nos Estados Unidos, a ingestão de Se pela população em geral, excede o valor da RDA. Na Europa, a ingestão é de cerca de $30 \mu \mathrm{g} /$ dia e, na Nova Zelândia há ingestões menores que esse valor. Em regiões rurais de países em desenvolvimento têm sido relatadas ingestões ainda mais baixas, como regiões chinesas que apresentam consumo alimentar menor do que $10 \mu \mathrm{g} / \mathrm{dia}(81,82,83)$.

No Brasil, segundo Cozzolino (84), a disponibilidade de Se é diferenciada em diversas regiões do país. Supõe-se que as regiões sudeste e centro-oeste apresentem menores concentrações do mineral no solo, o que aponta para a deficiência de Se em indivíduos destas regiões, comparado com as regiões norte e nordeste. 
A região Amazônica é provavelmente a que possui o solo mais rico em Se, local onde se encontra a maior abundância de castanheiras, árvore que tem como fruto a castanha-do-Brasil (Bertholletia excelsa), principal fonte alimentar de Se. Vale ressaltar que as castanhas provenientes desta região têm conteúdo mais elevado quando comparadas a outras regiões do Brasil $(85,86)$.

Entre as regiões sudeste e nordeste, um estudo comparativo mostrou que o feijão produzido no Estado de São Paulo $(0,016 \mu \mathrm{g}$ de Se/g) tem menor concentração que o do Ceará $(1,2 \mu \mathrm{g}$ de $\mathrm{Se} / \mathrm{g})$ (87). Outra pesquisa realizada em indivíduos residentes nos dois Estados mostrou maior ingestão e concentração de Se no plasma da população cearense comparada com a de São Paulo (88). Estes resultados confirmam a influência da concentração de Se no solo no estado nutricional da população (87). Vale destacar que no nordeste há poucos estudos realizados sobre o status de selênio, sendo encontrados apenas os dois supracitados no Estado do Ceará.

Na região norte estão disponíveis dados de apenas três estudos: Gonzaga (74) em crianças de Macapá (AP) e Belém (PA); Rocha (89) em crianças ribeirinhas de duas localidades de Porto Velho e Bortoli (90) em mulheres adultas ribeirinhas do estado do Amazonas. Nesses estudos da região norte observaram-se concentrações elevadas de Se sanguíneo quando comparados com os estudos da região sudeste.

A revisão elaborada por Carmona-Fonseca (91), que compilaram resultados do status de Se sérico/plasmático de estudos em países da Europa e America Latina, observou que a concentração média de Se diferiu entre os indivíduos do mesmo continente e entre indivíduos de um continente e outro. Em alguns países europeus a concentração média de Se plasmático encontrada foi mais baixa (Hungria - 57,8 $\pm 12,1 \mu \mathrm{g} / \mathrm{L}$; Repúlbica Theca $58,3, \pm 11,6 \mu \mathrm{g} / \mathrm{L}$; Iugoslávia - 51,3 $\pm 16,6 \mu \mathrm{g} / \mathrm{L}$ ), enquanto em outros foi mais alta (Noruega - 117,2 \pm 15,7 $\mu \mathrm{g} / \mathrm{L}$; Portugal - 90,0 \pm 16,0 $\mu \mathrm{g} / \mathrm{L}$; Suíça - 96,0 \pm 12,8 $\mu \mathrm{g} / \mathrm{L}$; Turquía - 108,4 $\pm 23,4 \mu \mathrm{g} / \mathrm{L})$. Na América Latina, os valores de Se plasmático foram baixos no Peru - acima do nível do mar - $(59 \mu \mathrm{g} / \mathrm{L})$ e altos no Chile $(113 \mu \mathrm{g} / \mathrm{L})$ e Peru abaixo do nível do mar - $(117 \mu \mathrm{g} / \mathrm{L})$. Estes valores foram ainda menores que as médias encontradas em estudos nos Estados Unidos e Canadá, $125 \mu \mathrm{g} / \mathrm{L}$.

No Brasil, ainda há poucos estudos sobre avaliação do status de selênio, realizadas principalmente pelo grupo do laboratório de Nutrição - Minerais da Faculdade de Ciências Farmacêuticas (FCF) da Universidade de São Paulo (USP). Em indivíduos saudáveis, há apenas três estudos realizados por este grupo nesta região, dois no Ceará, um na Amazônia e outro em Rondônia (Figura 4). 
Figura 4. Concentrações plasmáticas e eritrocitárias de Se $(\mu \mathrm{g} / \mathrm{L})$ de indivíduos adultos nos Estados do Ceará, São Paulo, Amazonas e Rondônia

Se plasmático $(\mu \mathrm{g} / \mathrm{L})$

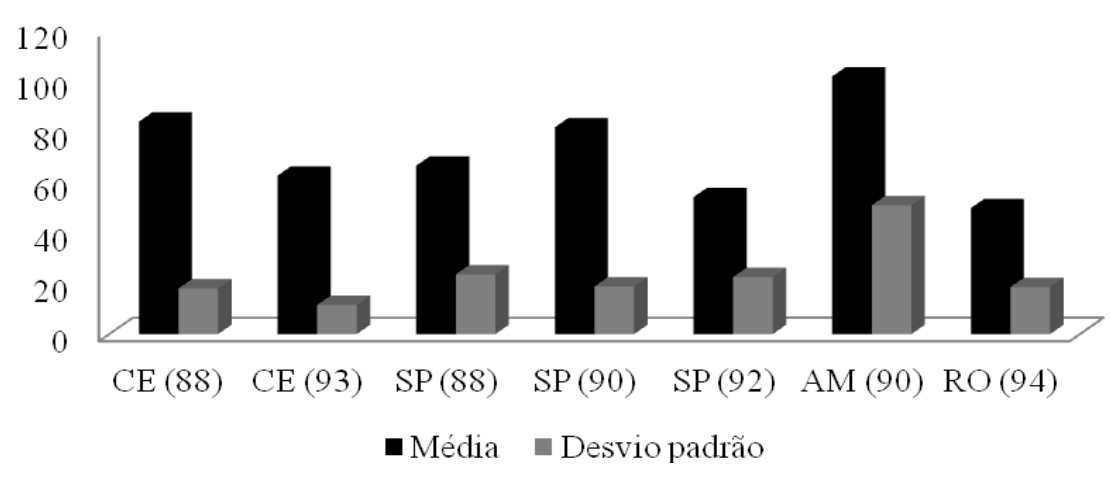

Se eritrocitário $(\mu \mathrm{g} / \mathrm{L})$

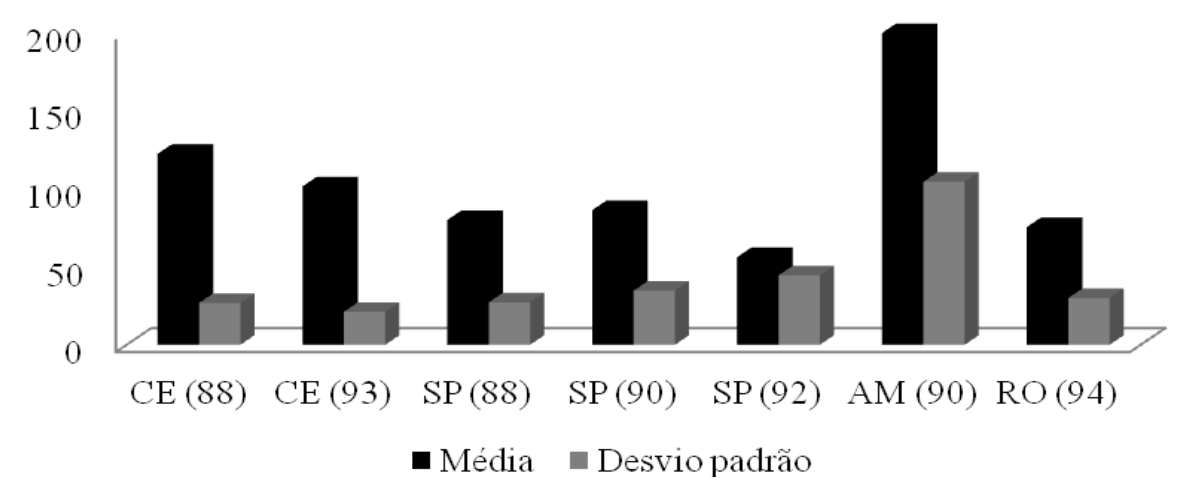

Legenda: CE - Ceará; SP - São Paulo; AM - Amazonas; RO - Rondônia

Outros estudos realizados em São Paulo em indivíduos acometidos por doenças mostraram que estes poderiam estar com o estado nutricional comprometido em relação ao mineral. Pacientes com insuficiência renal crônica tinham concentração plasmática de 18,8 $\mu \mathrm{g} / \mathrm{L}$ e eritrocitária de 72,4 $\mu \mathrm{g} / \mathrm{L}$ (95); pacientes com Alzheimer com 32,59 $\mu \mathrm{g} \mathrm{Se} / \mathrm{L}$ plasmático e 46,74 $\mu \mathrm{g} \mathrm{Se} / \mathrm{L}$ eritrocitário (96); mulheres obesas com 55,7 $\mu \mathrm{gSe} / \mathrm{L}$ plasmático e 60,5 $\mu \mathrm{g} \mathrm{Se} / \mathrm{L}$ eritrocitário (97); e indivíduos com doença de Graves com 57,0 $\mu \mathrm{gSe} / \mathrm{L}$ plasmático e 78,6 $\mu \mathrm{gSe} / \mathrm{L}$ eritrocitário (88). Portanto, em todos os casos, as concentrações desse elemento no sangue encontravam-se abaixo das faixas observadas na literatura.

Importante salientar que no Brasil não existe uma faixa de referência para as concentrações de Se sanguíneas e em muitos estudos são adotados os pontos de corte da população americana de 60 a $120 \mu \mathrm{g} / \mathrm{L}$ para Se plasmático e 90 a $190 \mu \mathrm{g} / \mathrm{L}$ para Se 
eritrocitário, que possuem concentrações de Se no solo diferentes das do Brasil (98). Tal fato pode gerar limitações na interpretação dos dados obtidos nas pesquisas sobre Se no Brasil, uma vez que as referências adotadas não refletem a realidade do país.

Outros pontos de corte foram sugeridos por Thomson (79), definidos a partir de estudos em áreas endêmicas ou não endêmicas de deficiência em Se na China e Nova Zelândia, sendo para o Se plasmático, $21 \mu \mathrm{g} / \mathrm{L}$, valor mínimo para o não surgimento da doença de Keshan - cardiomiopatia causada pela deficiência de selênio; e 80 a $90 \mu \mathrm{g} / \mathrm{L}$, necessário para a otimização da atividade da GPx e selenoproteína $\mathrm{P}$ plasmáticas. Aparentemente, estes valores são mais adequados para o uso em pesquisas, pois apresentam valores conhecidos para o risco de apresentar a doença de Keshan e para a otimização da atividade enzimática de selenoproteínas. No entanto, se referem apenas ao Se plasmático. De fato, é necessário que sejam estabelecidos valores de referências próprios para cada país. No entanto, na América Latina, bem como África e Ásia, exceto Japão, há poucos estudos sobre as concentrações de Se nos diversos compartimentos corporais (91), justificando estudos nessa área.

Medidas da concentração ou da atividade de selenoproteínas são outras formas de avaliar o status de Se, pois dependendo da concentração no organismo podem ter sua funcionalidade alterada $(99,100)$. É o caso, por exemplo, de alguns estudos que mostram uma atividade reduzida da enzima GPx, durante a baixa concentração de Se, ou aumentada com a suplementação $(83,93,101,102,103,104,105,106,107,108,109)$.

Os polimorfismos genéticos também podem influenciar o status de Se, visto que alguns indivíduos podem ter uma resposta biológica diferente em relação à ingestão de Se, que dependerá da variação genética. Por isso, enfatiza-se a importância da avaliação de polimorfismo de nucleotídeo único em genes que codificam selenoproteínas nos estudos que envolvem o Se (100).

\subsection{6 - POLIMORFISMO DE NUCLEOTÍDEO ÚNICO E GPx1}

Pesquisas envolvendo variações genéticas que poderiam estar relacionadas com maior risco para o desenvolvimento de doenças, tiveram um grande crescimento após a publicação dos primeiros resultados em 2001 do Projeto Genoma Humano. Este projeto iniciado em 1985 foi de grande importância para a área da genética não só pela conclusão do sequenciamento quase completo do genoma humano (ainda há regiões repetitivas e 
altamente condensadas não sequênciadas), como também pela descoberta de variações na sequência dos genes (110).

Os polimorfismos aparecem como consequência de mutações, e as diferentes classificações são definidas dependendo da mutação original. A categoria mais básica de polimorfismo é originada de uma mutação simples, modificando um nucleotídeo por outro (111), e foi chamada de SNP, do inglês "single nucleotide polymorphism", ou polimorfismo de nucleotídeo único (112). Os SNP podem estar localizados em várias regiões do gene: promotora, codificadora (éxons) e não codificadora (região 5' nãotraduzida no começo do gene, íntrons no meio do gene, e $3^{\prime}$ não-traduzida no final do gene) e dependendo da troca ou da região onde ocorrem podem interferir mais ou menos no fenótipo (113). SNP na região promotora e codificadora têm maior probabilidade de modificar o funcionamento do gene e consequentemente da proteína formada. Se estes polimorfismos ocorrerem em genes que codificam enzimas antioxidantes, por exemplo, podem aumentar o risco para o desenvolvimento de DCNT $(114,115)$.

Por definição, SNP são alterações em uma base do DNA onde o alelo raro ou menos frequente acomete $1 \%$ ou mais de indivíduos em uma determinada população (112). Estima-se que existam cerca de três milhões de SNP no genoma humano, mas que ocorrem em frequências que são estáveis em uma determinada população e que por si só não dão origem a fenótipos imprevistos. Para influenciar o fenótipo, alguns fatores devem ser considerados, como por exemplo: a dieta, fatores ambientais, região do gene onde ocorre o polimorfismo e variações genéticas adicionais (39).

Entretanto, grande parte dos SNP ocorre em regiões não codificadoras dos genes e por isso não causam mudanças observáveis nos indivíduos. Dessa forma, esses SNP são utilizados como marcadores em genética de populações (113). SNP estão sendo catalogados em grande escala (por exemplo, pelo consórcio internacional HapMap Project) e mapeados para uso na identificação de genes que contribuem com a incidência de doenças. A relação entre incidência de doenças, a genética de populações e os SNP está estruturada no conceito de haplótipos e desequilíbrio de ligação ou LD (Linkage Disequilibrium). Haplótipos são combinações específicas de alelos de um mesmo gene que ocorrem em uma população. A maioria dos SNP surgiu por uma mutação ocorrida em um locus do cromossomo há milhares de anos e essa região com seus alelos vizinhos tende a se manter intacto ao longo das gerações, se a população estiver em equilíbrio. Nesta situação, na qual o novo alelo e outros polimorfismos vizinhos tendem a ser herdados juntos, definese um forte desequilíbrio de ligação $(112,116)$. Sendo assim, se neste haplótipo estiver um 
alelo relacionado a uma doença, e houver um forte desequilíbrio de ligação, a identificação de apenas um SNP é suficiente como preditor da existência dos outros e, portanto do risco para a doença (117).

Um elevado número de mutações não apresenta consequências funcionais por diferentes motivos: por não causarem alteração de aminoácido na sequência da proteína ou porque a modificação de aminoácido não tem efeito, nem função. Consequentemente, o maior desafio da atualidade é identificar polimorfismos que apresentem consequências funcionais como alteração na função e no metabolismo das proteínas. Em relação às selenoproteínas, polimorfismos na região codificadora do gene podem ter como consequência a alteração do aminoácido na tradução da proteína (118), na região promotora podem alterar a regulação do funcionamento do gene e na região 3'UTR podem alterar a incorporação do selênio nas proteínas, sendo assim, seu estudo é de fundamental importância (39).

Nesse contexto, SNP em diversas selenoproteínas foram descobertos e podem apresentar consequências funcionais, como por exemplo, alterarem as concentrações de biomarcadores ou estarem associados com maior risco de diversas doenças, principalmente câncer, doença cardiovascular e diabetes.

Um exemplo de SNP em selenoproteínas humanas que pode levar a alterações passíveis de serem detectadas é o Pro198Leu (rs1050450) localizado no gene da GPx1 no cromossomo 3p21.3. Este polimorfismo é caracterizado pela substituição da base citosina por timina $(\mathrm{C} \rightarrow \mathrm{T})$ no exon 2 do nucleotídeo 594 da enzima, que resulta na substituição do aminoácido prolina (Pro) por leucina (Leu) no códon 198. É suposto que essa alteração pode causar mudanças conformacionais secundárias e terciárias na estrutura final da proteína, pois a prolina é o único aminoácido sem um grupo amino livre no átomo de carbono $\alpha$ e é conhecido por promover uma dobra única na estrutura secundária de peptídeos resultando em mudanças na atividade da enzima $(14,119,21,17)$.

Várias pesquisas têm mostrado uma associação entre a presença do alelo Leu do Pro198Leu e o risco aumentado de câncer de pulmão, mama, bexiga e colo-retal (14, 17, $119,120,121)$. No entanto, a associação entre a atividade da GPx1 e as variantes genotípicas do Pro198Leu não é suficiente para o entendimento da interação entre o seu genótipo e atividade enzimática. Assim, é importante avaliar como a atividade da GPx1 pode ser alterada em indivíduos com diferentes genótipos, em relação ao status de Se ou a suplementação deste mineral (122). Além disso, também é importante identificar a 
presença de outros polimorfismos no gene dessa enzima que podem também influenciar a sua atividade.

Outros exemplos de polimorfismos no gene da GPx1 são o -602A/G (rs3811699) e o Arg5Pro (rs8179169). O primeiro ocorre na região promotora do gene e leva a troca da base guanina $(\mathrm{G})$ por adenina $(\mathrm{A})$ no nucleotídeo 602 e, o segundo, ocorre no éxon do gene e leva a troca da base $\mathrm{G}$ por $\mathrm{C}$ no nucleotídeo 14, resultando na substituição do aminoácido arginina (Arg) por prolina (Pro) no códon 5. Observou-se na literatura apenas três artigos que estudaram estes SNP: Iida et al. (123) e Mistry et al. (124), que não encontraram o alelo variante do SNP Arg5Pro; Huang et al. (125) que verificaram uma alta frequência do alelo variante do SNP -602A/G e Hamanishi et al. (21) que encontraram haplótipo entre o alelo A do -602A/G e Pro do Pro198Leu com frequência de 89,9\%. Também foram realizadas analises preliminares destes dois SNP no Laboratório de Nutrição-Minerais da FCF/USP (dados em processo de submissão) e observou-se uma boa frequência destes, o que justifica a necessidade de uma maior exploração do seu comportamento frente à atividade da enzima GPx e balanço redox.

De acordo com Suzen et al. (122) os polimorfismos genéticos são um dos principais fatores para a susceptibilidade individual à doenças complexas, sendo que havendo interações entre as espécies reativas de oxigênio (ERO) e espécies reativas de nitrogênio (ERN) e o material genético, SNP em genes que codificam enzimas antioxidantes podem ter um papel fundamental para diferenças inter-individuais na manutenção da integridade do genoma humano.

Dessa forma, um aspecto importante a se considerar em estudos relacionados ao status de indivíduos quanto ao Se e variantes genéticas de selenoproteínas é o grau de estresse oxidativo a que os indivíduos podem estar submetidos. Pois, devido às propriedades antioxidantes do Se serem exercidas por meio de selenoproteínas (126), as variantes genéticas podem influenciar sua atividade, e consequentemente o estresse oxidativo e o risco de doenças (127).

Dois dos poucos estudos realizados correlacionando o estresse oxidativo e a variação genética de selenoproteínas em indivíduos saudáveis foi o de Takata et al. (127) e o de Miranda-Vilela et al. (128). O primeiro observou uma associação significativa entre variantes genéticas da selenoproteína $\mathrm{P}$ e concentrações elevadas de MDA. O segundo estudo mostrou uma associação entre o genótipo heterozigoto (Pro/Leu) do Pro198Leu da GPx1 com danos ao DNA. 
Há poucos estudos que relacionaram a atividade da GPx, o estresse oxidativo e o polimorfismo genético desta enzima em resposta à suplementação com Se. Cominetti et al. (109) foi o primeiro estudo com mulheres obesas a realizar essa associação e observou que, após a suplementação, o grupo homozigoto variante (Leu/Leu) apresentou maior nível de dano ao DNA em comparação ao grupo com genótipo selvagem (Pro/Pro), o que pôde ser atribuído ao baixo status antioxidante verificado no grupo Leu/Leu, no qual havia uma correlação significativamente negativa entre a atividade da GPx e o nível de dano ao DNA. 


\section{0 - JUSTIFICATIVA}

Inúmeros trabalhos que investigam a relação entre SNP no gene da enzima GPx foram realizados para avaliar o risco para o desenvolvimento de DCNT. Por outro lado, estudos em populações saudáveis para averiguar como os SNP podem influenciar os biomarcadores do estado nutricional relativo ao Se são mais escassos. Na atualidade, o uso das ferramentas da biologia molecular pode auxiliar na interpretação dos resultados de estudos populacionais ou de intervenção, com a possibilidade de definir biomarcadores mais robustos para avaliação do estado nutricional dos indivíduos em relação a nutrientes específicos, e, ao mesmo tempo, servir como indicadores para intervenções direcionadas a partir do genótipo individual.

É importante destacar que o diagnóstico do estado nutricional relativo ao Se é dificultado pela inexistência de um padrão de referência de normalidade, que possa ser utilizado de forma generalizada em pesquisas populacionais. Assim, este trabalho será de grande importância no sentido de contribuir para a criação de um banco de dados do estado nutricional relativo ao selênio da população brasileira, e ao mesmo tempo, verificar a influência dos SNP no estado nutricional, com influência ainda no estresse oxidativo, uma vez que a função primordial do Se é participar do sitio ativo de uma enzima antioxidante. 


\section{0 - OBJETIVOS}

\section{1 - OBJETIVO GERAL}

Avaliar o estado nutricional relativo ao Se em indivíduos adultos relacionando-o com polimorfismos no gene da enzima GPx e sua influência sobre a enzima e o balanço redox.

\section{2 - OBJETIVOS ESPECÍFICOS}

- Avaliar o estado nutricional dos indivíduos;

- Avaliar a adequação do consumo de macronutrientes dos participantes;

- Determinar o status de selênio;

- Analisar o balanço redox;

- Determinar a frequência dos polimorfismos Pro198Leu, -602A/G e Arg5Pro da GPx1;

- Avaliar a influência do estado nutricional geral dos indivíduos e dos polimorfismos Pro198Leu, -602A/G e Arg5Pro no status de Se e no balanço redox dos participantes. 


\section{0 - METODOLOGIA}

\section{1 - CASUÍSTICA}

O estudo é de natureza transversal e investiga o estado nutricional de indivíduos adultos em relação ao Se. A população do estudo foi constituída de 343 voluntários de ambos os sexos, com idade entre 20 e 50 anos, recrutados no Campus Ministro Petrônio Portella da Universidade Federal do Piauí da cidade de Teresina-PI. Os critérios adotados para seleção dos participantes foram: não fazer uso de suplementos vitamínico e/ou mineral ou de anti-inflamatórios; não ser atleta de elite; não consumir bebidas alcoólicas cronicamente; não ingerir castanha-do-brasil diariamente; não apresentar DCNT. A ausência de DCNT foi auto-relatada pelos participantes.

\section{2 - TAMANHO AMOSTRAL}

Esta pesquisa tem como um dos principais objetivos comparar a concentração de selênio entre indivíduos com genótipo Leu/Leu (homozigoto recessivo), Pro/Pro (homozigoto dominante) e Pro/Leu (heterozigoto) do polimorfismo Pro198Leu da enzima GPx1, ou seja, deseja-se realizar uma comparação de um fator (concentração de selênio) com os três genótipos (Leu/Leu, Pro/Pro e Pro/Leu). Para tanto, o cálculo do tamanho amostral foi realizado pelo Instituto de Matemática e Estatística (IME) da Universidade de São Paulo (USP) que utilizaram dados de concentrações de selênio de indivíduos saudáveis residentes na cidade de Fortaleza/Ceará, os quais faziam parte do grupo controle do estudo de Maia (88), sob responsabilidade do Laboratório de Nutrição-Minerais (FCF/USP). Destaca-se que o emprego deste estudo prévio no cálculo da amostra foi importante devido à utilização de dados da região nordeste do Brasil.

Desta forma, utilizou-se no cálculo estatístico os seguintes parâmetros: desvio padrão da concentração de selênio eritrocitário nos indivíduos estudados na pesquisa anteriormente citada $(26,79 \mu \mathrm{g} / \mathrm{L})$, maior diferença entre as médias de selênio eritrocitário em relação aos genótipos encontrados que se deseja detectar no estudo ( $15 \mu \mathrm{g} / \mathrm{L})$, nível de significância de $1 \%$ e poder do teste $(1-\beta)$ de 0,90. Assim, seriam necessários 113 indivíduos em cada genótipo, 339 participantes no total. 


\section{3 - ASPECTOS ÉTICOS}

O protocolo da pesquisa foi aprovado pelo Comitê de Ética da Faculdade de Ciências Farmacêuticas da USP (CAAE \# 03935412.1.0000.0067 - Anexo II e III) com anuência do Comitê de Ética da Universidade Federal do Piauí (Anexo IV). Para participar da pesquisa, os indivíduos assinaram um termo de consentimento livre e esclarecido (TCLE), após receberem informações a cerca do estudo. O termo foi elaborado de acordo com a "Declaração de Helsinque III", capítulo 50, parágrafo 50.20/27, que trata da proteção dos participantes e orienta quanto aos procedimentos referentes à pesquisa com humanos. O TCLE foi aplicado pelo pesquisador responsável, sendo que todo o procedimento iniciou-se após a sua assinatura (Apêndice I).

\section{4 - PROTOCOLO DO ESTUDO}

Os participantes responderam um questionário com informações sócioeconômicas e estilo de vida (Apêndice II). Os mesmos foram submetidos à coleta sanguínea e de urina de 24 horas para determinação de Se, perfil lipídico, marcadores de estresse oxidativo (atividade da SOD e GPx, MDA e capacidade total antioxidante) e de polimorfismos da enzima GPx. Também foi realizada avaliação antropométrica e dietética (três registros alimentares) para obtenção de informações sobre o consumo alimentar de Se e macronutrientes. Os participantes receberam explicações e orientações por escrito de como coletar a urina e os dados da dieta (Apêndice III e IV).

A análise do consumo e do Se urinário foi possível em 272 e 294 participantes, respectivamente, pois foram estes os que entregaram o material solicitado. As análises de Se plasmático $(\mathrm{n}=342)$, Se eritrocitário $(\mathrm{n}=338)$, GPx $(\mathrm{n}=334)$, SOD $(\mathrm{n}=335)$, MDA $(\mathrm{n}=229)$ e ORAC $(\mathrm{n}=339)$ não foram realizadas em todos os participantes devido à quantidade reduzida da amostra biológica ou à exclusão de resultados que se apresentaram como outliers.

\section{5 - ANÁLISES}

\subsection{1 - AVALIAÇÃO DO CONSUMO ALIMENTAR}

Foi utilizado o método do registro alimentar de três dias, sendo dois dias na semana e um dia de final de semana. A composição da dieta em macronutrientes e selênio foi analisada no programa Nutwin da Escola Paulista de Medicina/UNIFESP. Em seu banco 
de dados foram inseridos valores de selênio de alimentos nacionais analisados por Ferreira et al. (129) e pelo Laboratório de Nutrição - Minerais da Faculdade de Ciências Farmacêuticas da USP, e alguns que não foram analisados por essas duas primeiras fontes, foram selecionados da tabela USDA Food Search for Windows, versão 1.0, SR23. Junto aos valores de selênio, também foram acrescentados os dados de energia e macronutrientes da Tabela de Composição de Alimentos (TACO) da Universidade Estadual de Campinas (UNICAMP). Os valores obtidos de macronutrientes e Se foram corrigidos pela energia pelo método do resíduo e pela variabilidade intra e interpessoal $(130,131,132)$. Os resultados dos macronutrientes foram comparados com a referência de adequação da AMDR proposta pelas ingestões dietéticas de referência (133). Para o Se, determinou-se o percentual de inadequação de acordo com a EAR (necessidade média estimada) para indivíduos com idade acima de 19 anos de ambos os sexos (45 $\mu \mathrm{g} / \mathrm{dia})$ (5). Para tanto, foi realizado o cálculo para obtenção do $Z$ escore através da diferença entre a EAR e a ingestão média do grupo dividido pelo desvio padrão (132).

\subsection{2 - AVALIAÇÃO ANTROPOMÉTRICA}

Foram aferidas medidas de peso, estatura, circunferência da cintura e bioimpedância elétrica para o diagnóstico do estado nutricional antropométrico dos participantes. Todas essas medidas foram realizadas em triplicata, sendo as medidas finais correspondentes à média aritmética obtida, e foram realizadas no mesmo dia da coleta sanguínea com os indivíduos ainda em jejum.

Para aferição da altura utilizou-se um estadiômetro móvel da marca Sanny®, com capacidade para aferir até dois metros e sensibilidade de um centímetro, fixado em parede lisa, sem rodapé e sobre um plano liso. O participante foi colocado de pé e de costas para a parede, tendo-se o cuidado de observar a posição correta no momento dessa aferição, qual seja, os pés em paralelo, e os calcanhares, panturrilhas, região glútea, escápulas e cabeça em contato com o plano vertical.

O peso dos participantes foi aferido em balança antropométrica da marca Filizola ${ }$, modelo 31, com capacidade para $150 \mathrm{~kg}$ e sensibilidade de $100 \mathrm{~g}$. No momento da tomada de peso os participantes estavam descalços, posicionando-se no centro da balança e com os braços estendidos. Para aferição desta medida, bem como da impedância bioelétrica, foi solicitado aos participantes que usassem roupas leves. 
A circunferência da cintura foi aferida com o indivíduo em pé, com os pés juntos e braços estendidos ao longo do corpo, utilizando uma fita métrica não extensível. A mesma foi circundada no indivíduo no ponto médio entre a última costela e a crista ilíaca, sendo a leitura feita no momento da expiração.

Para o teste de bioimpedância, foi recomendado aos participantes que não comessem ou bebessem líquidos e não fizessem exercícios físicos nas quatro horas e nas doze horas antes do teste, respectivamente. Também foi solicitado que fossem ao banheiro evacuar e/ou urinar trinta minutos antes do teste e que retirassem qualquer tipo de metal, como relógios e brincos. Os indivíduos ficaram deitados, em decúbito dorsal, com as pernas e os braços afastados do corpo. Após a limpeza da pele, foram colocados os dois eletrodos (um distal e outro proximal) no pé direito: o eletrodo distal na base do dedo médio e o eletrodo proximal um pouco acima da linha da articulação do tornozelo, entre os maléolos medial e lateral da tíbia; e na mão direita: o eletrodo distal na base do dedo médio e o eletrodo proximal um pouco acima da linha da articulação do punho, coincidindo com o processo estiloide. O aparelho de bioimpedância elétrica utilizado foi da marca Compcorp da RJL Sistems Inc ${ }^{\circledR}$.

As medidas de peso e estatura foram expressas como índice de massa corpórea (IMC) em $\mathrm{kg} / \mathrm{m}^{2}$. Os resultados de IMC e circunferência da cintura foram analisados de acordo com a classificação proposta pela Organização Mundial de Saúde (134). O percentual de gordura obtido pelo teste de bioimpedância elétrica foi avaliado de acordo com a classificação de Lohman (135) (Quadro 1).

Quadro 1. Classificação das medidas antropométricas

\begin{tabular}{|c|c|c|c|}
\hline Variáveis & Categorias & \multicolumn{2}{|c|}{ Referência } \\
\hline $\operatorname{IMC}\left(\mathrm{kg} / \mathrm{m}^{2}\right)$ & $\begin{array}{c}\text { Baixo Peso } \\
\text { Eutrofia } \\
\text { Excesso de peso } \\
\text { Obesidade } \\
\end{array}$ & & $\begin{array}{l}5 \\
24,9 \\
9,9 \\
\end{array}$ \\
\hline $\mathrm{CC}(\mathrm{cm})$ & $\begin{array}{c}\text { Sem risco } \\
\text { Risco elevado } \\
\text { Risco muito elevado }\end{array}$ & $\begin{array}{c}\text { Feminino } \\
<80 \\
80-88 \\
\geq 88\end{array}$ & $\begin{array}{c}\text { Masculino } \\
<94 \\
94-102 \\
\geq 102\end{array}$ \\
\hline$\% \mathrm{GC}$ & $\begin{array}{c}\text { Risco de doenças e } \\
\text { distúrbios associados à } \\
\text { desnutrição } \\
\text { Abaixo da média } \\
\text { Média } \\
\text { Acima da média } \\
\text { Risco de doenças } \\
\text { associadas à obesidade }\end{array}$ & $\begin{array}{c}\text { Feminino } \\
\quad \leq 8 \\
9-22 \\
23 \\
24-31 \\
\geq 32\end{array}$ & $\begin{array}{c}\text { Masculino } \\
\leq 5 \\
6-14 \\
15 \\
16-24 \\
\geq 25\end{array}$ \\
\hline
\end{tabular}


Fonte: Organização Mundial de Saúde (134); Lohman (135).

Legenda: IMC - índice de massa corpórea; CC - circunferência da cintura; \% de GC -

percentual de gordura corporal;

\subsection{3 - COLETA E PROCESSAMENTO DE SANGUE E URINA}

A coleta de sangue venoso foi realizada em jejum de no mínimo 8 horas e máximo de 12 horas, por um técnico de enfermagem. A quantidade de sangue coletada foi de 20 mL com seringas plásticas descartáveis e agulhas de aço inoxidável, e, posteriormente foram transferidos para tubos de polietileno com EDTA. O sangue coletado foi utilizado para análise de perfil lipídico, Se, dos polimorfismos da enzima GPx, da atividade das enzimas SOD e GPx, e das concentrações de MDA e capacidade total antioxidante.

Para análise do perfil lipídico, $5 \mathrm{~mL}$ de sangue total foram separados em tubos de polietileno com gel para separação do soro, sendo analisados no mesmo dia da coleta. Para os polimorfismos, 1,0 mL de sangue total foi separado em microtubo estéril e armazenado em freezer $-80^{\circ} \mathrm{C}$ para a posterior extração do DNA genômico necessário para esta análise. O restante do sangue foi processado em centrífuga refrigerada, para obtenção do plasma e eritrócitos. O processamento do sangue foi realizado da seguinte maneira: o plasma foi separado do sangue total por centrifugação a $1157 \mathrm{~g}$ durante 15 minutos a $4^{\circ} \mathrm{C}$, em centrífuga da marca Eppendorf ${ }^{\circledR}$, e acondicionado em microtubos comuns de polipropileno. A massa eritrocitária foi lavada três vezes com $5 \mathrm{~mL}$ de solução salina à $0,9 \%$, homogeneizada lentamente por inversão e centrifugada a $12857 \mathrm{~g}$ por 10 minutos a $4^{\circ} \mathrm{C}$, utilizando-se a mesma centrífuga para a separação do plasma, sendo o sobrenadante descartado, em todas as lavagens. Após o terceiro descarte do sobrenadante, a massa eritrocitária foi cuidadosamente extraída com micropipeta, e colocada em microtubos de polipropileno. As amostras de plasma e eritrócitos foram armazenadas a $-80^{\circ} \mathrm{C}$ para posterior análise.

Também foram coletadas amostras de urina de 24 horas, em frasco sem contaminantes e livre de solventes orgânicos para análise dos níveis de excreção de selênio. Estas também foram armazenadas em freezer $-80^{\circ} \mathrm{C}$ até o momento da análise. 


\subsection{4 - REAGENTES}

Todos os reagentes utilizados nas análises foram de grau de pureza analítica P. A., e a água utilizada no preparo das soluções e diluição das amostras foi do tipo MiliQ ${ }^{\circledR}$, com exceção da água utilizada na análise do polimorfismo que foi autoclavada.

\subsection{5 - CONTROLE DE CONTAMINAÇÃO}

Todo o material utilizado (vidrarias, plásticos, ponteiras, microtubos, etc) para a análise de selênio foi desmineralizado, utilizando-se um banho de ácido nítrico a 30\%, por no mínimo 12 horas, e depois enxaguados pelo menos 10 vezes consecutivas com água deionizada, minimizando assim a contaminação por minerais. Os materiais utilizados para a extração do DNA, tais como pipetas e microtubos foram previamente autoclavados.

\subsection{6 - DETERMINAÇÃO DA CONCENTRAÇÃO Se SANGUÍNEO E URINÁRIO}

A determinação de selênio nas amostras de plasma, eritrócitos e urina foram realizadas por meio do método de espectrometria de absorção atômica por geração de hidretos acoplados a cela de quartzo (HGQTAAS) (74). As amostras de plasma foram primeiramente digeridas por via úmida ácida, em tubos de vidro pirex. Nestas foram adicionados $5 \mathrm{~mL}$ de ácido nítrico 68\% P.A. (MERCK) e mantidos em repouso durante a noite. Em seguida a digestão foi realizada em bloco digestor com temperatura inicial de $50^{\circ} \mathrm{C}$, aumentando-se gradativamente até alcançar, no máximo, $150^{\circ} \mathrm{C}$, a fim de eliminar as substâncias orgânicas e reduzir o Se presente na solução (VI) para selênio IV. Em seguida foram acrescidos $5 \mathrm{~mL}$ de HCL 1,2N e aquecidos durante duas horas a uma temperatura de $100^{\circ} \mathrm{C}$. Após este procedimento essas soluções foram diluídas para $25 \mathrm{~mL}$ com água deionizada e submetidas à leitura de selênio. Para o controle da metodologia de análise de Se adotou-se como padrão de referência o material certificado SERONORM $^{\circledR}$, cujo conteúdo do frasco foi dissolvido conforme orientação do fabricante, e realizado o processamento por digestão ácida via úmida, como nas demais amostras. Os resultados foram expressos em $\mu \mathrm{g} / \mathrm{L}$, com exceção do Se urinário, que foi expressado por grama de creatinina. 


\subsection{7 - DETERMINAÇÃO DE CREATININA}

Foi realizada dosagem de creatinina na urina pelo método cinético com Kit comercial da ROCHE $^{\circledR}$, lido em analisador bioquímico automático COBAS INTEGRA, em comprimento de onda de $510 \mathrm{~nm}$.

\subsection{8 - DETERMINAÇÃo DOS POLIMORFISMOS Pro198Leu, -602A/G e Arg5Pro DA ENZIMA GPx1}

Para análise de genotipagem o DNA do sangue total foi extraído a partir do kit Purelink Genomic DNA, da Invitrogen, Life Technologies. O DNA foi quantificado em espectrofotômetro Nanodrop, sendo o resultado expresso em ng/mL. Utilizou-se a razão 260/280 superior a 1,7 e inferior a 2,0, como parâmetro de qualidade do DNA. Amostras com a razão abaixo desse valor foram reextraídas. Em seguida, a concentração do DNA genômico de todas as amostras foi ajustado com água autoclavada para uma concentração de $10 \mathrm{ng} / \mathrm{mL}$ e volume final de $20 \mu \mathrm{L}$. Um total de $2 \mu \mathrm{L}$ de DNA foi usado para a reação em cadeia da polimerase e $18 \mu \mathrm{L}$ de solução contendo o master mix específico para o ensaio de genotipagem (Taqman ${ }^{\circledR}$ genotyping master mix - Applied Biosystems ${ }^{\circledR}$ ) com sondas Taqman (Custom Taqman® ${ }^{\circledR}$ SNP Genotyping Assay, Human; Alelo 1: VIC/MGBNFQ; Alelo 2: FAM/MGB-NFQ). Foram desenhados primers específicos pela Life Technologies para os SNP Pro198Leu (primer forward - CATCGAAGCCCTGCTGTCT; primer reverse - CACTGCAACTGCCAAGCA) e Arg5Pro (primer forward GCTGGCTTCTTGGACAATTGC; primer reverse - GCGCCGAGAAGGCATACA). Os primers específicos do SNP -602A/G foram adquiridos também da Life Technologies, porém já customizados. Para tal, a sequência utilizada foi a seguinte:

CCCTCCCTGGCCTCCTCAGGCTGCA[C/T]TCACCCTACCCCCAAATCTGAACCA.

A genotipagem da população do estudo foi realizada pelo sistema TaqMan SNP Genotyping Assays, da Applyed Biosystems, utilizando as condições de termociclagem recomendadas pelo fabricante. Este sistema é baseado na análise end-point da RT-PCR (Real time - PCR, ou Reação em cadeia da Polimerase em Tempo Real). 


\subsection{9 - DETERMINAÇÕES DOS PARÂMETROS LIPÍDICOS}

A determinação do perfil lipídico foi realizada em um analisador bioquímico automático (COBAS INTEGRA) segundo o método colorimétrico enzimático utilizando kit comercial Roche. Os parâmetros avaliados foram colesterol total (CT), triglicerídeos (TG), lipoproteína de baixa densidade (LDL) e lipoproteína de alta densidade (HDL), os quais foram classificados de acordo com o Quadro 2 abaixo.

Quadro 2. Classificação das medidas de perfil lipídico de acordo com a Sociedade Brasileira de Cardiologia (136).

\begin{tabular}{|c|c|c|}
\hline Variáveis & Categorias & Referência \\
\hline $\mathrm{CT}(\mathrm{mg} / \mathrm{dL})$ & $\begin{array}{c}\text { Ótimo } \\
\text { Limítrofe } \\
\text { Alto }\end{array}$ & $\begin{array}{c}<200 \\
200-239 \\
\geq 240\end{array}$ \\
\hline LDL (mg/dL) & $\begin{array}{c}\text { Ótimo } \\
\text { Desejável } \\
\text { Limítrofe } \\
\text { Alto } \\
\text { Muito alto }\end{array}$ & $\begin{array}{c}<100 \\
100-129 \\
130-159 \\
160-189 \\
\geq 190\end{array}$ \\
\hline HDL (mg/dL) & $\begin{array}{c}\text { Baixo } \\
\text { Limítrofe } \\
\text { Alto }\end{array}$ & $\begin{array}{c}<40 \\
40-60 \\
\geq 60\end{array}$ \\
\hline $\mathrm{TG}(\mathrm{mg} / \mathrm{dL})$ & $\begin{array}{c}\text { Ótimo } \\
\text { Limítrofe } \\
\text { Alto } \\
\text { Muito alto }\end{array}$ & $\begin{array}{c}<150 \\
150-200 \\
200-499 \\
\geq 500\end{array}$ \\
\hline
\end{tabular}

Legenda: CT - colesterol total; TG - triglicerídeos; HDL - lipoproteína de alta densidade; LDL - lipoproteína de baixa densidade;

\subsubsection{0 - AVALIAÇÃO DO BALANÇO REDOX}

\subsubsection{1 - DETERMINAÇÃO DA CONCENTRAÇÃO PLASMÁTICA DE MDA}

A peroxidação lipídica foi determinada no Departamento de Análises Clínicas e Toxicológicas da Faculdade de Ciências Farmacêuticas da Universidade de São Paulo (USP), mediante análise das concentrações de MDA no plasma por cromatografia líquida de alta eficiência (HPLC/PDA), quantificando a reação do MDA com dinitrofenilhidrazina (DNPH) utilizando absorbância de 308 nm, seguindo-se método adaptado de Rezaei, Jamshidzadeh e Sanati (137). 
Antes do processamento das amostras foi construída uma curva de calibração utilizando uma solução estoque de MDA com $22 \mu \mathrm{L}$ de tetramethoxypropano e $10 \mathrm{~mL}$ de ácido sulfúrico a $1 \%$. Os pontos da curva utilizados foram 0,$0 ; 0,25 ; 0,5 ; 1,0 ; 2,0 ; 4,0 ; 6,0$ e $12,0 \mu \mathrm{M}$.

O HPLC utilizado é da marca Shimadzu (Kyoto, Japão), equipado com coluna Phenomenex Reverse-phase C18 de $240 \mathrm{~mm}$ x 4,6 $\mathrm{mm}$ com partículas de $5 \mu \mathrm{m}$ (Phenomenex, Torrance, CA). A temperatura no amostrador foi mantida em $4^{\circ} \mathrm{C}$, e a temperatura da coluna a $25^{\circ} \mathrm{C}$. A eluição foi realizada em modo isocrático com uma fase móvel constituída de $50 \%$ de $\mathrm{H}_{2} \mathrm{O}$ deionizada e $50 \%$ de acetronitrila, acidificada com $2 \%$ de ácido acético. A taxa de fluxo de ingestão da amostra foi de $1 \mathrm{~mL} / \mathrm{minuto} \mathrm{e} \mathrm{o} \mathrm{tempo} \mathrm{de}$ corrida de 15 minutos.

Em microtubos, contendo $100 \mu \mathrm{L}$ de plasma foram adicionados $10 \mu \mathrm{L}$ de hidróxido de sódio 4M. Esta hidrólise alcalina teve o objetivo de liberar o MDA das proteínas plasmáticas. Após agitação no vórtex, as amostras foram incubadas no aparelho vortemp® a $60^{\circ} \mathrm{C}$ durante 30 minutos, para em seguida serem incubadas no gelo por 5 minutos.

Após resfriamento, acrescentou-se $150 \mu \mathrm{L}$ de ácido sulfúrico a $1 \%$ e agitou-se no vórtex vigorosamente, para precipitação das proteínas. Depois incubou-se novamente no gelo por mais 5 minutos. Em seguida, procedeu-se a centrifugação a $14000 \mathrm{rpm}$ por 10 minutos e retirou-se $175 \mu \mathrm{L}$ do sobrenadante, que foram transferidos para um novo microtubo, no qual foi acrescido $25 \mu \mathrm{L}$ de $\mathrm{DNPH}(0,001 \mathrm{~g} / \mathrm{mL})$ permanecendo à temperatura ambiente por 30 minutos, protegidos da luz. Posteriormente, centrifugou-se o microtubo a $14000 \mathrm{rpm}$ por 5 minutos e transferiu-se $150 \mu \mathrm{L}$ do sobrenadante para um vial, do qual foi injetado $100 \mu \mathrm{L}$ no HPLC.

\subsubsection{2 - DETERMINAÇÃO DA ATIVIDADE DA ENZIMA GPX}

A determinação da atividade da GPx foi realizada em eritrócitos com o auxílio de kits comerciais (Ransel 505 - Randox Laboratories, Crumlin/UK) adaptados para o uso em analisador bioquímico automático LABMAX.

O método se baseia na reação em que a GPx catalisa a oxidação da glutationa reduzida por um peróxido de hidrogênio. Na presença de GPx e NADPH, a glutationa oxidada é imediatamente convertida à forma reduzida com a oxidação concomitante do NADPH em NADH ${ }^{+}$. A leitura das amostras é realizada em absorbância de 340 nm (138). 
Para determinação da GPx, foram adicionados a $50 \mu \mathrm{L}$ da amostra $1 \mathrm{~mL}$ do diluente fornecido pelo kit, e após 5 minutos de incubação à temperatura ambiente, acrescentou-se $1 \mathrm{~mL}$ de drabkin concentrado. A concentração de hemoglobina do hemolisado foi determinada e o resultado final expresso em unidades de enzima por grama de hemoglobina.

A dosagem de hemoglobina $(\mathrm{Hb})$ foi realizada pelo método da cianometahemoglobina com Kit LABTEST ${ }^{\circledR}$ e lido em leitor de microplaca automatizado Biotech Synergy H1, com comprimento de onda de $540 \mathrm{~nm}$.

\subsubsection{3 - DETERMINAÇÃO DA ATIVIDADE DA ENZIMA SOD}

A determinação da enzima SOD também foi realizada nos eritrócitos, pelo método in vitro, em um analisador bioquímico LABMAX, usando kit comercial da Randox Laboratories (Ransod; Randox Laboratories, Crumlin/UK), conforme metodologia recomendada pelo fabricante.

Este método emprega xantina $(0,05 \mathrm{mmol} / \mathrm{L})$ e xantina oxidase $(80 \mathrm{U} / \mathrm{L})$ para gerar radicais superóxidos que irão reagir com 2-(4-iodofenil)-3-(4 nitrofenol)-5-cloreto de feniltetrazol para formar o composto vermelho de formazan. A atividade da SOD é medida por meio do grau de inibição desta reação. Para tanto, a amostra é diluída com tampão fosfato $(0,01 \mathrm{~mol} / \mathrm{L} \mathrm{pH} \mathrm{7,0)} \mathrm{de} \mathrm{forma} \mathrm{que} \mathrm{o} \mathrm{grau} \mathrm{de} \mathrm{inibição} \mathrm{fique} \mathrm{entre} 30 \%$ e $60 \%$.

A amostra foi diluída em dois lisados, sendo que o primeiro era composto de 100 $\mu \mathrm{L}$ da amostra diluído em $900 \mu \mathrm{L}$ de tampão fosfato, e o segundo, $100 \mu \mathrm{L}$ do lisado anterior em 2,9 mL de tampão fosfato. A concentração da hemoglobina também foi utilizada para expressar o resultado da enzima em unidades por grama de hemoglobina.

\subsubsection{4 - DETERMINAÇÃO DA CAPACIDADE DE ABSORÇÃO DE RADICAIS DE OXIGÊNIO (ORAC)}

A capacidade antioxidante total do plasma foi avaliada através do método ORAC (oxygen radical absorbance capacity) e determinada de acordo com Prior et al (139). As amostras de plasma foram desproteinizadas pela adição de $400 \mu \mathrm{L}$ de ácido perclórico 0,5M, sendo homogeneizadas em vórtex por 5 segundos e centrifugadas a $14000 \mathrm{rpm}$ por 5 minutos a $20^{\circ} \mathrm{C}$ para a retirada do sobrenadante. Em seguida, as amostras foram diluídas $5 \mathrm{x}$ em tampão fosfato $75 \mathrm{mM} \mathrm{pH} \mathrm{7,4.} 25 \mu \mathrm{L}$ de plasma, $150 \mu \mathrm{L}$ de fluoresceína (40nm) em tampão fosfato $75 \mathrm{mM}$ e $25 \mu \mathrm{L}$ de 2,2'-azobis (2-methylpropionamidine) dihydrocloride 
(AAPH - $153 \mathrm{nM}$ ) em água foram adicionados na microplaca, sendo apenas o primeiro realizado manualmente. A solução de AAPH foi preparada no momento da análise e antes de sua adição, a placa foi incubada a $37^{\circ} \mathrm{C}$. O tampão fosfato foi utilizado como branco e como padrão, preparou-se solução de Trolox em tampão fosfato utilizados no preparo da curva, nas seguintes concentrações: $100 \mu \mathrm{M}, 50 \mu \mathrm{M}, 25 \mu \mathrm{M}, 12,5 \mu \mathrm{M}, 6,25 \mu \mathrm{M}$. Após a adição de todos os reagentes na placa, a fluorescência foi lida a cada minuto, por 80 minutos e usados os filtros de emissão de $520 \mathrm{~nm}$ e excitação de $485 \mathrm{~nm}$. A leitura foi obtida por meio de um leitor de microplaca automatizado Biotech Synergy H1 e os reagentes adicionados através do uso de dispensadores acoplados ao equipamento. A capacidade antioxidante foi determinada pela curva resultante da perda de fluorescência versus a concentração de antioxidante e foi expressa em mol equivalentes de Trolox/ $\mathrm{mL}$ de plasma. As determinações foram realizadas em triplicata.

\section{6 - ANÁLISE ESTATÍSTICA}

As análises estatísticas deste trabalho foram realizadas no software R versão 3.0.2. Inicialmente verificou-se a presença de outliers utilizando o gráfico de caixas (boxplot) e decidiu-se pela exclusão ou não das amostras. Em seguida, testou-se a normalidade dos dados usando o teste de Kolmogorov-Smirnov, e a homogeneidade de variância, pelo teste de Levene. Para a comparação entre duas médias, quando os dados apresentaram-se normais e homogêneos utilizou-se o teste $\mathrm{t}$ de Student para amostras independentes, e quando não, o teste de Mann-Whitney. Para a comparação entre mais de duas médias, quando os dados apresentaram-se normais e homogêneos utilizou-se o teste de ANOVA, e quando não, o teste de Kruskal-Wallis, seguidos do pós-teste de Tukey. Também utilizouse o teste de qui-quadrado considerando-se um grau de liberdade, para a determinação do equilíbrio de Hardy-Weinberg. Para a investigação da existência de blocos de haplótipos entre os SNP avaliados, bem como dos valores D e $\mathrm{r}^{2}$, utilizou-se o software Haploview 4.2. Os dados foram considerados significativos com $\mathrm{p}$ menor que $5 \%$.

Construiu-se três modelos de regressão linear univariados para a variável dependente GPx, tendo como variáveis independentes em cada um deles os SNP Pro198Leu, -602A/G e Arg5Pro. Também se construiu um modelo de regressão múltipla para cada uma das variáveis dependentes: Se plasmático, Se eritrocitário, GPx, SOD, MDA e ORAC. As variáveis independentes testadas no modelo foram: prática de atividade física, 
consumo de álcool e hábito de fumar (categorização: sim ou não); renda familiar (categorização: acima ou abaixo de dois salários mínimos); IMC, CT, TG, LDL, HDL e circunferência da cintura com e sem categorização (categorização: com e sem excesso ou tercil); \% de gordura corporal com e sem categorização (categorização: aumentado ou não ou tercil); idade; consumo de proteínas, carboidratos, lipídios com ou sem categorização (categorização: tercil); polimorfismos Pro198Leu, -602A/G e Arg5Pro. As variáveis categorizadas em tercil e os três polimorfismos foram classificadas em Dummys para serem testadas nos modelos.

Para os modelos do Se plasmático, Se eritrocitário, GPx, MDA e ORAC utilizou-se uma regressão linear e para a SOD, utilizou-se a regressão linear generalizada com distribuição gama e função de ligação log. Em todos os modelos, o método de seleção para as variáveis foi o forward e, adotou-se como critério para a seleção das variáveis na modelagem o valor de $\mathrm{p} \leq 0,20$ nas regressões simples. Para a manutenção das variáveis no modelo, os critérios adotados foram: $\mathrm{p} \leq 0,05$ ou redução em pelo menos $10 \%$ o valor do $\beta_{\text {estimado }}$ de pelo menos uma das demais variáveis quando comparados ao modelo anterior.

Para verificação das suposições feitas para o ajuste dos modelos, foi feita a análise de diagnóstico e de sensibilidade dos modelos finais, constatando-se que os modelos estavam bem ajustados. 


\section{0 - RESULTADOS}

\section{1 - CARACTERIZAÇÃO DA POPULAÇÃO}

\subsection{1 - DADOS SOCIOECONÔMICOS E CLÍNICOS}

Participaram do estudo 343 indivíduos adultos com idade média de 24,4 \pm 5,0 anos, sendo $57,7 \%$ do sexo feminino. Destes participantes, 53,3\% possuíam renda familiar entre 1 e 3 salários mínimos, 85,1\% tinham o ensino superior incompleto e 91,7\% eram de descendência sul-americana, não havendo indivíduos orientais (Tabela 1 e Tabela 2).

Pela classificação do índice de massa corporal (IMC) observa-se que 12,5\% apresentaram déficit de peso, 23,8\% apresentam excesso de peso e 6\% obesidade (Tabela $1)$.

A medida da circunferência da cintura (CC) mostrou que 12,6\% dos indivíduos têm risco de complicações metabólicas. A classificação do percentual de gordura corporal indicou que 70,2\% dos indivíduos possuem risco de doenças associadas ao sobrepeso e obesidade (Tabela 1).

A análise do perfil lipídico apontou que os valores de CT, TG e LDL encontravamse dentro da faixa recomendada para $80,8 \%, 88,3 \%$ e $83,6 \%$ dos indivíduos, respectivamente. No entanto, 39,9\% dos participantes apresentaram baixas concentrações de HDL (Tabela 1).

Tanto as médias das medidas antropométricas quanto do perfil lipídico encontravam-se dentro da faixa recomendada. Com exceção do percentual de gordura corporal que apresentou média acima do recomendado (Tabela 2).

As doenças mais relatadas no histórico de doenças dos familiares dos participantes foram diabetes, doenças cardiovasculares e hipertensão. O total de participantes que relataram beber, fumar e não praticar exercícios físicos foi 33,6\%, 2,3\% e 59,2\%, respectivamente (Tabela 1 ). 
Tabela 1. Distribuição dos indivíduos adultos do estado do Piauí segundo os aspectos socioeconômicos e clínicos

\begin{tabular}{|c|c|c|c|}
\hline Variáveis & Classificação & $\mathbf{n}$ & $\%$ \\
\hline \multicolumn{4}{|c|}{ Dados Socioeconômicos } \\
\hline \multirow{3}{*}{ Sexo } & Feminino & 198 & 57,7 \\
\hline & Masculino & 145 & 42,3 \\
\hline & Total & 343 & 100,0 \\
\hline \multirow{7}{*}{ Renda } & $<1 \mathrm{SM}$ & 12 & 3,5 \\
\hline & $>1$ a $2 \mathrm{SM}$ & 92 & 27,1 \\
\hline & $>2$ a $3 \mathrm{SM}$ & 89 & 26,2 \\
\hline & $>3$ a $4 \mathrm{SM}$ & 49 & 14,4 \\
\hline & $>4$ a $5 \mathrm{SM}$ & 45 & 13,2 \\
\hline & $>5 \mathrm{SM}$ & 53 & 15,6 \\
\hline & Total & 340 & 100,0 \\
\hline \multirow{3}{*}{ Exercício } & Sim & 139 & 40,8 \\
\hline & Não & 202 & 59,2 \\
\hline & Total & 341 & 100,0 \\
\hline \multirow{3}{*}{ Beber } & Não & 227 & 66,4 \\
\hline & Sim & 115 & 33,6 \\
\hline & Total & 342 & 100,0 \\
\hline \multirow{3}{*}{ Fumar } & Não & 334 & 97,7 \\
\hline & Sim & 8 & 2,3 \\
\hline & Total & 342 & 100,0 \\
\hline \multirow{5}{*}{ Escolaridade } & EFI & 1 & 0,3 \\
\hline & EMC & 4 & 1,2 \\
\hline & ESI & 292 & 85,1 \\
\hline & ESC & 46 & 13,4 \\
\hline & Total & 343 & 100,0 \\
\hline \multicolumn{4}{|c|}{ Doenças de antecedentes familiares } \\
\hline \multirow{3}{*}{ Obesidade } & Não & 244 & 71,6 \\
\hline & Sim & 97 & 28,4 \\
\hline & Total & 341 & 100,0 \\
\hline \multirow{3}{*}{ Hipertensão } & Não & 115 & 33,7 \\
\hline & Sim & 226 & 66,3 \\
\hline & Total & 341 & 100,0 \\
\hline \multirow{3}{*}{ Diabetes } & Não & 188 & 55,1 \\
\hline & Sim & 153 & 44,9 \\
\hline & Total & 341 & 100,0 \\
\hline \multirow{3}{*}{$\begin{array}{l}\text { Doenças } \\
\text { Cardiovasculares }\end{array}$} & Não & 203 & 59,9 \\
\hline & Sim & 136 & 40,1 \\
\hline & Total & 339 & 100,0 \\
\hline \multirow{3}{*}{ Dislipidemia } & Não & 210 & 61,9 \\
\hline & Sim & 129 & 38,1 \\
\hline & Total & 339 & 100,0 \\
\hline
\end{tabular}




\begin{tabular}{|c|c|c|c|}
\hline \multirow[b]{3}{*}{ Câncer } & Não & 338 & 98,5 \\
\hline & Não sabiam & 5 & 1,5 \\
\hline & Total & 343 & 100,0 \\
\hline \multicolumn{4}{|c|}{ Variáveis antropométricas } \\
\hline \multirow{8}{*}{ IMC } & Magreza Classe III & 1 & 0,3 \\
\hline & Magreza Classe II & 6 & 1,8 \\
\hline & Magreza Classe I & 35 & 10,4 \\
\hline & Eutrofia & 194 & 57,7 \\
\hline & Pré-obesidade & 80 & 23,8 \\
\hline & Obesidade Classe I & 15 & 4,5 \\
\hline & Obesidade Classe II & 5 & 1,5 \\
\hline & Total & 336 & 100,0 \\
\hline \multirow{4}{*}{$\mathrm{CC}$} & Sem risco & 297 & 87,4 \\
\hline & Risco elevado & 30 & 8,8 \\
\hline & Risco muito elevado & 13 & 3,8 \\
\hline & Total & 340 & 100,0 \\
\hline \multirow{6}{*}{ \% de GC } & $\begin{array}{l}\text { Risco de doença associado a } \\
\text { sobrepeso e obesidade }\end{array}$ & 73 & 21,9 \\
\hline & Risco acima da média & 161 & 48,3 \\
\hline & Risco médio & 13 & 3,9 \\
\hline & Risco abaixo da média & 85 & 25,5 \\
\hline & Risco de doença & 1 & 0,3 \\
\hline & Total & 333 & 100,0 \\
\hline \multicolumn{4}{|c|}{ Perfil lipídico } \\
\hline \multirow{4}{*}{ CT } & Ótimo & 277 & 80,8 \\
\hline & Limítrofe & 48 & 14,0 \\
\hline & Alto & 18 & 5,2 \\
\hline & Total & 343 & 100,0 \\
\hline \multirow{5}{*}{ TG } & Ótimo & 303 & 88,3 \\
\hline & Limítrofe & 24 & 7,0 \\
\hline & Alto & 15 & 4,4 \\
\hline & Muito alto & 1 & 0,3 \\
\hline & Total & 343 & 100,0 \\
\hline \multirow{4}{*}{ HDL } & Baixo & 80 & 23,3 \\
\hline & Limítrofe & 192 & 56,0 \\
\hline & Desejável & 71 & 20,7 \\
\hline & Total & 343 & 100,0 \\
\hline \multirow{6}{*}{ LDL } & Ótimo & 185 & 53,9 \\
\hline & Desejável & 102 & 29,7 \\
\hline & Limítrofe & 36 & 10,5 \\
\hline & Alto & 15 & 4,4 \\
\hline & Muito alto & 5 & 1,5 \\
\hline & Total & 343 & 100,0 \\
\hline
\end{tabular}

Legenda: EFI - ensino fundamental incompleto; EMC - ensino médio completo; ESI - ensino superior incompleto; ESC - ensino superior completo; IMC - índice de massa corpórea; CC - circunferência da cintura; \% de GC - percentual de gordura corporal; CT - colesterol total; TG - triglicerídeos; HDL lipoproteína de alta densidade; LDL - lipoproteína de baixa densidade; 
Tabela 2. Medidas de tendência central e dispersão das variáveis idade, antropometria e perfil lipídico de indivíduos adultos do estado do Piauí

\begin{tabular}{|c|c|c|c|c|}
\hline Variáveis & $\mathbf{n}$ & Mínimo & Máximo & Média (DP) \\
\hline Idade & 343 & 20 & 49,9 & $24,4(5,0)$ \\
\hline IMC & 336 & 13 & 38 & $22,8(4,0)$ \\
\hline CC Feminino & 195 & 55,5 & 102,9 & $71,2(7,7)$ \\
\hline Masculino & 145 & 62,3 & 119,0 & $82,4(10,6)$ \\
\hline$\%$ de GC Feminino & 190 & 8,0 & 51,0 & $26,9(6,5)$ \\
\hline Masculino & 143 & 6,0 & 35,0 & $19,7(6,5)$ \\
\hline CT & 343 & 91,7 & 322 & $172,7(36,7)$ \\
\hline TG & 343 & 29 & 707 & $100,0(63,9)$ \\
\hline LDL & 343 & 19 & 240 & $102,7(31,8)$ \\
\hline HDL & 343 & 24 & 104 & $50,0(13,75)$ \\
\hline
\end{tabular}

Legenda: DP - desvio padrão; IMC - índice de massa corpórea; CC - circunferência da cintura; $\%$ de GC - percentual de gordura corporal; CT - colesterol total; TG - triglicerídeos; HDL lipoproteína de alta densidade; LDL - lipoproteína de baixa densidade;

\subsection{2 - CONSUMO ALIMENTAR}

Foi possível avaliar o consumo alimentar de 285 participantes, os quais responderam os registros alimentares. A média do consumo energético foi 2139,24 \pm 680,70 kcal/dia. Quanto aos macronutrientes, a média do percentual de contribuição calórica de proteínas, carboidratos e lipídios foi de 19,7\%, 56,8\% e 30,6\%, respectivamente. Cerca de $25,4 \%$ e $26,7 \%$ dos indivíduos consumiam carboidratos e lipídios acima do recomendado, respectivamente (Figura 5). 
Figura 5. Distribuição dos indivíduos adultos segundo a adequação da ingestão dos macronutrientes de acordo com a recomendação da distribuição em percentual da energia (133)

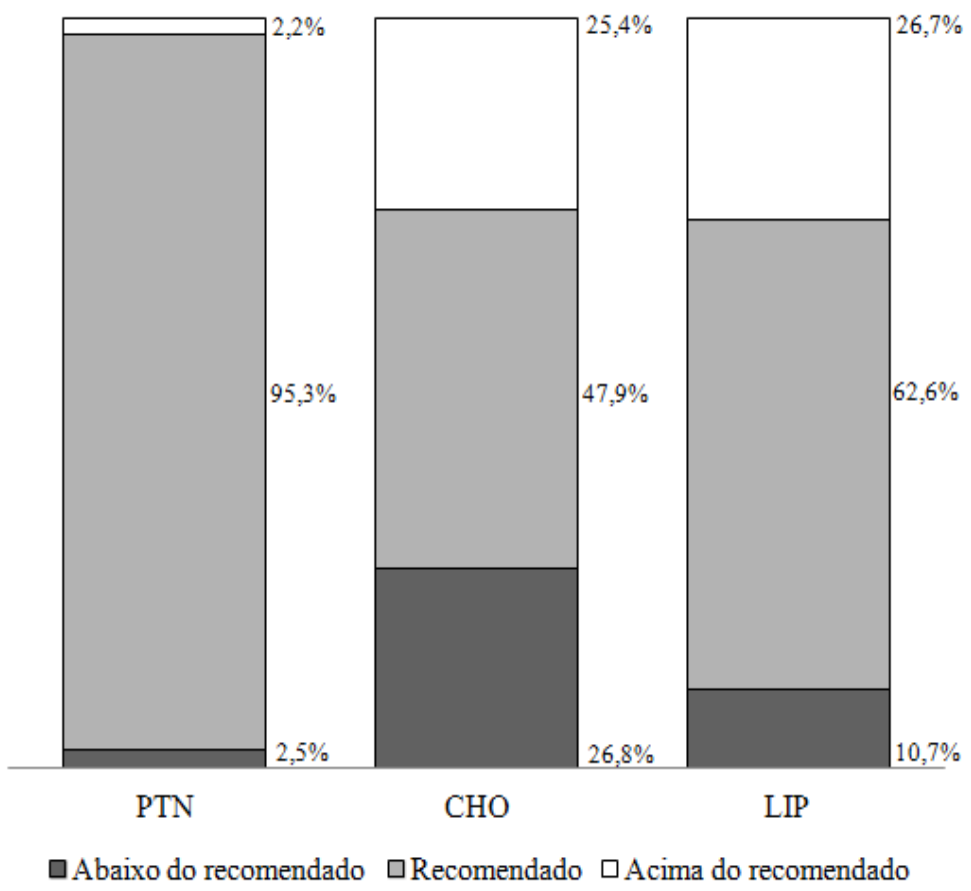

A avaliação da ingestão alimentar de selênio indicou prevalência de inadequação de 9,18\% entre os participantes. A média de ingestão do mineral foi de 60,53 $\pm 11,64 \mu \mathrm{g} / \mathrm{dia}$, não diferindo entre os sexos (Tabela 3).

Tabela 3. Ingestão alimentar de selênio ( $\mu \mathrm{g} / \mathrm{dia})$ dos indivíduos adultos do estado do Piauí segundo o sexo

\begin{tabular}{lcccccc}
\hline Se consumido & $\mathrm{n}$ & Mínimo & Máximo & Média (DP) & $\begin{array}{c}\text { Probabilidade } \\
\text { de inadequação }\end{array}$ & $\mathrm{p}^{*}$ \\
\hline Feminino & 164 & 31,9 & 101,89 & $60,13(11,37)$ & 9,18 & \\
Masculino & 108 & 34,8 & 117,5 & $61,14(12,08)$ & 9,01 & 0,487 \\
Total & 272 & 31,9 & 117,5 & $60,53(11,64)$ & 9,18 & \\
\hline
\end{tabular}

Legenda: DP - desvio padrão; * - teste t de Student para amostras independente considerando $\mathrm{p}<0,05$ aplicado para os valores da concentração de Se ingerido entre os sexos.

\subsection{3 - GENOTIPAGEM DOS POLIMORFISMOS Pro198Leu, -602A/G e Arg5Pro DA GPx1}

Do total de participantes foi identificado que $47,81 \%, 90,67 \%$ e $2,62 \%$ eram carreadores do alelo variante dos SNP Pro198Leu (rs1050450), -602A/G (rs3811699) e 
Arg5Pro, respectivamente. A população estava em equilíbrio de Hardy-Weinberg para todos os SNP, pois a probabilidade associada aos valores do qui-quadrado $\left(\chi^{2}\right)$, considerando um grau de liberdade, foi maior que 5\% (Tabela 4).

Tabela 4. Distribuição dos indivíduos adultos do estado do Piauí de acordo com os genótipos dos polimorfismos Pro198Leu, -602A/G e Arg5Pro da GPx1

\begin{tabular}{|c|c|c|c|c|c|c|c|}
\hline \multirow[t]{2}{*}{ SNP } & \multirow[t]{2}{*}{ Genótipo } & \multicolumn{2}{|c|}{ Frequência } & \multirow{2}{*}{$\begin{array}{c}\mathbf{n}^{\mathbf{o}} \text { de } \\
\text { IE }\end{array}$} & \multirow{2}{*}{$\begin{array}{c}\mathbf{n}^{\mathbf{0}} \text { de } \\
\text { IO }\end{array}$} & \multirow{2}{*}{$\begin{array}{c}\% \text { de } \\
\text { IO }\end{array}$} & \multirow[t]{2}{*}{$\chi^{2}$} \\
\hline & & Genótipo & Alelo & & & & \\
\hline & Pro/Pro & 0,514 & Pro - 0,717 & 176,4 & 179 & 52,2 & \\
\hline \multirow[t]{4}{*}{ Pro198Leu } & Pro/Leu & 0,406 & Leu - 0,283 & 139,1 & 134 & 39,1 & 0,47 \\
\hline & Leu/Leu & 0,080 & & 27,4 & 30 & 8,7 & \\
\hline & Total & & & 343,0 & 343 & 100,0 & \\
\hline & GG & 0,082 & $G-0,287$ & 28,3 & 32 & 9,3 & \\
\hline \multirow[t]{4}{*}{$-602 A / G$} & GA & 0,409 & $A-0,713$ & 140,4 & 133 & 38,8 & 0,95 \\
\hline & AA & 0,508 & & 174,3 & 178 & 51,9 & \\
\hline & Total & & & 343,0 & 343 & 100,0 & \\
\hline & Arg/Arg & 0,974 & Arg - 0,987 & 334,1 & 334 & 97,4 & \\
\hline \multirow[t]{3}{*}{ Arg5Pro } & Arg/Pro & 0,026 & Pro - 0,013 & 8,9 & 9 & 2,6 & 0,06 \\
\hline & Pro/Pro & 0,000 & & 0,1 & 0 & 0,0 & \\
\hline & Total & & & 343,0 & 343 & 100,0 & \\
\hline
\end{tabular}

Legenda: IO - indivíduos observados; IE - indivíduos esperados

A análise de haplótipos com os sujeitos desta pesquisa apontou um forte desequilíbrio de ligação ( $\mathrm{D}^{\prime}=0,79 ; \mathrm{r}^{2}=0,97$ ) entre os SNP Pro198Leu e $-602 \mathrm{~A} / \mathrm{G}$, indicando que os indivíduos que possuíam o alelo Pro do SNP Pro198Leu também tinham o alelo A do -602A/G e aqueles com o alelo Leu do Pro198Leu também tinham o G do 602A/G. Desta forma, as informações obtidas para o alelo Leu do SNP Pro198Leu serão as mesmas para o alelo $\mathrm{G}$ do $-602 \mathrm{~A} / \mathrm{G}$ e serão comentadas a seguir. 


\section{3 - MARCADORES BIOQUÍMICOS DO ESTADO NUTRICIONAL DE Se}

A média (desvio padrão) das concentrações de Se nos compartimentos biológicos plasma, eritrócitos, urina e no consumo alimentar foi de 54,91 $(13,21)(\mu \mathrm{g} / \mathrm{L}), 70,85(15$, 30) $(\mu \mathrm{g} / \mathrm{L}), 6,43(2,64)(\mu \mathrm{g} \mathrm{Se} / \mathrm{g}$ de creatinina) e 60,53 $(11,64)(\mu \mathrm{g} / \mathrm{dia})$, respectivamente. Apenas o Se eritrocitário e urinário ( $\mu \mathrm{g} \mathrm{Se} / \mathrm{g}$ de creatinina) apresentaram diferença significativa $(\mathrm{p}<0,01)$ para o SNP Arg5Pro, sendo que aqueles que eram carreadores do alelo variante tinham maior média de Se (Tabela 5).

Segundo o modelo de regressão linear do Se plasmático, observou-se que os sujeitos que ingerem bebida alcoólica tem $4,58 \mu \mathrm{g} / \mathrm{L}$ a mais de Se que aqueles que não ingerem (Tabela 6) e, aqueles que têm renda familiar menor que dois salários mínimos têm 3,57 $\mu \mathrm{g} / \mathrm{L}$ a menos que aqueles com renda superior a dois salários mínimos.

O modelo do Se eritrocitário evidenciou que indivíduos com renda familiar menor que dois salários mínimos têm $6,01 \mu \mathrm{g} / \mathrm{L}$ a menos que aqueles com renda superior a dois salários mínimos; a presença do alelo Pro do SNP Arg5Pro aumenta o Se eritrocitário em $16,19 \mu \mathrm{g} / \mathrm{L}$; e indivíduos que não praticam exercício físico têm $5,03 \mu \mathrm{g} / \mathrm{L}$ de Se a mais que aqueles que praticam exercício (Tabela 6).

Tabela 5. Medidas de tendência central e dispersão das concentrações de Se plasmático, eritrocitário e urinário dos indivíduos adultos do estado do Piauí de acordo com os genótipos dos SNP Pro198Leu, -602A/G e Arg5Pro

\begin{tabular}{|c|c|c|c|c|c|c|c|}
\hline Parâmetro & SNP & Genótipo & $\mathbf{n}$ & Mínimo & Máximo & MD (DP) & $\mathbf{p}$ \\
\hline \multirow{9}{*}{$\begin{array}{c}\mathrm{Se} \\
\text { plasmático } \\
(\mu \mathrm{g} / \mathrm{L})\end{array}$} & \multirow[b]{3}{*}{ Pro198Leu } & Pro/Pro & 179 & 24,84 & 89,37 & $54,36(13,90)$ & \multirow{3}{*}{$0,419^{\S}$} \\
\hline & & Pro/Leu & 133 & 32,81 & 87,83 & $56,03(12,41)$ & \\
\hline & & Leu/Leu & 30 & 29,52 & 80,71 & $53,26(12,39)$ & \\
\hline & \multirow[b]{3}{*}{$-602 \mathrm{~A} / \mathrm{G}$} & GG & 32 & 29,52 & 80,71 & $53,56(12,05)$ & \multirow{3}{*}{$0,458^{\S}$} \\
\hline & & GA & 132 & 32,81 & 87,83 & $56,00(12,46)$ & \\
\hline & & $\mathrm{AA}$ & 178 & 24,84 & 89,37 & $54,40(14,00)$ & \\
\hline & & Arg/Arg & 333 & 24,84 & 89,37 & $55,00(13,30)$ & \multirow{3}{*}{$0,769^{\dagger}$} \\
\hline & Arg5Pro & Arg/Pro & 9 & 34,25 & 64,03 & $53,63(10,00)$ & \\
\hline & \multicolumn{2}{|c|}{ Total } & 342 & 24,84 & 89,37 & $54,91(13,21)$ & \\
\hline \multirow{7}{*}{$\begin{array}{c}\mathrm{Se} \\
\text { eritrocitário } \\
(\mu \mathrm{g} / \mathrm{L})\end{array}$} & & Pro/Pro & 176 & 43,22 & 109,85 & $71,32(15,50)$ & \multirow{3}{*}{$0,377^{\S}$} \\
\hline & & Pro/Leu & 132 & 45,40 & 111,37 & $71,07(15,40)$ & \\
\hline & Pro198Leu & Leu/Leu & 30 & 45,64 & 89,65 & $67,14(13,64)$ & \\
\hline & & GG & 32 & 45,42 & 102,53 & $67,57(15,15)$ & \multirow{3}{*}{$0,416^{\S}$} \\
\hline & & GA & 131 & 45,4 & 111,37 & $70,83(15,21)$ & \\
\hline & $-602 A / G$ & $\mathrm{AA}$ & 175 & 43,22 & 109,85 & $71,47(15,41)$ & \\
\hline & Arg5Pro & Arg/Arg & 329 & 43,22 & 111,37 & $70,45(15,18)$ & $\mathbf{0 , 0 0 3}^{\dagger}$ \\
\hline
\end{tabular}




\begin{tabular}{|c|c|c|c|c|c|c|c|}
\hline & \multicolumn{2}{|r|}{ Arg/Pro } & 9 & 68,22 & 104,6 & $85,80(12,64)$ & \\
\hline & Tot & & 338 & 43,22 & 111,37 & $70,85(15,30)$ & \\
\hline \multirow{9}{*}{$\begin{array}{l}\text { Se na urina } \\
(\mu \mathrm{g} / \mathrm{L})\end{array}$} & \multirow[b]{3}{*}{ Pro198Leu } & Pro/Pro & 154 & 1,16 & 18,31 & $6,63(4,50)$ & \multirow{3}{*}{0,839} \\
\hline & & Pro/Leu & 114 & 1,00 & 18,52 & $6,83(4,20)$ & \\
\hline & & Leu/Leu & 26 & 1,99 & 18,40 & $7,13(4,61)$ & \\
\hline & \multirow[b]{3}{*}{$-602 \mathrm{~A} / \mathrm{G}$} & $\mathrm{GG}$ & 28 & 1,99 & 18,4 & $7,00(4,50)$ & \multirow{3}{*}{$0,887^{\S}$} \\
\hline & & GA & 113 & 1 & 18,52 & $6,90(4,20)$ & \\
\hline & & $\mathrm{AA}$ & 153 & 1,16 & 18,31 & $6,64(4,50)$ & \\
\hline & \multirow[b]{2}{*}{ Arg5Pro } & Arg/Arg & 286 & 1 & 18,52 & $6,70(4,30)$ & \multirow{3}{*}{$0,183^{\dagger}$} \\
\hline & & Arg/Pro & 8 & 2,28 & 17,51 & $9,81(6,40)$ & \\
\hline & \multicolumn{2}{|c|}{ Total } & 294 & 1,00 & 18,52 & $6,75(4,40)$ & \\
\hline \multirow{9}{*}{$\begin{array}{l}\text { Se na urina } \\
\text { ( } \mu \mathrm{g} \mathrm{Se} / \mathrm{g} \text { de } \\
\text { creatinina) }\end{array}$} & \multirow[b]{3}{*}{ Pro198Leu } & Pro/Pro & 143 & 1,82 & 14,06 & $6,50(2,70)$ & \multirow{3}{*}{$0,871^{\S}$} \\
\hline & & Pro/Leu & 102 & 0,62 & 13,87 & $6,34(2,70)$ & \\
\hline & & Leu/Leu & 23 & 3 & 10,21 & $6,63(2,30)$ & \\
\hline & \multirow[b]{3}{*}{$-602 \mathrm{~A} / \mathrm{G}$} & GG & 25 & 3,00 & 10,21 & $6,63(2,30)$ & \multirow{3}{*}{$0,899^{\S}$} \\
\hline & & GA & 101 & 0,62 & 13,87 & $6,36(2,70)$ & \\
\hline & & AA & 142 & 1,82 & 14,06 & $6,45(2,70)$ & \\
\hline & & Arg/Arg & 261 & 0,62 & 14,06 & $6,40(2,60)$ & \multirow{3}{*}{$\mathbf{0 , 0 0 6} \mathbf{6}^{\dagger}$} \\
\hline & Arg5Pro & Arg/Pro & 7 & 2,96 & 13,31 & $9,13(3,60)$ & \\
\hline & \multicolumn{2}{|c|}{ Total } & 268 & 0,62 & 14,06 & $6,43(2,64)$ & \\
\hline \multirow{9}{*}{$\begin{array}{c}\mathrm{Se} \\
\text { consumido } \\
(\mu \mathrm{g} / \mathrm{dia})\end{array}$} & \multirow[b]{3}{*}{ Pro198Leu } & Pro/Pro & 142 & 31,90 & 117,50 & $60,30(12,22)$ & \multirow{3}{*}{$0,209^{\S}$} \\
\hline & & Pro/Leu & 105 & 34,80 & 93,58 & $59,92(11,20)$ & \\
\hline & & Leu/Leu & 25 & 49,60 & 88,66 & $64,42(9,60)$ & \\
\hline & \multirow[b]{3}{*}{$-602 \mathrm{~A} / \mathrm{G}$} & $\mathrm{GG}$ & 27 & 49,60 & 88,66 & $64,72(9,29)$ & \multirow{3}{*}{$0,139^{\S}$} \\
\hline & & GA & 104 & 34,80 & 93,58 & $59,84(11,23)$ & \\
\hline & & AA & 141 & 31,90 & 117,50 & $60,24(12,24)$ & \\
\hline & & Arg/Arg & 266 & 31,90 & 117,50 & $60,56(11,50)$ & \multirow{3}{*}{$0,839^{\dagger}$} \\
\hline & Arg5Pro & Arg/Pro & 6 & 39,18 & 86,01 & $59,58(18,35)$ & \\
\hline & \multicolumn{2}{|c|}{ Total } & 272 & 31,90 & 117,50 & $60,53(11,64)$ & \\
\hline
\end{tabular}

Legenda: MD - média; DP - desvio padrão; $\S$ - teste de ANOVA; $\uparrow$ - teste t de Student para amostras independentes; valor $\mathrm{p}$ considerado significativo abaixo de $5 \%$.

Valores de Referências:

Se consumido - Thomson (79): proteção contra alguns cânceres (> $120 \mu \mathrm{g} \mathrm{Se} / \mathrm{dia}$ ); maximização da atividade da GPx e selenoproteína P (> 45 - $50 \mu \mathrm{g}$ Se/dia); atividade ótima das desiodases (> $30 \mu \mathrm{g} \mathrm{Se/dia);} \mathrm{prevenção}$ da doença de Keshan (> $20 \mu \mathrm{g} \mathrm{Se/dia).}$

Se plasmático - Van Dael e Deesltra (98): 60 a $120 \mu \mathrm{g} / \mathrm{L}$; Nève (158): > $70 \mu \mathrm{g} / \mathrm{L}$; Alegria (159): 53 a 109 $\mu \mathrm{g} / \mathrm{L}$; Thomson (79): Proteção contra alguns cânceres (>115 $\mu \mathrm{g} / \mathrm{L}$ de Se plasmático), Maximização da GPx e selenoproteína P (> 80 - $95 \mu \mathrm{g} / \mathrm{L}$ de Se plasmático), Otimização da atividade das deiodinases $(>65 \mu \mathrm{g} / \mathrm{L}$ de Se plasmático) e Prevenção do surgimento da doença de Keshan (> $21 \mu \mathrm{g} / \mathrm{L}$ de Se plasmático).

Se eritrocitário - Van Dael e Deelstra (98): 90 a $190 \mu \mathrm{g} / \mathrm{L}$; Pleban et al. (160): 149 a $250 \mu \mathrm{g} / \mathrm{L}$. 
Tabela 6. Modelos de regressão linear múltiplo para as variáveis dependentes Se plasmático e Se eritrocitário dos indivíduos adultos do estado do Piauí

\begin{tabular}{clccccc}
\hline & & & & \multicolumn{2}{c}{ Intervalo de Confiança de $\beta$ de } \\
Variável & $\begin{array}{c}\text { Variável } \\
\text { Dependente }\end{array}$ & independente & $\boldsymbol{\beta}$ & $\mathbf{p}$ & Limite inferior & Limite Superior \\
\hline & Constante & 54,87 & $<0,001$ & 52,61 & 57,14 \\
Se Plasmático & Beber & 4,58 & $\mathbf{0 , 0 1 1}$ & 1,05 & 8,10 \\
$(\mu \mathrm{g} / \mathrm{L})$ & Renda & $-3,57$ & $\mathbf{0 , 0 4 4}$ & $-7,09$ & $-0,04$ \\
\hline & (Constant) & 68,94 & $<0,001$ & 65,79 & 72,09 \\
& Renda & $-6,01$ & $\mathbf{0 , 0 0 4}$ & $-10,03$ & $-1,99$ \\
Se Eritrocitário & Arg5Pro & 16,19 & $\mathbf{0 , 0 0 9}$ & 4,02 & 28,37 \\
$(\mu \mathrm{g} / \mathrm{L})$ & Exercício & 5,03 & $\mathbf{0 , 0 0 9}$ & 1,25 & 8,82 \\
\hline
\end{tabular}

Referências das variáveis independentes: Beber - indivíduos que ingerem bebida alcoólica comparados aos que não ingerem bebida alcoólica; Renda - renda $<2$ salários mínimos comparados com os de renda $>2$ salários mínimos; Arg5Pro - genótipo Arg/Pro comparados com os de genótipo Arg/Arg; Exercício - não praticam atividade física comparados com os que praticam.

\section{4 - PARÂMETROS DE AVALIAÇÃO DO BALANÇO REDOX}

A média dos parâmetros atividade da GPx e SOD, ORAC e MDA foram respectivamente, 46,12 U/g de $\mathrm{Hb}, 1403,12 \mathrm{U} / \mathrm{g}$ de $\mathrm{Hb}, 0,68 \mu \mathrm{M} / \mathrm{L}$ e $0,89 \mu \mathrm{mol}$ equivalente de trolox/mL de plasma. Houve diferença significativa $(\mathrm{p}<0,05)$ apenas nas concentrações da GPx e ORAC entre os genótipos do SNP Arg5Pro e Pro198Leu, respectivamente (Tabela 7). Aqueles com o genótipo Arg/Pro tinham maior atividade da GPx que aqueles com genótipo Arg/Arg e, os indivíduos com genótipo Leu/Leu tinham maior concentração de ORAC que os com genótipo Pro/Pro. Também houve correlação significativa e positiva entre GPx e MDA ( $r=0,166 ; \mathrm{p}<0,01)$ e SOD e MDA ( $r=0,210 ; \mathrm{p}<0,001)$, e inversa entre ORAC e MDA $(r=-0,204 ; p<0,001)$ e ORAC e SOD $(r=-0,158 ; p<0,01)$. 
Tabela 7. Medidas de tendência central e dispersão dos marcadores do balanço redox de indivíduos saudáveis adultos do estado do Piauí de acordo a presença dos polimorfismos Pro198Leu, -602A/G e Arg5Pro da GPx1

\begin{tabular}{|c|c|c|c|c|c|c|c|}
\hline Parâmetro & SNP & Genótipo & $\mathrm{n}$ & Min & Max & Média (DP) & $\mathrm{p}$ \\
\hline \multirow{9}{*}{$\begin{array}{c}\text { GPx } \\
(\mathrm{U} / \mathrm{g} \text { de } \mathrm{Hb})\end{array}$} & & Pro/Pro & 176 & 16,89 & 102,12 & $47,90(16,06)$ & \\
\hline & & Pro/Leu & 128 & 18,31 & 101,54 & $44,83(13,80)$ & \\
\hline & Pro198Leu & Leu/Leu & 30 & 16,49 & 58,54 & $41,22(10,12)$ & $0,139^{\mathrm{T}}$ \\
\hline & & GG & 32 & 16,49 & 58,54 & $42,00(10,25)$ & \\
\hline & & GA & 127 & 18,31 & 101,54 & $44,76(13,82)$ & \\
\hline & $-602 \mathrm{~A} / \mathrm{G}$ & AA & 175 & 16,89 & 102,12 & $47,85(16,10)$ & $0,052^{\dagger}$ \\
\hline & & Arg/Arg & 325 & 16,49 & 102,12 & $45,80(14,71)$ & \\
\hline & Arg5Pro & Arg/Pro & 9 & 35,17 & 74,88 & $58,72(16,60)$ & $\mathbf{0 , 0 1} 1^{\S}$ \\
\hline & \multicolumn{2}{|c|}{ Total } & 334 & 16,49 & 102,12 & $46,12(14,90)$ & \\
\hline \multirow{9}{*}{$\begin{array}{c}\text { SOD } \\
(\mathrm{U} / \mathrm{g} \text { de } \mathrm{Hb})\end{array}$} & & Pro/Pro & 177 & 665,58 & 2308,52 & $1354,06(367,20)$ & \multirow[b]{3}{*}{$0,050^{\dagger}$} \\
\hline & & Pro/Leu & 128 & 704,19 & 2337,33 & $1458,75(407,85)$ & \\
\hline & Pro198Leu & Leu/Leu & 30 & 765,81 & 2141,05 & $1455,27(357,70)$ & \\
\hline & \multirow[b]{3}{*}{$-602 \mathrm{~A} / \mathrm{G}$} & GG & 32 & 765,81 & 2141,05 & $1443,56(349,70)$ & \multirow[b]{3}{*}{$0,050^{\dagger}$} \\
\hline & & GA & 127 & 704,19 & 2337,33 & $1460,94(408,71)$ & \\
\hline & & $\mathrm{AA}$ & 176 & 665,58 & 2308,52 & $1354,06(368,23)$ & \\
\hline & & Arg/Arg & 326 & 704,19 & 2337,33 & $1400,60(383,61)$ & \multirow{3}{*}{$0,468^{\S}$} \\
\hline & Arg5Pro & Arg/Pro & 9 & 665,58 & 2057,74 & $1495,16(442,32)$ & \\
\hline & \multicolumn{2}{|c|}{ Total } & 335 & 665,58 & 2337,33 & $1403,13(384,90)$ & \\
\hline \multirow{9}{*}{$\operatorname{MDA}(\mu \mathrm{M} / \mathrm{L})$} & & Pro/Pro & 171 & 0,25 & 1,24 & $0,70(0,22)$ & \multirow[b]{3}{*}{$0,509^{\dagger}$} \\
\hline & & Pro/Leu & 129 & 0,23 & 1,21 & $0,67(0,22)$ & \\
\hline & Pro198Leu & Leu/Leu & 29 & 0,25 & 1,09 & $0,65(0,21)$ & \\
\hline & \multirow[b]{3}{*}{$-602 \mathrm{~A} / \mathrm{G}$} & $\mathrm{GG}$ & 31 & 0,25 & 1,09 & $0,66(0,21)$ & \multirow[b]{3}{*}{$0,598^{\dagger}$} \\
\hline & & GA & 128 & 0,23 & 1,21 & $0,67(0,22)$ & \\
\hline & & AA & 170 & 0,25 & 1,24 & $0,70(0,22)$ & \\
\hline & \multirow[b]{2}{*}{ Arg5Pro } & Arg/Arg & 320 & 0,23 & 1,24 & $0,68(0,21)$ & \multirow{3}{*}{0,712} \\
\hline & & Arg/Pro & 9 & 0,35 & 1,22 & $0,70(0,32)$ & \\
\hline & \multicolumn{2}{|c|}{ Total } & 329 & 0,23 & 1,24 & $0,68(0,22)$ & \\
\hline \multirow{9}{*}{$\begin{array}{c}\text { ORAC } \\
\text { (umol } \\
\text { equivalente } \\
\text { de trolox/mL } \\
\text { de plasma) }\end{array}$} & & Pro/Pro & 178 & 0,45 & 1,47 & $0,96(0,22)$ & \multirow[b]{3}{*}{$\mathbf{0 , 0 3 0}{ }^{\dagger}$} \\
\hline & & Pro/Leu & 132 & 0,44 & 1,52 & $1,01(0,22)$ & \\
\hline & Pro198Leu & Leu/Leu & 29 & 0,54 & 1,52 & $1,04(0,22)$ & \\
\hline & & GG & 31 & 0,54 & 1,52 & $1,03(0,22)$ & \multirow[b]{3}{*}{$0,050^{\dagger}$} \\
\hline & & GA & 131 & 0,44 & 1,52 & $1,01(0,22)$ & \\
\hline & $-602 \mathrm{~A} / \mathrm{G}$ & AA & 177 & 0,45 & 1,47 & $0,96(0,22)$ & \\
\hline & & Arg/Arg & 330 & 0,44 & 1,52 & $0,99(0,22)$ & \multirow{3}{*}{$0,736^{\S}$} \\
\hline & Arg5Pro & Arg/Pro & 9 & 0,77 & 1,18 & $0,96(0,12)$ & \\
\hline & \multicolumn{2}{|c|}{ Total } & 339 & 0,44 & 1,52 & $0,98(0,22)$ & \\
\hline
\end{tabular}

Legenda: $\dagger$ - teste t de ANOVA; Ғ - teste de Kruskal-Wallis; $\S$ - teste de t de Student; $\$$ - teste de MannWhitney; valor-p considerado significativo abaixo de $5 \%$. 
Segundo o modelo de regressão linear univariado construído para a GPx com cada um dos SNP estudados, todos mostraram influência sobre a variável principal: indivíduos com o genótipo Leu/Leu têm 7,63 U/g de Hb de GPx a menos que aqueles com os genótipos Pro/Pro e Pro/Leu; indivíduos com o genótipo GG têm 6,59 com U/g de $\mathrm{Hb}$ de GPx a menos que aqueles com os genótipos GA e AA; sujeitos com o Arg/Pro têm 12,75 U/g de Hb de GPx a mais que aqueles com o genótipo Arg/Arg (Tabela 8)

Tabela 8. Modelos de regressão linear univariado para a variável dependente GPx dos indivíduos adultos do estado do Piauí

\section{Intervalo de confiança de $\beta$} de $95 \%$

\begin{tabular}{clcccc}
$\begin{array}{c}\text { Variável } \\
\text { Dependente }\end{array}$ & \multicolumn{1}{c}{$\begin{array}{c}\text { Variável } \\
\text { Independente }\end{array}$} & $\boldsymbol{\beta}$ & $\mathbf{p}$ & $\begin{array}{c}\text { Limite } \\
\text { inferior }\end{array}$ & $\begin{array}{c}\text { Limite } \\
\text { Superior }\end{array}$ \\
\hline Constante & 48,32 & 0,00 & 45,75 & 50,89 \\
$(\mathrm{U} / \mathrm{g}$ de $\mathrm{Hb})$ & Pro198Leu Dummy 1 & $-3,76$ & $\mathbf{0 , 0 6}$ & $-7,72$ & 0,21 \\
& Pro198Leu Dummy 2 & $-7,63$ & $\mathbf{0 , 0 2}$ & $-14,10$ & $-1,16$ \\
\hline $\mathrm{GPx}$ & Constante & 48,28 & 0,00 & 45,69 & 50,86 \\
$(\mathrm{U} / \mathrm{g} \mathrm{de} \mathrm{Hb})$ & -602A/G Dummy 1 & $-3,81$ & $\mathbf{0 , 0 6}$ & $-7,80$ & 0,18 \\
\hline $\mathrm{GPx}$ & -602A/G Dummy 2 & $-6,59$ & $\mathbf{0 , 0 4}$ & $-12,87$ & $-0,32$ \\
$(\mathrm{U} / \mathrm{g} \mathrm{de} \mathrm{Hb})$ & Constante & 45,84 & 0,00 & 43,95 & 47,73 \\
\hline
\end{tabular}

Legenda: Pro198Leu (Dummy 1) - comparação do genótipo Pro/Leu com Pro/Pro e Leu/Leu; Pro198Leu (Dummy 2) - comparação do genótipo Leu/Leu com Pro/Pro e Pro/Leu; -602A/G (Dummy 1) - comparação do genótipo GA com GG e AA; -602A/G (Dummy 2) - comparação do genótipo GG com GA e AA; Arg5Pro - comparação do genótipo Arg/Pro com Arg/Arg;

O modelo de regressão linear múltiplo construído para a GPx indicou aumento da atividade enzimática com aumento do Se eritrocitário (Tabela 9). Também houve correlação significativa entre as concentrações de Se eritrocitário e atividade da GPx, mais especificamente nos genótipos Arg/Arg ( $\mathrm{r}=0,286 ; \mathrm{p}<0,001)$ do SNP Arg5Pro; nos genótipos Pro/Pro ( $\mathrm{r}=0,361 ; \mathrm{p}<0,001)$ e Pro/Leu ( $\mathrm{r}=0,226 ; \mathrm{p}=0,030)$ do SNP Pro198Leu; e nos genótipos AA $(r=0,374 ; p<0,001)$ e GA $(r=0,214 ; p=0,040)$ do SNP $-602 \mathrm{~A} / \mathrm{G}$.

O modelo da GPx também indicou aumento da atividade da enzima com a idade e redução com a presença do genótipo Leu/Leu, o tabagismo e o consumo de proteína entre 90 a 98 g/dia (Tabela 9). 
Tabela 9. Modelos de regressão linear múltiplo para a variável dependente GPx dos indivíduos adultos do estado do Piauí

\begin{tabular}{|c|c|c|c|c|c|}
\hline \multirow{2}{*}{$\begin{array}{c}\text { Variável } \\
\text { Dependente }\end{array}$} & \multirow{2}{*}{$\begin{array}{c}\text { Variável } \\
\text { Independente }\end{array}$} & \multirow[b]{2}{*}{$\boldsymbol{\beta}$} & \multirow[b]{2}{*}{$\mathbf{p}$} & \multicolumn{2}{|c|}{$\begin{array}{c}\text { Intervalo de } \\
\text { Confiança de } \beta \text { de } \\
95 \%\end{array}$} \\
\hline & & & & $\begin{array}{c}\text { Limite } \\
\text { Inferior }\end{array}$ & $\begin{array}{c}\text { Limite } \\
\text { Superior }\end{array}$ \\
\hline \multirow{10}{*}{$\begin{array}{c}\text { GPx } \\
(\mathrm{U} / \mathrm{g} \text { de } \mathrm{Hb})\end{array}$} & Constante & $-25,32$ & 0,166 & $-61,22$ & 10,59 \\
\hline & Log de Se Eritrocitário & 44,81 & $<0,01$ & 25,97 & 63,65 \\
\hline & Idade (Dummy 1) & 0,44 & 0,840 & $-3,85$ & 4,73 \\
\hline & Idade (Dummy 2) & 5,40 & 0,014 & 1,10 & 9,71 \\
\hline & Fumar & $-16,92$ & 0,036 & $-32,70$ & $-1,14$ \\
\hline & Pro198Leu (Dummy 1) & $-3,52$ & 0,061 & $-7,20$ & 0,16 \\
\hline & Pro198Leu (Dummy 2) & $-6,22$ & 0,044 & $-12,36$ & $-0,07$ \\
\hline & Se consumido & $-0,12$ & 0,116 & $-0,27$ & 0,03 \\
\hline & PTN (Dummy 1) & $-4,67$ & $\mathbf{0 , 0 3 2}$ & $-8,94$ & $-0,40$ \\
\hline & PTN (Dummy 2) & $-4,94$ & 0,052 & $-8,67$ & 0,03 \\
\hline
\end{tabular}

Legenda: Idade (Dummy 1) - comparação do $2^{\circ}$ tercil com o $1^{\circ}$ e $3^{\circ}$ tercis de Idade; Idade (Dummy 2) comparação do $3^{\circ}$ tercil com o $1^{\circ}$ e o $2^{\circ}$ tercis de Idade; Pro198Leu (Dummy 1) - comparação do genótipo Pro/Leu com Pro/Pro e Leu/Leu; Pro198Leu (Dummy 2) - comparação do genótipo Leu/Leu com Pro/Pro e Pro/Leu; PTN (Dummy 1) - comparação do $2^{\circ}$ tercil com o $1^{\circ}$ e $3^{\circ}$ tercis de PTN; PTN (Dummy 2) comparação do $3^{\circ}$ tercil com o $1^{\circ}$ e o $2^{\circ}$ tercis de PTN; Tercis de Idade - $1^{\circ}$ Tercil (menos que 21,79 anos), $2^{\circ}$ Tercil (entre 21,79 e 24,50 anos), $3^{\circ}$ Tercil (mais que 24,50 anos); Tercis de PTN - $1^{\circ}$ Tercil (menos que $90,73 \mathrm{mg} / \mathrm{dL}$ ), $2^{\circ}$ Tercil (entre 90,73 a 98,62 mg/dL), $3^{\circ}$ Tercil (mais que 98,62 mg/dL).

Segundo o modelo de regressão linear generalizado da variável atividade da SOD, este parâmetro aumenta com o consumo de lipídios e com a idade (Tabela 10).

Para a variável ORAC, a regressão linear indicou aumento com o consumo de bebida alcoólica, IMC e presença do genótipo Leu/Leu do SNP Pro198Leu e, redução com o consumo de lipídios (Tabela 11). Em relação a variável beber, é importante elucidar que mais da metade dos participantes não ingeriam bebidas alcoólicas, enquanto 1,6\% ingeriam vinho e $30 \%$, cerveja. Entre aqueles que bebiam vinhos, a frequência de consumo era de 1 a 2 vezes por semana e a quantidade relatada foi de 1 a 4 copos. Entre os participantes que ingeriam cervejas, a frequência de consumo era de 1 a 2 vezes por semana para a maioria (98,7\%), 36\% ingeriam entre 1 e 4 copos enquanto $64 \%$ ingeriam cinco ou mais copos.

Também em relação a variável beber do modelo construído para ORAC, não foi possível incluir as variáveis tipos de bebida alcoólica ingerida, frequência de ingestão e quantidade de ingestão porque estas variáveis apresentaram colinearidade perfeita $(r \geq$ 0,90) entre si e também entre estas e a variável beber. 
No modelo final da variável MDA apenas Se plasmático foi significativo. Este modelo apontou relação inversa entre as variáveis, ou seja, a cada $\mu \mathrm{g} / \mathrm{L}$ de Se plasmático há uma redução de $0,003 \mu \mathrm{Mol} / \mathrm{L}$ de MDA (Tabela 12).

Tabela 10. Modelos de regressão linear generalizado para a variável dependente SOD dos indivíduos adultos do estado do Piauí

\begin{tabular}{|c|c|c|c|c|c|}
\hline $\begin{array}{l}\text { Variável } \\
\text { dependente }\end{array}$ & Variável independente & $\boldsymbol{\beta}$ & OR & IC(OR) & $\mathbf{P}$ \\
\hline \multirow{20}{*}{$\begin{array}{c}\text { SOD } \\
(\mathrm{U} / \mathrm{g} \text { de } \mathrm{Hb})\end{array}$} & Idade - Dummy 1 & & & & \\
\hline & $1^{\circ}$ e $3^{\circ}$ Tercis & 0,0 & 1,0 & & \\
\hline & $2^{\circ}$ Tercil & 0,046 & 1,047 & 0,9631 a 1,1390 & 0,280 \\
\hline & Idade - Dummy 2 & & & & \\
\hline & $1^{\circ}$ e $2^{\circ}$ Tercis & 0,0 & 1,0 & & \\
\hline & $3^{\circ}$ Tercil & 0,107 & 1,113 & 1,0231 a 1,2110 & $\mathbf{0 , 0 1 3}$ \\
\hline & Lipídios & 0,006 & 1,006 & 1,0011 a 1,0114 & $\mathbf{0 , 0 1 7}$ \\
\hline & Se Eritrocitário - Dummy 1 & & & & \\
\hline & $1^{\circ}$ e $3^{\circ}$ Tercis & 0,0 & 1,0 & & \\
\hline & $2^{\circ}$ Tercil & $-0,082$ & 0,922 & 0,8488 a 1,0006 & 0,052 \\
\hline & Se Eritrocitário - Dummy 2 & & & & \\
\hline & $1^{\circ}$ e $2^{\circ}$ Tercis & 0,0 & 1,0 & & \\
\hline & $3^{\circ}$ Tercil & $-0,073$ & 0,930 & 0,8560 a 1,0102 & 0,085 \\
\hline & Pro198Leu - Dummy 1 & & & & \\
\hline & Pro/Pro e Leu/Leu & 0,0 & 1,0 & & \\
\hline & Pro/Leu & 0,044 & 1,045 & 0,9724 a 1,1226 & 0,085 \\
\hline & Pro198Leu - Dummy 2 & & & & \\
\hline & Pro/Pro e Pro/Leu & 0,0 & 1,0 & & \\
\hline & Leu/Leu & 0,107 & 1,112 & 0,9884 a 1,2521 & 0,078 \\
\hline & Triglicerídeos (mg/dL) & 0,000 & 1,000 & 0,9999 a 1,0010 & 0,084 \\
\hline \multicolumn{6}{|c|}{$\begin{array}{l}\text { Legenda: Idade - Dummy } 1 \text { - comparação do } 2^{\circ} \text { tercil com o } 1^{\circ} \text { e } 3^{\circ} \text { tercis de Idade; Idade - Dummy } 2 \\
\text { comparação do } 3^{\circ} \text { tercil com o } 1^{\circ} \text { e o } 2^{\circ} \text { tercis de Idade; Se eritrocitário - Dummy } 1 \text { - comparação do } 2^{\circ} \\
\text { tercil com o } 1^{\circ} \text { e } 3^{\circ} \text { tercis de Se eritrocitário; Se eritrocitário - Dummy } 2 \text { - comparação do } 3^{\circ} \text { tercil com o } \\
1^{\circ} \text { e o } 2^{\circ} \text { tercis de Se eritrocitário; Pro198Leu (Dummy 1) - comparação do genótipo Pro/Leu com } \\
\text { Pro/Pro e Leu/Leu; Pro198Leu (Dummy 2) - comparação do genótipo Leu/Leu com Pro/Pro e Pro/Leu } \\
\text { Tercis de Idade - } 1^{\circ} \text { Tercil (menos que } 21,7 \text { anos), } 2^{\circ} \text { Tercil (entre } 21,7 \text { e } 24,49 \text { anos), } 3^{\circ} \text { Tercil (mais } \\
\text { que } 24,49 \text { anos); Tercis de Se eritrocitário - } 1^{\circ} \text { Tercil (menos que } 60,79 \text { ug/L), } 2^{\circ} \text { Tercil (entre } 60,79 \text { e } \\
75,27 \text { ug/L), } 3^{\circ} \text { Tercil (mais que } 75,27 \text { ug/L); IC - Intervalo de confiança de } 95 \% \text {; OR - odds ratio. }\end{array}$} \\
\hline
\end{tabular}


Tabela 11. Modelos de regressão linear múltiplo para a variável dependente ORAC dos indivíduos adultos do estado do Piauí

\begin{tabular}{|c|c|c|c|c|c|}
\hline \multirow[b]{2}{*}{$\begin{array}{c}\text { Variável } \\
\text { Dependente }\end{array}$} & \multirow[b]{2}{*}{$\begin{array}{c}\text { Variável } \\
\text { Independente }\end{array}$} & \multirow[b]{2}{*}{$\beta$} & \multirow[b]{2}{*}{$\mathbf{p}$} & \multicolumn{2}{|c|}{$\begin{array}{c}\text { Intervalo de confiança de } \\
95 \% \text { de } \beta\end{array}$} \\
\hline & & & & $\begin{array}{c}\text { Limite } \\
\text { inferior }\end{array}$ & $\begin{array}{c}\text { Limite } \\
\text { Superior }\end{array}$ \\
\hline \multirow{7}{*}{$\begin{array}{c}\text { ORAC } \\
\text { (umol } \\
\text { equivalente } \\
\text { de trolox/mL } \\
\text { de plasma) }\end{array}$} & Constante & 0,234 & 0,392 & $-0,3043$ & 0,7731 \\
\hline & Log_IMC & 0,602 & $\mathbf{0 , 0 0 3}$ & 0,2115 & 0,9934 \\
\hline & Log_TG & 0,116 & 0,062 & $-0,0059$ & 0,2378 \\
\hline & Beber & 0,061 & $\mathbf{0 , 0 2 4}$ & 0,0080 & 0,1135 \\
\hline & Pro198Leu (Dummy 1) & 0,067 & 0,011 & 0,0156 & 0,1182 \\
\hline & Pro198Leu (Dummy 2) & 0,143 & 0,001 & 0,0558 & 0,2311 \\
\hline & Lipídios (g) & $-0,005$ & 0,004 & $-0,0090$ & $-0,0018$ \\
\hline
\end{tabular}

Legenda: IMC - índice de massa corpórea; TG - triglicerídeos; LDL - lipoproteína de alta densidade; Referência: Beber - indivíduos que não ingerem bebida alcóolica (vinho e cerveja); Pro198Leu (Dummy 1) - comparação do genótipo Pro/Leu com Pro/Pro e Leu/Leu; Pro198Leu (Dummy 2) comparação do genótipo Leu/Leu com Pro/Pro e Pro/Leu;

Tabela 12. Modelos de regressão linear múltiplo para a variável dependente MDA dos indivíduos adultos do estado do Piauí

\begin{tabular}{|c|c|c|c|c|c|}
\hline \multirow[b]{2}{*}{$\begin{array}{c}\text { Variável } \\
\text { Dependente }\end{array}$} & \multirow[b]{2}{*}{$\begin{array}{c}\text { Variável } \\
\text { Independente }\end{array}$} & \multirow[b]{2}{*}{$\beta$} & \multirow[b]{2}{*}{$\mathbf{p}$} & \multicolumn{2}{|c|}{ Intervalo de confiança de $\beta$} \\
\hline & & & & $\begin{array}{c}\text { Limite } \\
\text { inferior }\end{array}$ & $\begin{array}{c}\text { Limite } \\
\text { Superior }\end{array}$ \\
\hline & $\begin{array}{l}\text { Constante } \\
\text { Se plasmático }\end{array}$ & 0,824 & $<0,001$ & 0,706 & 0,943 \\
\hline $\operatorname{MDA}(\mu \mathrm{Mol} / \mathrm{L})$ & $(\mu \mathrm{g} / \mathrm{L})$ & $-0,003$ & 0,015 & $-0,005$ & $-0,001$ \\
\hline
\end{tabular}

Legenda: MDA - malondialdeído 


\section{0 - DISCUSSÃO}

A avaliação do estado nutricional é uma tarefa complexa, especialmente quando aborda a análise de micronutrientes e contempla a interpretação de marcadores antropométricos, bioquímicos e ingestão alimentar.

$\mathrm{Na}$ avaliação antropométrica, o ideal é que a determinação do IMC seja acompanhada da aferição da gordura corporal a fim de se obter informações adicionais quanto à distribuição e a composição da gordura corporal, pois o IMC não possibilita a distinção entre massa magra e massa gorda.

Os resultados do IMC foram menores que os observados pela pesquisa VIGITEL Brasil (140) na cidade de Teresina-PI, que verificaram no total de participantes $49,1 \%$ com excesso de peso e $16,2 \%$ com obesidade.

Neste estudo, evidenciou-se limitação do IMC na avaliação do estado nutricional, pois um elevado percentual de estudantes que apresentaram excesso de gordura corporal foi classificado como eutrófico com base no IMC. Também se observou uma alta frequência de participantes com risco de doenças associadas ao excesso de peso e com baixas concentrações de HDL. Alterações na concentração sérica de HDL podem contribuir para o surgimento de doenças cardiovasculares uma vez que essa lipoproteína atua na remoção do excesso de colesterol das paredes arteriais, exercendo importante função na modulação do desenvolvimento e progressão da aterosclerose (141). Além disso, a HDL atua na diminuição do risco de trombose pela inibição da agregação plaquetária (142, 143). Ressalta-se a importância desses resultados por se tratar de uma população jovem com média de idade de 24,4 anos.

Houve uma alta frequência relatada do hábito de beber e não praticar exercícios físicos, bem como de histórico de DCNT dos familiares dos participantes. As DCNT são problemas de saúde pública cada vez mais graves na população brasileira. Em 2007 as doenças cardiovasculares, diabetes, câncer e doenças respiratórias crônicas foram responsáveis por $58 \%$ das mortes no Brasil, e juntamente com seus quatro fatores de risco em comum (tabagismo, inatividade física, uso excessivo de álcool e alimentação não saudável) foi foco do plano de ação 2008-2013 da OMS (144).

Em relação à ingestão alimentar, percebe-se que a média do consumo energético deste estudo foi maior que o encontrado na Pesquisa de Orçamentos Familiares (POF 2008/2009) (145), na região Nordeste, (aproximadamente 1928 kcal - levando em conta apenas os indivíduos adultos). Quanto aos macronutrientes, os valores observados neste 
estudo estavam de acordo com a faixa de distribuição aceitável de macronutrientes (AMDR) do Institute of Medicine (133), porém a média do percentual de contribuição calórica de proteínas, carboidratos e lipídios foi maior que a encontrada na POF 2008/2009 (145) de $17 \%, 56 \%$ e $25 \%$, respectivamente.

Estudos epidemiológicos têm mostrado que dietas inadequadas, especialmente quando associadas ao sedentarismo, podem aumentar o risco de DCNT. O padrão de consumo alimentar da população brasileira tem sofrido mudanças nas últimas décadas, e tem sido caracterizado por um aumento significativo no consumo de alimentos com alto teor de carboidratos simples e lipídios e, redução de frutas, vegetais e fibras, que configuram o processo de transição nutricional (146). Estes estudos corroboram com os resultados deste trabalho que observou consumo de carboidratos e lipídios acima do recomendado, bem como pelos resultados antropométricos e a reduzida prática de atividade física.

No que diz respeito ao consumo de Se, observou-se que a ingestão média, 60,5 $\mu \mathrm{g} /$ dia, foi superior à recomendação da $\operatorname{EAR}(45 \mu \mathrm{g} /$ dia $)$ e a prevalência de inadequação entre os participantes foi de 9,18\%. Segundo os resultados da POF 2008/2009 (145), a média do consumo de selênio da população do Nordeste do sexo masculino e feminino com idade entre 19 e 59 anos foi de 103,3 $\mu \mathrm{g} /$ dia e 79,3 $\mu \mathrm{g} / \mathrm{dia}$, e o percentual de inadequação da ingestão desse mineral foi de 3,9\% e 12,1\%, respectivamente.

De acordo com as pesquisas realizadas no Laboratório de Nutrição - Minerais, a ingestão de selênio na população adulta brasileira varia de 40 a $200 \mu \mathrm{g} /$ dia. É o que tem sido observado em indivíduos adultos dos estudos de Donadio (92): São Paulo (SP) - 41,2 $\mu \mathrm{g} /$ dia; Bortoli (90): São Paulo (SP) - 57,1 $\mu \mathrm{g} /$ dia, Cubatão (SP) - 53,3 $\mu \mathrm{g} /$ dia e Novo

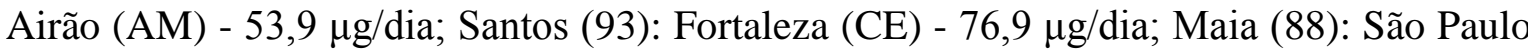
(SP) - 110,00 $\mu \mathrm{g} / \mathrm{dia}$ e Fortaleza (CE) - 200,00 $\mu \mathrm{g} / \mathrm{dia}$.

As diferenças observadas no consumo de Se em diversos estados brasileiros podem ser explicadas pela variabilidade do mineral no solo, que, por conseguinte, afeta a sua concentração nas fontes alimentares $(99,147)$. Somado a isso, ainda existem as limitações decorrentes dos erros inerentes aos métodos de avaliação da ingestão alimentar e das poucas tabelas de composição alimentar que apresentam a concentração do Se nos alimentos, principalmente em alimentos regionais (129).

Para avaliar a ingestão alimentar de Se também foram considerados os pontos de corte estabelecidos por Thomson (79). Dessa forma, pode-se perceber que todos os participantes desta pesquisa consomem Se em quantidades suficientes para o não 
surgimento da doença de Keshan e para a atividade ótima das DIO, e 95,96\% (261/272) para a maximização da atividade da GPx e Selenoproteína P. Por outro lado, $100 \%$ dos participantes não atingiram a quantidade necessária para a proteção de câncer.

\section{1 - GENOTIPAGEM DOS POLIMORFISMOS Pro198Leu, -602A/G e Arg5Pro DA GPx1}

Considerando-se que a frequência dos alelos e dos genótipos do polimorfismo Pro198Leu da GPx1 são dependentes da etnia, é importante conhecer a sua distribuição na população estudada. No quadro abaixo há frequências de indivíduos adultos de diversas regiões do mundo compilados por Suzen et al. (122). Nele, também foram incluídos dados de alguns estudos brasileiros (Quadro 3).

Quadro 3. Frequência dos alelos e genótipos do polimorfismo Pro198Leu da GPx1 observados em diversas populações

\begin{tabular}{|l|c|c|c|c|c|c|c|}
\hline \multirow{2}{*}{\multicolumn{1}{|c|}{ População }} & n & \multicolumn{2}{c|}{$\begin{array}{c}\text { Frequência dos } \\
\text { alelos }\end{array}$} & \multicolumn{2}{c|}{$\begin{array}{c}\text { Frequência dos } \\
\text { Genótipos }\end{array}$} & \multirow{2}{*}{ Referências } \\
\cline { 3 - 7 } & & Pro & Leu & Pro/Pro & Pro/Leu & Leu/Leu & \\
\hline Brasileira & 176 & 0,740 & 0,260 & 0,550 & 0,380 & 0,070 & 93 \\
Brasileira & 203 & 0,720 & 0,280 & 0,510 & 0,430 & 0,060 & 148 \\
Brasileira & 29 & 0,793 & 0,207 & 0,724 & 0,138 & 0,138 & 149 \\
Sueca & 214 & 0.727 & 0,273 & 0,528 & 0,397 & 0,075 & 150 \\
Inglesa & 761 & 0,752 & 0,248 & 0,576 & 0,352 & 0,072 & 151 \\
Alemã & 117 & 0,714 & 0,286 & 0,496 & 0,436 & 0,068 & 152 \\
Turca & 250 & 0,636 & 0,364 & 0,416 & 0,440 & 0,144 & 122 \\
Japonesa & 209 & 0,947 & 0,053 & 0,895 & 0,105 & 0,000 & 120 \\
Polonesa & 90 & 0,794 & 0,206 & 0,589 & 0,411 & 0,000 & 153 \\
Americana & 683 & 0,698 & 0,302 & 0,491 & 0,414 & 0,095 & 151 \\
Canadense & 372 & 0,675 & 0,325 & 0,454 & 0,441 & 0,105 & 154 \\
Dinamarquesa & 798 & 0,660 & 0,340 & 0,436 & 0,449 & 0,115 & 155 \\
America- & & & & & & & 156 \\
Africana & 119 & 0,651 & 0,349 & 0,429 & 0,445 & 0,126 & \\
Filandesa & 313 & 0,637 & 0,363 & 0,422 & 0,431 & 0,147 & 14 \\
\hline \multicolumn{7}{|c|}{ Fonte: Suzen et al. (122) }
\end{tabular}

As frequências dos alelos e genótipos do SNP Pro198Leu encontradas neste trabalho foram semelhantes a de dois estudos brasileiros $(93,148)$ e as frequências das populações sueca, inglesa e alemã $(150,151,152)$ (Quadro 3). 
Quanto aos outros dois SNP foram encontrados poucos trabalhos na literatura. Iida et al. (123) estudou o SNP Arg5Pro em população japonesa, alemã e africana e Mistry et al. (124) em uma população da Nova Zelândia, Austrália, Inglaterra e Irlanda e não encontraram o alelo variante. Huang et al. (125) analisaram o SNP -602A/G em uma população chinesa de 241 participantes e encontraram frequência do alelo variante de 0,911, enquanto neste estudo, esta foi menor, 0,713 (Tabela 4).

\section{2 - PARÂMETROS BIOQUÍMICOS}

O Se plasmático é certamente o parâmetro mais usado para avaliar o estado nutricional relativo ao mineral (98). No entanto, as suas concentrações plasmáticas são influenciadas por variações geográficas (157), idade, estado fisiológico e variações da ingestão alimentar. No entanto, a resposta à normalização dos valores é influenciada pelo grau de depleção, ingestão de Se e a forma de Se suplementada (158).

Em contraposição a variação a curto prazo do Se plasmático, o eritrocitário responde mais lentamente à mudança do estado nutricional relativo a esse mineral em razão da meia-vida de 120 dias dessa célula e, por isso, é considerado um marcador de exposição de médio prazo para a avaliação da concentração de $\mathrm{Se}$ (98).

No Brasil, o estado nutricional relativo ao Se tem sido pouco avaliado em indivíduos não doentes, sendo esta avaliação feita apenas em plasma e eritrócitos na maioria dos estudos. A concentração média de Se plasmático e eritrocitário observada nos participantes deste estudo foi menor do que os encontrados em pesquisas realizadas em SP $(88,90), \mathrm{CE}$ $(88,93)$ e AM (90) (Figura 4, Tabela 5).

Segundo Thomson (79) não há uma faixa de referência para as concentrações de Se sanguíneo devido à variação do estado nutricional relativo ao mineral na população em diferentes países, que apresentam, por exemplo, diferentes concentrações de Se no solo, consequentemente variando a quantidade de Se nos alimentos e na ingestão dos indivíduos, conforme comentado anteriormente. Portanto, não há parâmetros de referência totalmente aceitos como normais para os índices deste mineral.

Considerando os critérios de adequação de Se proposto pelos trabalhos de Alegria et al. (159), Van Dael e Deelstra (98) e Nève (158), a variação na deficiência de Se plasmático seria de 49,12\% (168/342), 65,50\% (224/342) e 85,96\% (294/342). 
Essa proporção se manteve crescente e semelhante quando classificamos a deficiência de Se plasmático dos indivíduos de acordo com os critérios dos autores e a presença do alelo variante dos SNP estudados. Assim, 49,08\% (80/163), 65,00\% (106/163) e 87,11\% (142/163) dos indivíduos carreadores do alelo Leu do SNP Pro198Leu; 48,80\% (80/164), 65,00\% (107/164) e 87,20\% (143/164) com o alelo G do SNP -602A/G; e 44,44\% (4/9), 55,56\% (5/9) e 100,00\% (9/9) com o alelo Pro do SNP Arg5Pro são deficientes em Se plasmático, respectivamente.

De acordo com o ponto de corte de Thomson (79) foram observados que todos os participantes desta pesquisa $(n=342)$ apresentam concentrações de Se plasmático em quantidades suficientes para o não surgimento da doença de Keshan. No entanto, 100\%, 95,61\% (327/342) e 77,49\% (265/342) dos participantes não possuem a quantidade de Se plasmático necessária para a proteção de câncer, para a maximização da atividade da GPx e Selenoproteína P e para a atividade ótima das DIO, respectivamente. Observando os participantes de acordo com a classificação para a maximização da atividade da GPx e Selenoproteína P e os SNP estudados verificamos que 95,71\% (156/163) dos indivíduos com o alelo Leu do Pro198Leu, 95,73\% com o alelo G do -602A/G e 100\% (9/9) com o alelo Pro do Arg5Pro são deficientes em Se plasmático.

Em relação aos pontos de corte utilizados para Se eritrocitário, todos os indivíduos (n = 338) estariam deficientes de acordo com os critérios de Pleban et al. (160) e, 86,7\% (293/338) segundo os de Van Dael e Deelstra (98). Considerando os SNP estudados e a classificação de Van Dael e Deelstra (98), 88,90\% (144/162) dos indivíduos que possuíam o alelo Leu do SNP Pro198Leu; 88,95\% (145/163), o alelo G do SNP -602A/G e 66,67\% (6/9), o alelo Pro do Arg5Pro eram deficientes em Se eritrocitário.

$\mathrm{Na}$ avaliação complexa do status de Se, deve-se considerar também que a excreção urinária desempenha importante controle metabólico, exercendo um controle inverso entre a perda urinária de Se e a sua concentração no plasma (98).

A maioria dos trabalhos publicados expressam as concentrações urinárias de Se em $\mu \mathrm{g} / \mathrm{L}$, sendo que a quantidade média normal observada em indivíduos é de até $30 \mu \mathrm{g} / \mathrm{L}$, com exceção onde a exposição ambiental ao Se é alta, considerada causa mais provável da excreção aumentada do mineral. No entanto, este parâmetro é dependente do volume excretado e está sujeito ao clima, a ingestão de líquidos, a transpiração e a função renal. Portanto, a melhor forma de expressar o Se urinário é pelo volume total de urina durante $24 \mathrm{~h}$ em conjunto com a concentração urinária de creatinina. A creatinina é um metabólito que sofre excreção constante e normalmente não passa por reabsorção renal, sendo 
utilizado como fator de correção do valor de Se urinário, pois é menos sensível a variações (161).

Neste estudo, notou-se que tanto o valor médio quanto o máximo da concentração urinária de Se expressa em $\mu \mathrm{g} / \mathrm{L}$ não alcançam $30 \mu \mathrm{g} / \mathrm{L}$, e quando expresso em $\mu \mathrm{g} / \mathrm{g}$ de creatinina o valor encontrado foi menor que o de Combs et al. (162), 55,3 $\mu \mathrm{g} / \mathrm{g}$ de creatinina em adultos saudáveis da Dakota do Norte, Estados Unidos, região com solo rico em Se.

Com o intuito de verificar se os SNP Pro198Leu, -602A/G e Arg5Pro bem como as variáveis de perfil lipídico, avaliação antropométrica, consumo alimentar e estilo de vida interferem no estado nutricional dos indivíduos quanto ao Se e no balanço redox, foram realizadas análises de regressão linear. A utilização dessas análises facilita a interpretação dos resultados, especialmente no caso do estabelecimento da relação entre os marcadores bioquímicos do status de Se e os diferentes genótipo, uma vez que a maioria dos estudos busca apenas determinar a prevalência dos genótipos nas populações ou estabelecer diferenças entre estes no risco para alguns tipos de câncer.

Nos modelos finais construídos para o Se plasmático e Se eritrocitário, observou-se que indivíduos com renda menor que dois salários mínimos têm menos Se que aqueles com renda superior a dois salários mínimos, respectivamente, o que poderia ser explicado pela baixa aquisição de alimentos que contêm Se. No entanto, a variável ingestão de Se não foi significativa para entrar na modelagem e por isso não explica as variáveis biológicas.

No modelo para o Se plasmático também se nota que os sujeitos que ingerem bebida alcoólica têm mais Se que aqueles que não ingerem. Este resultado difere dos encontrados por Sánchez et al. (163) e Adame et al. (164), que não observaram relação entre os parâmetros, mas é semelhante ao de Kafai e Ganji (165) e Arnaud et al. (166). A literatura sugere que o consumo moderado de álcool pode não afetar adversamente a concentração de Se sanguíneo em indivíduos com estado nutricional adequado em Se e que o $\mathrm{Se}$ sanguíneo reduz com o consumo abusivo de álcool e está associada com a deterioração das funções renais ou subnutrição $(167,168)$, que não é o caso da população deste estudo.

Entre os três SNP estudados, somente o Arg5Pro demonstrou influência sobre o estado nutricional do Se, apenas no compartimento biológico eritrocitário, indicando um aumento de Se para os participantes com genótipo Arg/Pro comparados aos com genótipo Arg/Arg. Este dado corrobora os resultados da estatística univariada, que demonstraram aumento no Se eritrocitário e excretado naqueles indivíduos com genótipo Arg/Pro em 
relação àqueles com genótipo Arg/Arg, provavelmente porque estes têm Se sanguíneo suficiente para as funções biológicas e seu excesso é eliminado pela urina.

Por fim, no modelo para Se eritrocitário, nota-se que indivíduos que não praticam exercício físico têm aumento de Se em relação a aqueles que praticam exercício. Este achado é semelhante ao de Sánchez et al. (163) em população adulta espanhola. A literatura não explica com clareza a relação entre as concentrações sanguíneas de Se e a prática da atividade física, sendo sugerido por Adame et al. (164) que esta relação pode ser influenciada pela ingestão energética, o que a torna subjetiva e dependente do hábito de se fazer atividade física e se alimentar bem ou não.

$\mathrm{Na}$ avaliação do estresse oxidativo, os marcadores do balanço redox refletem os danos causados pelas ERO e ERN sobre o sistema biológico e a eficiência da defesa antioxidante de contrapartida. Esta avaliação foi realizada neste estudo como um complemento para a avaliação do estado nutricional de indivíduos adultos quanto ao selênio, visto que o mineral faz parte do centro catalítico de enzimas antioxidantes como a GPx. Concentrações sanguíneas ou dietéticas reduzidas de Se poderão comprometer seu papel antioxidante no organismo, e este comprometimento poderá ainda ser exacerbado pela presença de polimorfismos.

Acredita-se que a correlação, positiva e significativa, encontrada neste estudo entre os parâmetros GPx e MDA e SOD e MDA indicam uma tentativa do organismo de reduzir a peroxidação lipídica, aumentando a atividade da GPX e da SOD para reduzir as concentrações de MDA. Enquanto que, a correlação, negativa e significativa, entre a capacidade antioxidante total com o MDA e também com a SOD, pode representar um maior consumo de antioxidantes na tentativa de reduzir as concentrações de MDA, havendo, aparentemente, um maior esforço e consequente consumo da SOD, provavelmente por ser a defesa de primeira linha no combate a ERO (169).

A média da atividade da GPx encontrada neste estudo, 46,12 (14,90) U/g de Hb, estava de acordo com o limite de referência proposto pela RANDOX (27,5 a 73,6 U/g de $\mathrm{Hb}$ ). Segundo esta recomendação, a atividade da enzima mostrou-se baixa em 7,80\% (26/334) dos indivíduos. Entre os que tinham o alelo Leu do SNP Pro198Leu e G do 602A/G, 8,86\% (14/158) e 8,81\% (14/159) apresentaram baixa atividade da enzima, respectivamente. Apesar de não haver diferença significativa entre as médias, os indivíduos com o genótipo Leu/Leu do Pro198Leu e GG do -602A/G tinham cerca de 13\% menos atividade da GPx que aqueles com os genótipos Pro/Pro e AA, respectivamente. Nenhum indivíduo carreador do alelo Pro do SNP Arg5Pro apresentou baixa atividade da 
enzima, segundo a referência da RANDOX, e a média da sua atividade foi significativamente maior $(28,2 \%)$ que os com genótipo Arg/Arg.

Segundo o modelo de regressão linear univariado construído para a GPx com cada um dos SNP estudados, todos mostraram influência sobre a variável principal. Confirmando a análise de haplótipos, tanto os indivíduos com o genótipo Leu/Leu do SNP Pro198Leu quanto os com GG do $-602 \mathrm{~A} / \mathrm{G}$ apresentaram menor atividade da enzima quando comparados aos demais genótipos dos seus SNP. Quanto ao SNP Arg5Pro, a análise univariada e a regressão indicaram que os indivíduos com o genótipo Arg/Pro tinham maior atividade da GPx que aqueles com genótipo Arg/Arg (Tabela 8). Portanto, acredita-se que a presença do alelo variante do SNP Arg5Pro seja benéfica para o estado nutricional relativo ao Se dos participantes deste estudo.

A literatura tem apontado uma redução de mais de 7\% na atividade da GPx em indivíduos com o genótipo variante em relação ao selvagem no SNP Pro198Leu. Em Arsova-Sarafinovska et al. (20), Ravn-Haren et al. (17) e Karunasinghe et al. (170), com população livre de doenças, a redução foi de 7,45\%, 8,69\% e 12,46\%, respectivamente. Em população com câncer de mama, Ravn-Haren et al. (17) mostraram redução de 9,09\%, e Cominetti et al. (109), em obesos, 18,44\%. Hamanishi et al. (21) estudaram haplótipos no gene da GPx1 e mostraram que a combinação do alelo Leu do SNP Pro198Leu com o alelo Ala6 do SNP polialanina de troca 5/6 no códon 7-11 ( $\mathrm{Ala}^{5} / \mathrm{Ala}^{6}$ ) reduz em 40\% a atividade da GPx e a combinação do alelo $\mathrm{G}$ do $-602 \mathrm{~A} / \mathrm{G}$ com o $\mathrm{T}$ do $+2 \mathrm{C} / \mathrm{T}$ reduz em $25 \%$ a atividade transcripcional da enzima e, sugeriram que as variantes funcionais no gene da GPx1 são associadas com o risco aumentado de aterosclerose em pacientes com diabetes tipo 2.

De acordo com o modelo de regressão linear múltiplo construído para a variável GPx, a atividade desta enzima aumenta com o aumento de Se eritrocitário. Além disso, observou-se correlação positiva e significativa entre estes parâmetros, sendo que a força da correlação bem como a sua significância reduzem com a presença do alelo variante do Pro198Leu ou GA do -602A/G. Esses dados confirmam a dependência do Se eritrocitário pela enzima GPx (164) e foram semelhantes a outros resultados $(100,164,170,171)$, com a diferença de que em Karunasinghe (170) a correlação foi mais forte no genótipo Pro/Leu que no Pro/Pro.

Vale ressaltar que, entre os parâmetros de avaliação de Se apenas o eritrocitário foi significativo para entrar no modelo múltiplo da GPx, pois o Se plasmático provavelmente não exerce influência sobre ele por estarem em compartimentos biológicos diferentes. 
Quanto ao Se consumido, este não mostrou correlação significativa com qualquer marcador do status de Se nem diferiu entre os genótipos dos SNP estudados.

O modelo de regressão linear múltiplo construído para a variável GPx permaneceu somente com o marcador genético Pro198Leu, visto que como os SNP Pro198Leu e 602A/G faziam parte do mesmo haplótipo mostraram colinearidade perfeita e não poderiam ser incluídos no mesmo modelo, e o Arg5Pro perdeu a significância ao longo da modelagem, provavelmente pelo pequeno $\mathrm{n}$ de participantes polimórficos. Este modelo, indicou que os participantes com genótipo Leu/Leu tinham 6,22 U/g de Hb de GPx a menos que aqueles com os demais genótipos do SNP Pro198Leu e, portanto, continuou revelando que a atividade da enzima reduzia com o alelo Leu deste SNP.

O modelo de regressão da GPx também revelou que indivíduos tabagistas têm 16,92 $\mathrm{U} / \mathrm{g}$ de $\mathrm{Hb}$ a menos na atividade da enzima, já verificado na literatura $(17,172)$. O cigarro contém altas concentrações de radicais livres que possuem efeito inflamatório e podem levar a várias situações que potencializam o processo carcinogênico, entre elas a redução das concentrações sanguíneas de antioxidantes (173).

Além disso, a atividade da GPx foi $4,67 \mathrm{U} / \mathrm{g}$ de $\mathrm{Hb}$ menor em indivíduos que consomem proteína entre 90 a $98 \mathrm{~g} /$ dia comparada com aqueles que consomem mais de 98 g/dia. Portanto, acredita-se que haja necessidade do aumento do consumo de alimentos proteicos, que em geral também são importantes fontes de Se, para elevar a atividade da enzima $(174,175)$.

Em relação à atividade da SOD, observou-se que a média, 1403,13 $(384,90)$ U/g de $\mathrm{Hb}$, dos participantes também estava dentro do limite de referência proposto pelo método da RANDOX (1102,0 a 1601,0 U/g de Hb) e 25,70\% (86/335) apresentaram baixa atividade. Entre os indivíduos com o alelo Leu do SNP Pro198Leu, G do -602A/G e Pro do Arg5Pro, 23,41\% (37/158), 23,30\% (37/159) e 22,22\% (2/9) tinham baixa atividade da enzima, respectivamente.

No modelo de regressão linear da SOD, bem como da GPx, participantes com idade superior a 24,5 anos têm, respectivamente, 0,107 U/g de $\mathrm{Hb}$ e 5,40 U/g de $\mathrm{Hb}$ a mais que aqueles com idade inferior a 24,5 anos. Alguns autores têm relatado o aumento da GPx e redução da SOD com o aumento da idade $(172,176,177)$. Bolzán et al. (177) observaram que essa redução da SOD não era linear e iniciava a partir dos 28 anos de idade e, Ceballos et al. (176) explicaram que essa redução pode ser devido à inativação progressiva da enzima por seus produtos $\mathrm{H}_{2} \mathrm{O}_{2}$ ou por um aumento na glicação da SOD. Essa relação inversa da SOD com a idade, esclarecida pelos autores, e não observadas nos participantes 
deste estudo, pode ser explicada pelo baixo percentual de indivíduos com idade acima de 28 anos, ou ainda, pela hipótese de que a SOD está sendo necessária para equilibrar o balanço redox, se mantendo aumentada, como comentado acima.

Entre os outros marcadores do balanço redox, apenas a determinação de ORAC mostrou influência dos marcadores genéticos, e, o MDA do Se sanguíneo. Nos modelos de regressão construídos, indivíduos com alelo Leu tem aumento de 0,143 $\mu$ mol equivalente de trolox/mL de plasma de ORAC em relação aos demais genótipos do SNP Pro198Leu e, a cada unidade de Se plasmático $(\mu \mathrm{g} / \mathrm{L})$, reduz-se em média 0,003 $\mu \mathrm{Mol} / \mathrm{L}$ de MDA. Acredita-se que os indivíduos com o alelo Leu do Pro198Leu tenham maior concentração do ORAC, a partir de outras fontes antioxidantes que o compõem, visto que a atividade da GPx estava baixa nestes participantes, e eles podem estar fazendo uso de outras formas de proteção contra radicais livres. Também acredita-se que a relação entre o MDA e o Se plasmático indique aumento da GPx plasmática a partir do Se, na tentativa de reduzir a peroxidação lipídica. No entanto, este marcador não foi avaliado neste estudo.

$\mathrm{Na}$ análise de regressão linear considerando o ORAC percebe-se que este aumenta significativamente com o aumento do IMC e reduz com o aumento do consumo de lipídios, enquanto no modelo da SOD o efeito do consumo de lipídios é positivamente significativo. É possível que a qualidade de lipídios consumidos pelos participantes deste estudo seja rico em ácidos graxos saturados que podem elevar a concentração de LDL (178). No entanto, esta composição em ácidos graxos não foi analisada neste estudo, apenas observado o alto percentual de lipídios na dieta. Esta avaliação também pode ser proposta para os indivíduos com IMC elevado, visto que houve correlação positiva e significativa entre o IMC e a LDL $(r=0,279 ; \mathrm{p}<0,01)$. Assim, acredita-se que a LDL pode estar sendo oxidada, as concentrações de MDA elevadas e o perfil antioxidante modificado, levando a alterações na concentração de ORAC. A atividade da SOD pode estar aumentada na tentativa de reduzir os danos oxidativos causados pelo MDA, o que confirma a correlação significativa encontrada entre MDA e SOD. Apesar da contribuição do consumo de lipídios no modelo de regressão do ORAC e da SOD ser aparentemente pequeno, acreditase que possa estar atuando da maneira como explicada acima. Além disso, concentrações reduzidas da atividade antioxidante total têm sido observadas em indivíduos com síndrome metabólica $(179,180)$ e com hiperlipidemia (169).

O modelo de regressão do ORAC também mostrou que em indivíduos que ingerem bebida alcoólica há aumento médio de $0,061 \mu \mathrm{Mol}$ equivalente de trolox/mL de plasma. 
Essa relação positiva entre os parâmetros também foi observada por Kolomvotsou et al. (181) ao avaliar a influência da dieta do Mediterrâneo na atividade antioxidante total em pacientes com obesidade abdominal, que identificaram um aumento de 9,18\% no ORAC após dois meses de consumo dessa dieta, os quais foram explicados pela ingestão de vinhos, ricos em polifenóis. O efeito positivo do consumo moderado de bebidas alcoólicas também tem sido identificado em doenças cardiovasculares $(182,183,184,185,186)$ e câncer $(187,188,189,190)$, pois a presença de componentes como o etanol aumentam as concentrações de HDL, inibem a agregação plaquetária e reduzem a inflamação sistêmica e, componentes fenólicos têm efeitos antioxidantes, inibem a oxidação de partículas de LDL e a agregação plaquetária, melhoram a função endotelial, reduzem a pressão sanguínea, a inflamação, a adesão celular e a ativação de proteínas que previnem a morte das células (191).

É importante enfatizar que os benefícios associados com vinho tinto e cerveja dependem do consumo regular e moderado. As recomendações para mulheres são de uma dose por dia (150 mL de vinho ou $10 \mathrm{~g}$ de álcool) e para os homens, duas doses diárias (300 ml de vinho ou $20 \mathrm{~g}$ de álcool), sendo que estas diferem entre os sexos porque as mulheres são mais sensíveis aos efeitos do álcool no organismo. Além disso, quaisquer efeitos saudáveis do vinho e cerveja não substituem uma dieta saudável e são maiores em combinação com esta (191).

Portanto, considerando todos os aspectos relacionados ao estado nutricional dos participantes desse estudo em relação ao selênio e as possíveis influências genéticas e ambientais, verificamos que os estudos nessa direção serão cada vez mais promissores e trarão novo olhar para as pesquisas relacionadas a micronutrientes. 


\section{0 - CONCLUSÃO}

- Os indivíduos participantes desse estudo em sua maioria tinham estado nutricional relativo ao selênio deficiente embora ingerindo quantidades de selênio consideradas adequadas.

- Os participantes carreadores do alelo Leu do SNP Pro198Leu e G do -602A/G apresentaram maior deficiência em Se e atividade mais baixa da enzima GPx.

- Indivíduos com alelo variante para o SNP Arg5Pro apresentaram melhores resultados para atividade enzimática (GPx) e parâmetros bioquímicos, sugerindo que este polimorfismo seja benéfico para o estado nutricional dos indivíduos relativo ao Se.

- O potencial redox sofreu influência dos polimorfismos, sendo que a capacidade antioxidante total dos indivíduos com alelo Leu do SNP Pro198Leu foi melhor, apesar da sua baixa atividade de GPx. 


\section{REFERÊNCIAS BIBLIOGRÁFICAS}

1. GOnZAGA, I. B.; MARTENS, A.; COZZOLinO, S. M. F. Selênio. In.: COZZOLINO, S. M. F. Biodisponibilidade de Nutrientes. 3. Ed. Atual. E ampl. Barueri, SP: Manole, 2009.

2. SUZUKI, K. T. Metabolomics of selenium: Se metabolites based on speciation studies. J Sci, v. 51; n. 2, p. 107-44, 2005.

3. LYONS, G.; STANGOULIS, J.; GRAHAM, R. High-selenium wheat: biofortification for better health. Nutr Res Rev, v. 16, n. 1; p. 45-60, 2003;

4. REILLY, C. Selenium in food and health. New York: Springer, 2006.

5. INSTITUTE OF MEDICINE. FOOD AND NUTRITION BOARD. Dietary Reference Intakes for Vitamin C, Vitamin E, Selenium, and Carotenoids. Washington, DC: National Academy Press: 2000.

6. MEHDI, Y. et al. Selenium in the Environment, Metabolism and Involvement in Body Functions. Molecules, v. 18, p. 3292-3311, 2013.

7. SCHRAUZER, G. N. Anticarcinogenic effects of selenium. Cell Mol Life Sci, v. 57, p.1864-73, 2000.

8. KAPUT, J.; RODRIGUEZ, R. L. Nutritional genomics: The next frontier in the postgenomic era. Phisiol Genomics, v. 16, n. 2, p. 166-77, 2004.

9. BRASIL. MINISTÉRIO DA SAÚDE. SECRETARIA DE VIGILÂNCIA EM SAÚDE. Diretrizes e recomendações para o cuidado integral das DCNTs. Brasília, 2008.

10. HOLBEN, D. H.; SMITH. A. M. The diverse role of selenium within selenoproteins: a review. J Am Diet Assoc, v. 99, p. 836-43, 1999.

11. ALARCÓN-NAVARRO, M; MARTINEZ, M. C. L. Essentiality of selenium in the human body: relationships with diferent disease. Sci Total Environ, v. 249, p. 347-71, 2000.

12. THOMAS, J. P.; GEIGER, P. G.; GIROTTI, A. W. Lethal damage to endothelial cells by oxidized low density lipoprotein. J Lipid Res, v. 34, p. 479-90, 1993.

13. VIVANCO, R. H. C.; MENGE, F. G. W.; BARRIGA, P. A.C. Variaciones de la fragilidad osmótica eritrocitaria en bovinos a pastoreo sobre praderas con bajo contenido de selenio y suplementados o no con selenio. Rev Cient, v. XVI, n. 3, p. 227-31, 2006.

14. RATNASINGHE, D. et al. Glutathione peroxidase codon 198 polymorphism variant increases lung cancer risk. Cancer Res, v. 60, p. 6381-83, 2000.

15. VILLETE, S. et al. A novel single nucleoide polymorphism in the 3'UTR of human GPx4 influences lipoxygenase metabolism. Blood Cell Mol Dis, v. 29, n. 2, p. 174-78, 2002.

16. RAACHOU-NIELSEN, O. et al. GPx1 Pro198Leu polymorphism, interactions with smoking and alcohol consumption, and risk for lung cancer. Cancer Lett, v. 247, p. 293-300, 2006; 
17. RAVN-HAREN, G. et al. Associations between GPX1 Pro198Leu polymorphism, erythrocyte GPX activity, alcohol consumption and breast cancer risk in a prospective cohort study. Carcinogenesis, v. 27, p. 820-25, 2006.

18. BERMANO, G. et al. Evidence that a polymorphism within the 3'UTR of GPx4 is functional and is associated with susceptibility to colorectal cancer. Genes Nutr, v. 2, n. 2, p. 225-232, 2007.

19. MÉPLAN, C. et al. Functional effects of a common single-nucleotide polymorphism $(\mathrm{GPx} 4 \mathrm{c} 718 \mathrm{t})$ in the glutathione peroxidase 4 gene: interaction with sex. Am J Clin Nutr, v. 87, n. 4, p. 1019-27, 2008.

20. ARSOVA-SARAFINOVSKA, Z. et al. Glutathione peroxidase 1 (GPX1) genetic polymorphism, erythrocyte GPX activity, and prostate cancer risk. Int Urol Nephrol, v. 41, p. $63-70,2009$.

21. HAMANISHI, T. et al. Functional Variants in the Glutathione Peroxidase-1 (GPX-1) Gene Are Associated With Increased Intima-Media Thickness of Carotid Arteries and Risk of Macrovascular Diseases in Japanese Type 2 Diabetic Patients. Diabetes, v. 53, p. 2456-60, 2004.

22. KUZUYA, M. et al. Glutathione peroxidase 1 Pro198Leu variant contributes to the metabolic syndrome in men in a large Japanese cohort. Am J Clin Nutr, v. 87, p. 1939-44, 2008.

23. KESHAN DISEASE RESEARCH GROUP OF THE CHINESE ACADEMY OF MEDICAL SCIENCES. Observation on the effect of sodium selenium in prevention of Keshan disease. Chin Med J, v. 92, p. 471-6, 1979.

24. ALMONDES, K. G. S. et al. O papel das selenoproteínas no câncer. Rev Assoc Med Bras, v. 56, n. 4, p. 484-8, 2010.

25. PAPP, L. V. et al. From Selenium to Selenoproteins: Synthesis, Identity, and Their Role in Human Health. Antioxid Redox Signal, v. 9, n. 7, 2007.

26. FAIRWEATHER-TAIT, S. J. Bioavailability of selenium. Eur J Clin Nut, v. 51, p. S20-S23, 1997.

27. FAIRWEATHER-TAIT, S.J.; COLLINGS, R.; HURST, R. Selenium bioavailability: Current knowledge and future research requirements. Am J Clin Nutr, v. 91, 1484S1491S, 2010.

28. GAMMELGAARD, B. et al. Estimating intestinal absorption of inorganic and organic selenium compounds by in vitro flux and biotransformation studies in Caco-2 cells and ICP-MS detection. Biol Trace Elem Res, v. 145, n. 2, p. 248-56, 2012.

29. WEEKLEY, C. M. et al. Metabolism of selenite in human lung cancer cells: X-ray absorption and fluorescence studies. J Am Chem Soc, v. 133, n. 45, 18272-9, 2011.

30. ROMAN, M.; JITARUB, P.; BARBANTE, C. Selenium biochemistry and its role for human health. Metallomics, v. 6, n. 25, p. 25-54, 2014.

31. SUZUKI, K. T.; DOI, C.; SUZUKI, N. Metabolism of 76Se-methylselenocysteine compared with that of 77Se-selenomethionine and 82Se-selenite. Toxicol Appl Pharmacol, v. 217, p. 185-195, 2006.

32. DONG, Y. et al. Characterization of the biological activity of gamma-glutamyl-Semethylselenocysteine: a novel, naturally occurring anticancer agent from garlic. Cancer Res, v. 61, p. 2923-28, 2001. 
33. NICKEL, A. et al. Characteristics of transport of selenoamino acids by epithelial amino acid transporters. Chem Biol Interact, v. 177, n. 234-41, 2009.

34. SUZUKI, K. T.; OGRA, Y. Metabolic pathway for selenium in the body: speciation by HPLC-ICP MS with enriched Se. Food Addit Contam, v. 19, n. 10, p. 974-83, 2002.

35. Schrauzer, GN. Selenomethionine: a review of its nutritional significance, metabolism and toxicity. J Nutr, v. 130, n 7, p. 1653-6.

36. BURK, R. F.; LEVANDER, O. A. Selenium. In: SHILS, M. E. et al. Modern Nutrition in Health and Disease, 9 ed., p. 285-302. Williams \& Wilkins, Baltimore, MD, 2003.

37. BUTLER, J. A.; WHANGER, P. D. Influence of dietary methionine on the metabolism of selenomethionine in rat. J Nutr, v. 119, p. 1001-9, 1989.

38. McCONNEL, K. P.; PORTMAN, O. W. Toxicity of fimethylselenide in the rat and mouse. Proc Soc Exp Biol Med, v. 79, p. 230-231, 1952.

39. HESKETH J. Nutrigenomics and Selenium: Gene Expression Patterns, Physiological Targets, and Genetics. Annu. Rev. Nutr, v. 28 p: 157-77, 2008.

40. LABUNSKYY V. M.; HATFIELD D. L.; GLADYSHEV V. N. Selenoproteins: molecular pathways and physiological roles. Physiol Rev, v. 94, p: 739-77, 2014.

41. SUZUKI Y. et al. Dynamic pathways of selenium metabolism and excretion in mice under different selenium nutritional statuses. Metallomics, v. 2, 126-32, 2010.

42. SPALlHOLTZ, J. E. et al. Selenium and immune system. Environ Res, v. 587, p. 123-39, 1990.

43. CASTRO, M. W. Selenio em los pacientes críticos com respuesta inflamatória sistêmica: revisión. Nutr Hosp, v. 22, n. 3, p. 295-306, 2007.

44. THOMSON, C. D. et a. Selenium: its role in health and disease. Asia Pac J Clin Nutr, v. 15, s. 3, p. 25-30, 2006.

45. K. T. Suzuki, Int J Med Health Sci, v. 51, p. 107-14, 2005.

46. BURK, R. F.; HILL, K. E. Selenoprotein P-expression, functions, and roles in mammals. Biochim Biophys Acta, v. 1790, p. 1441-47, 2009.

47. KUEHNELT, D. et al., Selenium metabolites in urine of cancer patients receiving Lselenomethionine at high doses. Toxicol Appl Pharmacol, v. 220, p. 211-15, 2007.

48. OHTA, Y.; SUZUKI, K. T. Methylation and demethylation of intermediates selenide and methylselenol in the metabolism of selenium. Toxicol Appl Pharmacol, v. 226, p. 169-77, 2008.

49. BEHNE, D. et al. Evidence for specific selenium target tissues and new biologically important selenoproteins. Biochim Biophys Acta, v. 966, p. 12-21, 1988.

50. BERMANO, G. et al. Tissue-specific regulation of selenoenzyme gene expression during selenium deficiency in rats. Biochem J, v. 311, p. 425-30, 1995.

51. EVENSON, J. K. et al. Selenoprotein mRNA is expressed in blood at levels comparable to major tissues in rats. J Nutr, v. 134, p. 2640-45, 2004. 
52. LEI, X. G. et al. Glutathione peroxidase and phospholipid hydroperoxide glutathione peroxidase are differentially regulated in rats by dietary selenium. J Nutr, v. 125, p. 1438-46, 1995.

53. CROSLEY, L. K. et al. Differential regulation of expression of cytosolic and mitochondrial thioredoxin reductase in rat liver and kidney. Arch Biochem Biophys, v. 459, p. 178-88, 2007.

54. MÜLLER, C.; WINGLER, K.; BRIGELIUS-FLOHÉ, R. 3_UTRs of glutathione peroxidases differentially affect selenium-dependent mRNA stability and selenocysteine incorporation efficiency. Biol Chem, v. 384, p. 11-8, 2003.

55. WINGLER, K. et al. mRNA stability and selenocysteine insertion sequence efficiency rank gastrointestinal glutathione peroxidase high in the hierarchy of selenoproteins. Eur J Biochem, v. 259, p. 149-57, 1999.

56. BRIGELIUS-FLOHÉ, R. Tissue-specific functions of individual glutathione peroxidases. Free Radic Biol Med, v. 27, n. 9/10, p. 951-65, 1999.

57. SCHOMBURG, L; SCHWEIZER, U. Hierarchical regulation of selenoprotein expression and sex-specific effects of selenium. Biochim Biophys Acta, v. 1790, p. 1453-62, 2009.

58. DUMITRESCU, A. M. et al. Mutations in SECISBP2 result in abnormal thyroid hormone metabolism. Nat Genet, v. 37, p. 1247-52, 2005.

59. CARLSON, B. A. et al. Selective restoration of the selenoprotein population in a mouse hepatocyte selenoproteinless background with different mutant selenocysteine tRNAs lacking Um34. J Biol Chem, v. 282, p. 32591-602, 2007.

60. BERMANO, G.; ARTHUR, J. R.; HESKETH, J. E. Role of the 3' untranslated region in the regulation of cytosolic glutathione peroxidase and phospholipid-hydroperoxide glutathione peroxidase gene expression by selenium supply. Biochem J, v. 320, p. 891-95, 2006.

61. CROSLEY, L. K. et al. Differential regulation of expression of cytosolic and mitochondrial thioredoxin reductase in rat liver and kidney. Arch Biochem Biophys, v. 459, p. 178-88, 2007.

62. STADTMAN, T. C. Biosynthesis and function of selenocysteine-containing enzymes. J Biol Chem, v. 266, p. 16257-60, 1991.

63. RAYMAN, M. P. The importance of selenium to human health. Lancet, v. 356, n. 9225, p. 233-41, 2000.

64. COMINETTI, C. et al. Estresse oxidativo, selênio e nutrigenética. J Brazilian Soc Food Nutr, v. 36, n. 3, p. 131-53, 2011.

65. Higdon, J.; Drake, V. J.; Whagner, P. D. Selenium. Oregon: Oregon State University, Linus Pauling Institute, Micronutrient Information Center. 2009. Disponível em: http://lpi.oregonstate.edu/mic/minerals/selenium. Acesso em 29 de abril de 2015.

66. KRYUKOV, G. V. et al. Characterization of mammalian selenoproteomes. Science, v. 300, p. 1439-43, 2003.

67. SQUIRES, J. E. et al. SBP2 binding affinity is a major determinant in differential selenoprotein mRNA translation and sensitivity to nonsense-mediated decay. Mol Cell Biol, v. 27, p. 7848-55, 2007. 
68. BERMANO, G. et al. Tissuespecific regulation of selenoenzyme gene expression during selenium deficiency in rats. Biochem J, v. 311, p. 425-430, 1995.

69. HARA, S. et al. Effects of selenium deficiency on expression of selenoproteins in bovine arterial endothelial cells. Biol Pharmaceutical Bull, v. 24, p. 754-59, 2001.

70. WEISS SACHDEV, S.; Sunde, R. A. Selenium regulation of transcript abundance and translational efficiency of glutathione peroxidase- 1 and -4 in rat liver. Biochem $\mathbf{J}, \mathrm{v}$. 357 , p. 851- 58, 2001.

71. DUCROS, V.; FAVIER, A. Selenium metabolism. EMC Endocrinol Nutr, v. 1, p. 19-28, 2004.

72. FERGUSONA, L. R. et al. Selenium and its' role in the maintenance of genomic stability. Mutation Research, v. 733, p. 100-10, 2012.

73. Rayman, M. P.; Infante, H. G. Sargent, M. Food-chain selenium and human health: spotlight on speciation. Br J Nutr, v. 100, p. 238-53, 2008.

74. GONZAGA, I. B. Avaliação nutricional relative ao selênio em crianças com dieta enriquecida de castanha-do-Brasil (Bertholletia excelsa, L.). 2002. 115 p. Tese (Doutorado em Ciências dos Alimentos) - Faculdade de Ciências Farmacêuticas, Universidade de São Paulo, São Paulo. 2002.

75. YANG, G. Q. et al. Studies of safe maximal daily dietary Se-intake in a seleniferous area in China. II. Relation between Se-intake and the manifestation of clinical signs and certain biochemical alterations in blood and urine. J Trace Elem Electrolytes Helth Dis, v. 3, p. 123-30, 1989.

76. KESHAN DISEASE RESEARCH GROUP OF THE CHINESE ACADEMY OF MEDICAL SCIENCES. Epidemiological studies on the etiologic relationship of selenium and Keshan disease. Chin Med J, v. 92, p. 477-82, 1979.

77. ALLANDER, E. Kashin-Beck disease. An analysis of research and public health activities based on a bibliography 1849-1992. Scand J Rheum, v. 23, n. 99, p. 1-36, 1994.

78. WORLD HEALTH ORGANIZATION. Kashin Beck disease and noncommunicable disease. Beijing: Chinese Academy of Preventive Medicine, 1990.

79. THOMSON, C. D. Assessment of requirements for selenium and adequacy of selenium status: a review. Eur J Clin Nutr, v. 58, p. 391-402, 2004.

80. OLDFIELD, J. E. Selenium. World Atlas. Oregon State University, Corvallis. Updated Edition, 2002.

81. DUFFIELD, A. J. An estimation of selenium requirements for New Zealanders. Am J Clin Nutr, v. 70; p. 896-903, 1999.

82. MORENO-REYES, R. et al. Kashin-Beck osteoarthropathy in rural Tibet in relation to selenium and iodine status. N Engl J Med, v. 339; p. 1112-20, 1998.

83. XIA et al. Effectiveness of selenium supplements in a low-selenium area of China. Am J Clin Nutr, v. 81, p. 829-34, 2005.

84. COZZOLINO, S. M. F. Deficiências de minerais. Estudos Avançados, v. 21, n. 60, p. 119-26, 2007.

85. CHANG, J. C. et al. Selenium Content of Brazil Nuts from Two Geographic Locations in Brazil. Chemosphere, v. 30, n. 4, p. 801-802, 1995. 
86. YANG, J. Brazil nuts and associated health benefits: A review. LWT - Food Science and Technology, v. 42, p. 1573-1580, 2009.

87. MARTENS, A.; COZZOLINO, S. M. F. Mapeamento da distribuição de selênio em território brasileiro por meio da análise de alimentos nativos: feijão (Faseolos vulgaris l.) e carne bovina para consumo humano e águas e solos oriundas. Relatório científico encaminhado a FAPESP. Processo $n^{\circ}$ 00/11578-3. São Paulo: FCF/USP: Departamento de Ciência dos Alimentos, 2002. 39 p.

88. MAIA, C. S. C. O selênio e a glândula tireoide: um estudo em pacientes com disfunções tireoidianas nos estados do Ceará e São Paulo. 2008. Tese de doutorado - Faculdade de Saúde Pública - Universidade de São Paulo, São Paulo. 2008.

89. ROCHA, A.V. et al. Selenium Status and Hair Mercury Levels in riverine children from Rondonia - Amazonia. Article in Press. http://dx.doi.org/10.1016/j.nut.2014.03.013. Nutrition, 2014.

90. BORTOLI, M. C. Avaliação dos níveis sanguíneos do hormônio tireoidiano ativo $T_{3}$ e do estado nutricional relativo ao selênio de mulheres residentes em área de exposição de mercúrio. 2009. 130 p. Tese de doutorado. Faculdade de Ciências Farmacêuticas. Universidade de São Paulo, São Paulo. 2009.

91. CARMONA-Fonseca, J. Selenio en suero y plasma: epidemiología y valores de referencia. Rev Panam Salud Publica, v. 28, n. 5, p. 7-11, 2010.

92. DONADIO, J. L. S. Associação entre polimorfismos nos genes da glutationa peroxidase e indicadores do estado nutricional relativo ao selênio em população saudável. Dissertação (Mestrado em Ciências dos Alimentos) - Faculdade de Ciências Farmacêuticas - Universidade de São Paulo, São Paulo. 2011.

93. SANTOS, L. B. Polimorfismo Pro198Leu no gene que codifica para a glutationa peroxidase 1 e sua relação com o estado nutricional relativo ao selênio em uma população adulta residente no município de Fortaleza, Ceará. 2013. Dissertação (Mestrado em Ciências dos Alimentos) - Faculdade de Ciências Farmacêuticas, Universidade de São Paulo, São Paulo. 2013.

94. ROCHA, A. V. Status de selênio de uma população residente em área de risco de contaminação por mercúrio. Influência de polimorfismos e ação sobre o estresse oxidativo. São Paulo. 2015. Tese (Doutorado em Ciências dos Alimentos) - Faculdade de Ciências Farmacêuticas, Universidade de São Paulo, São Paulo. 2015.

95. STOCKLER-PINTO, M. B. Effect of Brazil nut supplementation on the blood levels of selenium and glutathione peroxidase in hemodialysis patients. Nutrition, v. 26, p. 1065-69, 2010.

96. CARDOSO, B. R. et al. Nutritional status of selenium in Alzheimer's disease patients. Br J Nutr, v. 103, p. 803-6, 2010.

97. COMINETTI, C. Efeito da suplementação com castanha do Brasil (Bertholletia excelsa H. B. K.) sobre o estresse oxidativo em mulheres obesas e sua relação com o polimorfismo Pro198Leu no gene da glutationa peroxidase 1. 2010. $115 \mathrm{p}$. Tese (Doutorado em Ciências dos Alimentos). Faculdade de Ciências Farmacêuticas Universidade de São Paulo, São Paulo. 2010.

98. van DAEL, P.; DEELSTRA, H. Selenium. Int J Vitam Nutr Res, v. 63, n. 4, p. 312$16,1993$. 
99. GROMADZINSKA, J. et al. Selenium and cancer: biomarkers of selenium status and molecular action of selenium supplements. Eur J Nutr, v. 47, Suppl. 2; p. 29-50, 2008.

100. JABLONSKA, E. et al. Association between GPx1 Pro198Leu polymorphism, GPx1 activity and plasma selenium concentration in humans. Eur J Clin Nutr, v. 48, p. 383-86, 2009.

101. McKENZIE, R. L. et al. Selenium concentration and glutathione peroxidase activity in blood of New Zealand infants and children. Am J Clin Nutr, v. 31, p. 1413-14 18, 1978.

102. THOMSON, C. D.; ROBINSON, M. F. Selenium in human health and disease with emphasis on those aspects peculiar to New Zealand. Am J Clin Nut, v. 33; p. 303-23, 1980.

103. JOCHUM, F. et al. Effects of a low selenium state in patients with phenylketonuria. Acta Paediatr, v. 86; p. 775-77, 1997.

104. MORENO-REYES, R. et al. Selenium and iodine supplementation of rural Tibetan children affected by Kashin-Beck osteoarthropathy. Am J Clin Nutr, v. 78, p. 13744, 2003.

105. BURK, R. F. et al. Effects of Chemical Form of Selenium on Plasma Biomarkers in a High-Dose Human Supplementation Trial. Cancer Epidemiol Biomarkers Prev, v. 15, n. 4, p. 804-10, 2006.

106. THOMSON, C. D. et al. Brazil nuts: an effective way to improve selenium status. Am J Clin Nutr, v. 87, p. 379-384, 2008.

107. HURST, R. et al. Establishing optimal selenium status: results of a randomized, double-blind, placebo-controlled trial. Am J Clin Nutr, v. 91; p. 923-31, 2010.

108. XIA, Y. et al. Optimization of selenoprotein $\mathrm{P}$ and other plasma selenium biomarkers for the assessment of the selenium nutritional requirement: a placebocontrolled, double-blind study of selenomethionine supplementation in seleniumdeficient Chinese subjects. Am J Clin Nutr, v. 92, p. 525-31, 2010.

109. COMINETTI, C. et al. Associations between glutathione peroxidase-1 Pro198Leu polymorphism, selenium status, and DNA damage levels in obese women after consumption of Brazil nuts. Nutrition, v. 27, p. 891-96, 2011.

110. FUJII, T. M. M.; MEDEIROS, R.; YAMADA, R. Nutrigenômica e nutrigenética: importantes conceitos para a ciência da nutrição. J Brazilian Soc Food Nutr, v. 35, n. 1, p. 149-166, 2010.

111. SCHORK, N. J.; FALLIN, D.; LANCHBURY, S. Single nucleotide polymorphisms and the future of genetic epidemiology. Clin Genet, v. 58, p. 250-64, 2000.

112. BROOKES, A. J. The essence of SNP. Gene, v. 234, p. 177-86, 1999.

113. SYVÄNEN, A. Accessing genetic variation: genotyping single nucleotide polymorphisms. Nature Rev Genet, v.2, n.12, p. 930-42, 2001.

114. WANG, Z.; MOULT, J. SNP, protein structure and disease. Hum Mut, v. 17, n. 4, p 263-70, 2001. 
115. KAUWELL, G.P.A. Emerging concepts in nutrigenomics: A preview of what is to come. Nutr Clin Pract, v.20, n.1, p.75-87, 2005.

116. GABRIEL, S. B. The structure of haplotype blocks in the human genome. Science, v. 296 n.5576, p. 2225-9, 2002.

117. PASTERNAK, J. J. Genetic and physical mapping of the human genome. In: PASTERNAK, J. J. An Introduction to Human Molecular Genetics. Canadá: Wiley-Liss, p. 153-87, 2005.

118. RAMENSKY, V.; BORK, P.; SUNYAEV, S. Human non-synonymous SNP: server and survey. Nucl Acids Res, v. 30, n. 17, p. 3894-3900, 2002.

119. HU, Y. J.; DIAMOND, A. M. Role of glutathione peroxidase 1 in breast cancer: loss of heterozygosity and allelic differences in the response to selenium. Cancer Res, v. 63, p. 3347-51, 2003.

120. ICHIMURA, Y.; HABUCHI, T.; TSUCHIYA, N. Increased risk of bladder cancer associated with a glutathione peroxidase 1 codon 198 variant. J Urol, v. 172, p. 728 32, 2004.

121. HANSEN, R. D.; KRATH, B. N.; FREDERIKSEN, K. GPX1 Pro198Leu polymorphism, erythrocyte GPX activity, interaction with alcohol consumption and smoking, and risk of colorectal cancer. Mutat Res, v. 664, p. 13-9, 2009.

122. SUZEN, H. S. CAT C-262T and GPX1 Pro198Leu polymorphisms in a Turkish population. Mol Biol Rep, v. 37, p. 87-92, 2010.

123. IIDA, R. et al. Simultaneous genotyping of 11 non-synonymous SNP in the 4 glutathione peroxidase genes using the multiplex single base extension method. Clin Chim Acta, v. 402, p. 79-82, 2009.

124. MISTRY, H.D. et al. Association between maternal micronutrient status, oxidative stress, and common genetic variants in antioxidant enzymes at 15 weeks' gestation in nulliparous women who subsequently develop preeclampsia. Free Radic Biol Med, v. 78, p. 147-55, 2015.

125. HUANG, L. et al. Association Study of Polymorphisms in Selenoprotein Genes and Kashin-Beck Disease and Serum Selenium/Iodine Concentration in a Tibetan Population. PLoS ONE, v. 8, n. 8, p. e71411, 2013.

126. MOGHADASZADEH, B.; BEGGS, A. H. Selenoproteins and their impact on human health through diverse physiological pathways. Physiology (Bethesda), v. 21, p. 307315, 2006.

127. TAKATA, Y. et al. Genetic Variation in GPX1 Is Associated with GPX1 Activity in a Comprehensive Analysis of Genetic Variations in Selenoenzyme Genes and Their Activity and Oxidative Stress in Humans. J. Nutr. doi: 10.3945/jn.111.151845. 18 de janeiro de 2012. Epub ahead of print.

128. MIRANDA-VILELA, A. L. Gene polymorphisms against DNA damage induced by hydrogen peroxide in leukocytes of healthy humans through comet assay: a quasiexperimental study. Environ Health, v. 9, n. 21, p.: 1-9, 2010.

129. FERREIRA, K. S. et al. Concentrações de selênio em alimentos consumidos no Brasil. Pan Am J Public Health, v. 11, n. 3, p. 172-77, 2002. 
130. WILlET, W. C.; HOWE, G. R.; KUSHI, L. H. Adjustment for total energy in epidemiologic studies. Am J Clin Nutr, v. 65, p. 1220-28, 1997. (supply)

131. WILLET, W.; STAMPFER, M. Implications of total energy intake for epidemiologic analyses. In: WILLET, W. C. Nutrition epidemiology, 2ed, New York: Oxford University Press, p. 514, 1998.

132. SLATER, B.; MARCHIONI, D. L.; FISBERG, R. M. Estimando a prevalência da ingestão inadequada de nutrientes. Rev Saúde Pública, v. 33, n. 4, p. 599-605, 2004.

133. Institute of Medicine. Dietary Reference Intakes: The Essential Guide to Nutrient Requirements. Washington, DC: National Academy Press: 2006.

134. WORLD HEALTH ORGANIZATION. Obesity: Preventing and managing the global epidemic. Technical report series, Geneva, n.894, 2000. p. 9.

135. LOHMAN, T. G. Advances in body composition assessment. Current issues in exercise science series. Champaign: Human Kinetics Books; 1992

136. SOCIEDADE BRASILEIRA DE CARDIOLOGIA. V Diretriz Brasileira de Dislipidemias e Prevenção da Aterosclerose. Departamento de Aterosclerose da Sociedade Brasileira de Cardiologia. Arq Bras Cardiol, v. 101, Suppl. 1, p. 1-20, 2013.

137. REZAEI, Z.; JAMSHIDZADEH, A.; SANATI, E. A rapid and sensitive method for he determination of malondialdehyde as its hydralazine derivative in human plasma using high performance liquid chromatography. Anal Methods, v. 5, p. 2995-9, 2013.

138. PAGLIA, D. E.; VALENTINE, W. N. Studies on the quantitative and qualitative characterization of erythrocite glutathione peroxidase. J Lab \& Clin Med, v. 70, n.1, p. 159-69, 1967.

139. PRIOR, R.L. et al. Assays for hydrophilic and lipophilic antioxidant capacity (oxygen radical absorbance capacity (ORACFL) of plasma and other biological and food samples. J Agric Food Chem, v.51, p.3273-9, 2003.

140. BRASIL. MINISTÉRIO DA SAÚDE. SECRETARIA DE VIGILÂNCIA EM SAÚDE. Vigitel Brasil 2013: vigilância de fatores de risco e proteção para doenças crônicas por inquérito telefônico. Série G. Estatística e Informação em Saúde, $1^{\text {o }}$ edição, 2014.

141. SAVEL, J. et al. Very low levels of HDL cholesterol and atherosclerosis, a variable relationship - a review of LCAT deficiency. Vasc Health Risk Manag, v. 8, p. 35761, 2012.

142. TABET, F.; RYE, K. High-density lipoproteins, inflammation and oxidative stress. Clin Sci, v. 116, n. 2, p. 87-98, 2009.

143. BITZUR, R. et al. Triglycerides and HDL cholesterol. Stars or second leads in diabetes? Diabetes Care, v. 32, Suppl. 2, p. 373-77, 2009.

144. SCHMIDT, M. I. et a. Doenças crônicas não transmissíveis no Brasil: carga e desafios atuais. 2011 (Saúde no Brasil, 4). Disponível em: http://download.thelancet.com/flatcontentassets/pdfs/brazil/brazilpor4.pdf. Acesso em: 10 Jan. 2015.

145. MINISTÉRIO DO PLANEJAMENTO, ORÇAMENTO E GESTÃO. INSTITUTO BRASILEIRO DE GEOGRAFIA E ESTATÍSTICA. Pesquisa de Orçamentos Familiares 2008-2009. Análise do consumo alimentar pessoal no Brasil. Rio de Janeiro, 2011. 
146. PINHO, C. P. S. et al. Consumo de alimentos protetores e preditores do risco cardiovascular em adultos do estado de Pernambuco. Rev Nutr, v. 25, n. 3, p. 341-51, 2012.

147. RESZKA, E. et al. Relevance of selenoprotein transcripts for selenium status in humans. Genes Nutr, v. 7, p. 127-37, 2012.

148. NICHIMURA, L. S. Polimorfismo Pro198Leu no gene para a enzima antioxidante dependente de selênio glutationa peroxidase 1 e o risco de câncer epidemóide da cavidade oral e orofaringe. Dissertação (Mestrado em Ciências) Faculdade de Ciências Farmacêuticas, Universidade de São Paulo, São Paulo. 2010.

149. CARDOSO, B. R. et al. Glutathione Peroxidase 1 Pro198Leu Polymorphism in Brazilian Alzheimer's Disease Patients: Relations to the Enzyme Activity and to Selenium Status. J Nutrigenet Nutrigenomics, v. 5, p. 72-80, 2012.

150. FORSBERG, L. et al. Phenotype determination of a common Pro-Leu polymorphism in human glutathione peroxidase 1. Blood Cells Mol Dis, v. 26, p. 423-26, 2000.

151. LIGHTFOOT, T. J. et al. Polymorphisms in the oxidative stress genes, superoxide dismutase, glutathione peroxidase and catalase and risk of non-hodgking's lymphoma. Haematologica, v. 91, p. 1222-7, 2006.

152. ZARBOCK, R. et al. Pseudoxanthoma elasticum: genetic variations in antioxidant genes are risk factors for early disease onset. Clin Chem, v. 53, p. 1734-40, 2007.

153. MOSTOWSKA, A. et al. Polymorphism variants of genes encoding main antioxidant enzymes and the risk of CL/P-affected pregnancies. Clin Biochem, v. 40, p. 416-19, 2007.

154. KNIGHT, J. A. Genetic variants of GPX1 and SOD2 and breast cancer risk at the Ontario site of the breast cancer family registry. Cancer Epidemiol Biomarkers Prev, v. 13, p. 146-49, 2004.

155. RAASCHOU-NIELSEN, O. et al. GPX1 Pro198Leu polymorphism, interactions with smoking and alcohol consumption, and risk for lung cancer. Cancer Lett, v. 247, p. 293-300, 2007.

156. CHOI, J. Y. et al. Polymorphisms in oxidative stress- related genes are not associated with prostate cancer risk in heavy smokers. Cancer Epidemiol Biomarkers Prev, v. 16, p. 1115-20, 2007.

157. THOMASSEN, Y; AASETH, J. Human Tissues. In.: Occurrence and Distribution of Se (Ihnat, M., ed.) CRC-Press, Boca Raton, 1989, p. 169-212.

158. NÈVE, J. Methods in determination of selenium status. J Trace Elem Electrolytes Health Dis, v. 5, p. 1 - 17, 1991.

159. ALEGRIA, A.; BARBERÁ, R; CLEMENTE, G.; FARRÉ, R.; GARCÍA, M. J.; LAGARDA, M. J. Selenium and glutathione peroxidase reference values in whole blood and plasma of a reference population living in Valencia, Spain. J Trace Elem Med Res, v. 10, n. 4, p. 223-8, 1996.

160. PLEBAN, P. A.; MUNYANI, A.; BEACHUM, J. Determination of selenium concentration and glutathione peroxidase activity in plasma and erythrocytes. Clin Chem, v. 28, n. 2, p. 311-6, 1982.

161. ROBBERECHT, H. J.; DEELSTRA, H. A. Selenium in human urine determination, speciation and concentration levels. Talanta, v. 31, n. 7, p. 497-508, 1984. 
162. COMBS Jr, G. F. et al. Differential responses to selenomethionine supplementation by sex and genotype in healthy adults. Br J Nutr, v. 107, p. 1514-25, 2012.

163. SÁNCHEZ, C. et al. Plasma levels of copper, manganese and selenium in an adult population in southern Spain: Influence of age, obesity and lifestyle factors. Sci Total Environ, v. 408, p. 1014-20, 2010.

164. ADAME, E. M. et al. Deficient selenium status of a healthy adult Spanish population. Nutr Hosp. v. 27, n. 2, p. 524-28, 2012.

165. KAFAI, M. R.; GANJI, V. Sex, age, geographical location, smoking, and alcohol consumption influence serum selenium concentrations in the USA: third National Health and Nutrition Examination Survey, 1988-1994. J Trace Elem Med Biol, v. 17, n. 1, p. 13-8, 2003.

166. ARNAUD, J. et al. Serum selenium determinants in French adults: the SU.VI.M.AX study. Br J Nutr, v. 95, p. 313-20, 2006.

167. ROBBERECHT, H.; DEELSTRA, H. Factors influencing blood selenium concentration values: a literature review. J Trace Elem Electrolytes Health Dis, v. 8, p. 129-43, 1994.

168. ALFTHAN, G.; NÈVE, J. Reference values for serum selenium in various areas evaluated according to the TRACY protocol. J Trace Elem Med Biol, v. 10, p. 77-7, 1996.

169. ZACHWIEJA, J. et al. Decreased antioxidant activity in hypercholesterolemic children with nephrotic syndrome. Med Sci Monit, v. 9, n. 6, p. CR287-291, 2003.

170. KARUNASINGHE, N. et al. Serum selenium and single-nucleotide polymorphisms in genes for selenoproteins: relationship to markers of oxidative stress in men from Auckland, New Zealand. Genes Nutr, v. 7, p. 179-190, 2012.

171. XIONG, Y. M. et al. Association study between polymorphisms in selenoprotein genes and susceptibility to Kashin-Beck disease. Osteoarthritis Cartilage, v. 18, p. 817-24, 2010.

172. ANDERSEN, H. R.; NIELSEN, J. B.; NIELSEN, F.; GRANDJEAN, P. Antioxidative enzyme activities in human erythrocytes. Clin Chem, v. 43, n. 4, p. 562-68, 1997.

173. MENA, S.; ORTEGA, A.; ESTRELA, J. M. Oxidative stress in environmentalinduced carcinogenesis. Mutat Res, v. 674, n. 1-2, p. 36-44, 2009.

174. COMINETTI, C. et al. Brazilian nut consumption improves selenium status and glutathione peroxidase activity and reduces atherogenic risk in obese women. Nutr Res, v. 32, p. 403-7, 2012.

175. ALMONDES, K. G. S. et al. Selenium inadequacy is not associated with oxidative stress in child and adolescent acute lymphocytic leukemia survivors. Nutrition, v. 30, p. 563-68, 2014.

176. CEBALLOS-PICOT, I. et al. Age-correlated modifications of copper-zinc superoxide dismutase and glutathione-related enzyme activities in human erythrocytes. Clin Chem, v. 38, p. $66-70,1992$.

177. BOLZÁN, A. D.; BIANCHI, M. S.; BIANCHI, N. O. Superoxide Dismutase, Catalase and Glutathione Peroxidase Activities in Human Blood: Influence of Sex, Age and Cigarette Smoking. Clin Biochem, v. 30, n. 6, p. 449-54, 1997. 
178. SANTOS, R. D., et al. Sociedade Brasileira de Cardiologia. I Diretriz sobre o consumo de Gorduras e Saúde Cardiovascular. Arq Bras Cardiol, v. 100, supl. 3, p. 1-40, 2013.

179. MOLNAR, D.; DECSI, T.; KOLETZKO, B. Reduced antioxidant status in obese children with multimetabolic syndrome. Int J Obes, v. 28, p. 1197-202, 2004.

180. FERRARI, C. K. B. Capacidade antioxidante total (CAT) em estudos clínicos, experimentais e nutricionais. J Health Sci Inst, v. 28, n. 4, p. 307-10, 2010.

181. KOLOMVOTSOU, A. I. et al. Adherence to Mediterranean diet and close dietetic supervision increase total dietary antioxidant intake and plasma antioxidant capacity in subjects with abdominal obesity. Eur J Nutr, v. 52, p. 37-48, 2013.

182. ATHYROS et al. Association of drinking pattern and alcohol beverage type with the prevalence of metabolic syndrome, diabetes, coronary heart disease, stroke, and peripheral arterial disease in a Mediterranean cohort. Angiology, v. 58, n. 6, p. 689-97, 2008.

183. COSTANZO, S. et al. Wine, beer or spirit drinking in relation to fatal and non-fatal cardiovascular events: A meta-analysis. Eur J Epidemiol, v. 26, p. 833-850, 2011.

184. MARTINEZ, N. et al. Dealcoholised beers reduce atherosclerosis and expression of adhesion molecules in apoE-deficient mice. Br J Nutr, v. 105, p. 721-30, 2011.

185. ZAMORA-ROS et al. High urinary levels of resveratrol metabolites are associated with a reduction in the prevalence of cardiovascular risk factors in high-risk patients. Pharmacol Res, v. 65, n. 6, p. 615-20, 2012.

186. LEVANTESI et al. Wine consumption and risk of cardiovascular events after myocardial infarction: results from the GISSI-Prevenzione trial. Int J Cardiol, v. 163, n. 3, p. 282-7, 2013.

187. SCHOONEN, W.M. et al. Alcohol consumption and risk of prostate cancer in middle-aged men. Int J Cancer, v. 113, p. 133-40, 2005.

188. CHAO, C. Associations between beer, wine, and liquor consumption and lung cancer risk: A meta-analysis. Cancer Epidemiol Biomarkers Prev, v. 16, p. 2436-47, 2007.

189. AUSTIN et al. Moderate alcohol consumption protects against colorectal adenomas in smokers. Dig Dis Sci, v. 53, n. 1, p. 116-22, 2008.

190. HAN et al. Alcohol consumption and non-Hodgkin lymphoma survival. J Cancer Surviv, v. 4, n. 2, p. 101-9, 2010.

191. ARRANZ, S. et al. Wine, Beer, Alcohol and Polyphenols on Cardiovascular Disease and Cancer. Nutrients, v. 4, p. 759-781, 2012. 


\section{APÊNDICES}




\section{APÊNDICE I \\ TERMO DE CONSENTIMENTO LIVRE E ESCLARECIDO - TCLE}

1. Informações do Sujeito da Pesquisa

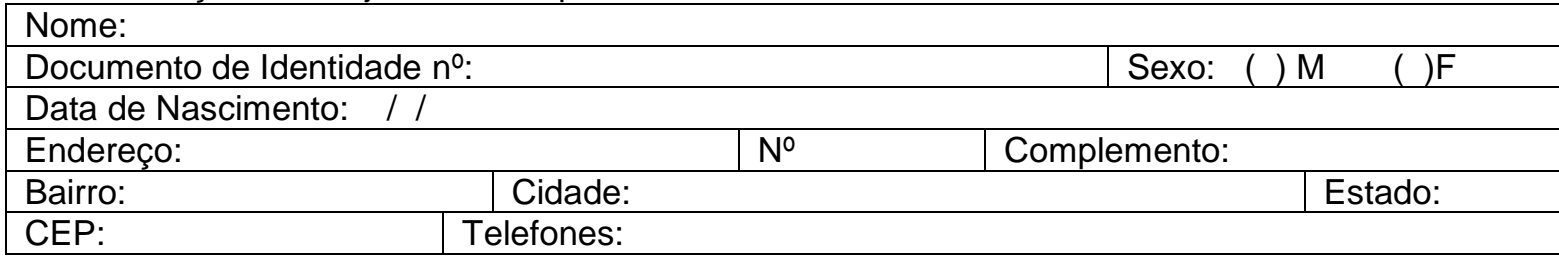

2. Informações do Responsável Legal

Nome: Silvia Maria Franciscato Cozzolino

\begin{tabular}{|l|ll}
\hline Documento de Identidade $\mathrm{n}^{0}$ : 3673981 & Sexo: $(\mathrm{)}) \mathrm{M}$ & $(\mathrm{x}) \mathrm{F}$
\end{tabular}

Data de Nascimento: $12 / 05 / 1947$

\begin{tabular}{|l|l|l} 
Endereço: Av. Prof Lineu Prestes & № 580 & Complemento: FCF-Bloco 14
\end{tabular}

\begin{tabular}{l|l|l} 
Bairro: Butantã & Cidade: São Paulo & Estado: SP
\end{tabular}

\begin{tabular}{l|l} 
CEP: 05508-900 & Telefones: (11) 3091-3509
\end{tabular}

3. Título do Projeto de Pesquisa: Estado nutricional relativo ao selênio e a influência do polimorfismo pro198leu na atividade da enzima glutationa peroxidase em uma população saudável da cidade de Teresina/PI

4. Duração da Pesquisa: 1 semana

5. Nome do pesquisador responsável: Silvia Maria Franciscato Cozzolino

Cargo/ Função: Professora Titular $\quad$ № do Registro do Conselho Regional: CRN 0621

Instituição: Universidade de São Paulo/ Faculdade de Ciências Farmacêuticas/ Departamento de

Alimentos e Nutrição Experimental

Caro Senhor(a), vimos por meio deste convidá-lo a participar como voluntário da pesquisa intitulada "Estado nutricional relativo ao selênio e a influência do polimorfismo pro198leu na atividade da enzima glutationa peroxidase em uma população saudável da cidade de Teresina/PI". Este estudo está sendo conduzido pela nutricionista e aluna de doutorado em Ciências dos Alimentos, Kaluce Gonçalves de Sousa Almondes, sob a orientação da Profa. Dra. Silvia Maria Franciscato Cozzolino (pesquisadora responsável pela pesquisa), da Faculdade de Ciências Farmacêuticas da USP, e da colaboração das Profas Dras. Nadir do Nascimento Nogueira e Dilina do Nascimento Marreiro, do Departamento de Nutrição da UFPI. Sua participação terá duração estimada de no máximo uma semana e, esta pesquisa é considerada de risco mínimo.

Uma alimentação saudável deve conter todos os nutrientes indispensáveis ao bom funcionamento do organismo. Um destes nutrientes é o selênio, um mineral que participa da estrutura de substâncias antioxidantes como a enzima glutationa peroxidase e ajuda a combater a presença de substâncias ruins ao organismo que levam ao surgimento de doenças crônicas não transmissíveis como câncer, diabetes, artrite, doenças cardiovasculares, respiratórias e mentais. $O$ selênio pode ser encontrado em alimentos como castanha-do-Brasil, nozes, peixes, carnes 
bovinas e de aves, feijão, arroz e pão. Por meio desta pesquisa será possível verificar as quantidades desse mineral no sangue e na urina dos participantes e se a alimentação está adequada. Além disso, será possível avaliar o equilíbrio entre as substâncias boas (glutationa peroxidase, superóxido dismutase, vitamina E, zinco e cobre) e ruins (malondialdeído, 8isoprostanos e 8-oxo-deoxiguanosina) ao corpo e conhecer a capacidade total do seu organismo em combater estas substâncias ruins (capacidade total antioxidante). Além disso, será possível saber se, havendo algum desequilíbrio entre estas, isso seria dependente de características individuais como, por exemplo, se o indivíduo possui algum polimorfismo, ou seja, alguma alteração genética no DNA da enzima que estamos pesquisando que é a glutationa peroxidase $1 \mathrm{e}$ também a superóxido dismutase 1 e 3 . Também será feita a avaliação dos seus níveis de colesterol. Ao final da pesquisa, os resultados serão entregues e os participantes serão orientados quanto à alimentação.

Durante a pesquisa, será realizada uma coleta de sangue $(20 \mathrm{~mL})$ com profissional habitado que utilizará material estéril. A coleta deverá ser realizada antes do café da manhã (jejum de 12 hs) no Laboratório de Nutrição Experimental do Departamento de Nutrição da UFPI. Além disso, será necessário coletar e armazenar toda a urina de um dia inteiro, em um frasco que será fornecido. Este frasco deverá ser mantido em geladeira e entregue no mesmo setor quando terminar de coletar a urina. O participante precisará, ainda, informar sobre sua alimentação anotando tudo o que comeu durante três dias aleatórios de uma semana, em um formulário que será fornecido para que o leve para sua casa. A anotação deverá ser feita durante dois dias inteiros do meio da semana e um dia do final da semana. O formulário deverá ser entregue no mesmo dia da entrega da urina. Também serão feitas medidas de peso, altura e um teste de bioimpedância elétrica, que consiste na passagem de uma corrente elétrica de baixa intensidade pelo seu corpo para avaliação da distribuição da gordura. Neste teste, o participante permanecerá deitado em uma maca e serão colocados eletrodos nas mãos e nos pés. Será uma medida rápida, não invasiva e normalmente não causa dores ou desconfortos, o que dependerá da sensibilidade do participante.

Os desconfortos e riscos da pesquisa são mínimos. O participante poderá sentir tonturas por estar em jejum para fazer o exame e leve dor devido à picada da agulha durante a coleta do sangue. Poderá também surgir uma mancha um pouco arroxeada no local da picada. Porém, o exame será feito, por uma pessoa experiente, e depois da coleta, o participante receberá um lanche, o que minimizará ainda mais estes riscos ou desconfortos.

Em qualquer etapa do estudo, o participante, seja ele aluno ou funcionário ligado ou não ao Departamento de Nutrição da UFPI, terá acesso aos profissionais responsáveis pela pesquisa para ter informações sobre a mesma, seja por telefone ou e-mail descritos no final deste termo ou mesmo pessoalmente durante o período das coletas ou ao final das coletas se dirigindo aos endereços indicados também no final deste termo. A participação no estudo não acarretará custos ao participante e não será disponível nenhuma compensação financeira adicional, porém em caso de haver gastos com transporte e/ou alimentação, e o participante não puder pagar, poderá ser oferecida a quantia referente a estes gastos, com recursos próprios do pesquisador. Os resultados 
desta pesquisa serão divulgados apenas em revistas e congressos científicos, e o nome e identidade do participante serão mantidos em segredo. O participante poderá desistir do estudo a qualquer momento, sem nenhum constrangimento, e sem nenhum prejuízo a continuidade dos seus estudos ou trabalho na universidade.

Caso você também permita, suas amostras serão armazenadas sob minha responsabilidade no Laboratório de Nutrição Minerais do Departamento de Alimentos e Nutrição Experimental da Faculdade de Ciências Farmacêuticas da USP e, possivelmente, serão utilizadas para novas pesquisas. Se isso for necessário, um novo projeto será submetido ao Comitê de Ética da Faculdade de Ciências Farmacêuticas da USP e você será consultado antes de iniciarmos qualquer novo estudo. Em qualquer momento que desejar, manifestando-se por escrito, você poderá retirar seu consentimento para que utilizemos o seu material biológico sem quaisquer gastos ou prejuízos. E, a partir do momento que finalizemos a pesquisa com suas amostras armazenadas ou que elas sejam destruídas, você será informado.

\section{AUTORIZAÇÃO PARA ARMAZENAMENTO DE MATERIAL BIOLÓGICO}

O seu material biológico poderá ser utilizado para pesquisas incluindo outros minerais, marcadores de estresse oxidativo, alterações genéticas no DNA ou expressão gênica relacionados aos minerais selênio, zinco e cobre.

Você permite que a urina, o sangue coletado e o DNA sejam armazenados sob minha responsabilidade:

( ) $\operatorname{sim}($ ) não

Escolha uma das opções abaixo:

( ) Permito a utilização do meu material biológico para novas pesquisas sem que haja necessidade de um novo TCLE

( ) Permito a utilização do meu material biológico para novas pesquisas mediante um novo TCLE.

Consentimento Pós-Esclarecido:

Declaro que, após convenientemente esclarecido pelo pesquisador e ter entendido o que me foi explicado, consinto em participar do presente Protocolo de Pesquisa.

Obs: O Termo de Consentimento Livre e Esclarecido - TCLE deve ser rubricado em todas as folhas, pelo sujeito da pesquisa ou responsável legal e pelo pesquisador responsável, constando 
as assinaturas na última página. Uma via deverá ser entregue ao sujeito da pesquisa e outra via ficará com o pesquisador responsável que guardará este termo por 5 (cinco) anos.

São Paulo de de

Assinatura do sujeito da pesquisa

Assinatura do responsável pela pesquisa

\section{Em caso de dúvidas sobre esta pesquisa ou se houver intercorrências clínicas entrar em contato com:}

Silvia Maria Franciscato Cozzolino - responsável pela pesquisa - (11) 3091-3509

Kaluce Gonçalves de Sousa Almondes - doutoranda colaboradora - (11) 6720 3261/(11) 8203 0824

Endereço: Universidade de São Paulo - Faculdade de Ciências Farmacêuticas - Bloco 14 - Av.

Prof. Lineu Prestes, 580 - CEP: 05508-900 São Paulo - SP

Nadir do Nascimento Nogueira - professora colaboradora - Departamento de Nutrição da UFPI (86) - 3215- 5863

Dilina do Nascimento Marreiro - professora colaboradora - Departamento de Nutrição da UFPI - (86) - 3215- 5863

Endereço: Campus Universitário Ministro Petrônio Portella - Departamento de Nutrição da UFPI Bairro Ininga - Teresina - PI - CEP: 64049-550

Emails: Silvia Cozzolino - smfcozzo@usp.br; Kaluce Almondes - kaluce@usp.br; Nadir Nogueira nadirn@uol.com.br; Dilina Marreiro - dilina.marreiro@gmail.com

Para qualquer questão, dúvida, esclarecimento ou reclamação sobre aspectos éticos dessa pesquisa, favor entrar em contato com o Comitê de Ética em Pesquisas da Faculdade de Ciências Farmacêuticas da Universidade de São Paulo - Av. Prof. Lineu Prestes, 580 - Bloco 13A - Butantã - São Paulo - CEP 05508-900. Fone: 3091-3622, fone-fax: 3091-3677 - e-mail: cepfcf@usp.br 


\section{APÊNDICE II}

Ficha Clínica

№:

Nome:

Endereço:

Telefone: E-mail:

Data de Nascimento: Data da Avaliação:

Idade: Sexo: ( ) F ( ) M

Naturalidade:

Qual a origem da sua família?

( ) africana

( ) européia

( ) norte - americana

( ) asiática

( ) sul - americana

\section{Renda Familiar:}

( ) $<1$ SM ( ) $1 \mid-2$ SM ( ) $2 \mid-3$ SM

( ) $3 \mid-4$ SM ( ) 4|-5 SM ( ) > 5 SM

\section{Vínculo com a UFPI:}

( ) Docente ( ) Técnico administrativo ( ) Terceirizado ( ) Discente

Obs.: Se você marcou a opção "docente", informar há quanto tempo está nesta posição:

Obs.: Se você marcou a opção "discente", informar curso, matrícula e período:

\section{Escolaridade:}

( ) Analfabeto

( ) Ensino Fundamental Incompleto ( ) Ensino Fundamental Completo

( ) Ensino Médio Incompleto

( ) Ensino Médio Completo

( ) Ensino Superior Incompleto

( ) Ensino Superior Completo

( ) Pós-graduando - Mestrado

( ) Pós-graduando - Doutorado

\section{Dados clínicos - Antecedentes familiares:}

Obesidade: Não ( ) Sim ( ) grau de parentesco:

Hipertensão arterial: Não ( ) Sim ( ) grau de parentesco:

Diabetes mellitus: Não ( ) Sim ( ) grau de parentesco:

Doença cardiovascular: Não ( ) Sim ( ) grau de parentesco:

Dislipidemia: Não ( ) Sim ( ) grau de parentesco:

Câncer: Não ( ) Sim ( ) grau de parentesco:

Se sim, qual o tipo:

Você está usando algum medicamento no momento? ( ) Sim （） Não Se sim, qual: 
Possui alergia alimentar? SIM ( ) NÃO ( )

Prática de exercício físico:

Não ( ) Sim ( ). Se sim, qual o tipo de exercício você faz:

Quantas vezes por semana:

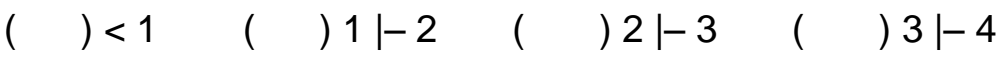

( ) $4|-5 \quad(\quad) 5|-6 \quad(\quad)$ todos os dias

Quanto tempo você costuma se exercitar:

( ) $30 \min (\quad) 45 \min (\quad) 1 \mathrm{~h} \mathrm{(} \mathrm{)} 1 \mathrm{~h} 30 \quad(\quad) 2 \mathrm{~h} \quad(\quad)>2 \mathrm{~h}$

\section{Hábito de fumar}

( ) Sim ( ) Não Se sim, quantos cigarros por dia?

Há quanto tempo você fuma?

\section{Hábito de beber}

( ) $\operatorname{Sim}($ ) Não

Se sim, o que você costuma beber?

Quantas vezes por semana:

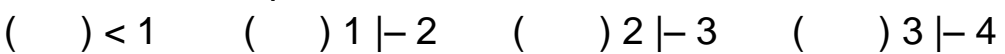

( ) $4|-5 \quad(\quad) 5|-6 \quad(\quad)$ todos os dias

Quantidade que bebe:

( ) 1 copo ( ) 2 copos ( ) 3 copos ( ) 4 copos ( ) 5 ou mais

\section{DADOS ANTROPOMÉTRICOS}

\begin{tabular}{|c|c|c|c|c|}
\hline VARIÁVEL & MEDIDA 1 & MEDIDA 2 & MEDIDA 3 & MÉDIA \\
\hline \multicolumn{5}{|l|}{ Peso (Kg) } \\
\hline \multicolumn{5}{|l|}{ Estatura (cm) } \\
\hline \multicolumn{5}{|l|}{$\operatorname{IMC}\left(\mathrm{Kg} / \mathrm{m}^{2}\right)$} \\
\hline \multicolumn{5}{|l|}{$\mathrm{CC}(\mathrm{cm})$} \\
\hline Bioimpedância & Medida & & & \\
\hline \multicolumn{5}{|l|}{ Resistência } \\
\hline \multicolumn{5}{|l|}{ Reactância } \\
\hline \multicolumn{5}{|l|}{$\%$ massa magra } \\
\hline \multicolumn{5}{|l|}{$\%$ massa gorda } \\
\hline \multicolumn{5}{|l|}{ TMB } \\
\hline \% água corporal & & & & \\
\hline
\end{tabular}




\section{APÊNDICE III \\ INSTRUÇÕES QUANTO À OBTENÇÃO DE URINA DE 24 HORAS}

A obtenção da urina será realizada em um frasco plástico com capacidade de 2 litros, sem conservantes, que deverá ser mantido SEMPRE em geladeira até a hora da entrega.

A urina deverá ser obtida da seguinte forma:

- pela manhã, ao acordar, o participante irá desprezar a primeira urina, ou seja, não deverá guardá-la na garrafa; a partir da segunda urina, todas deverão ser guardadas na garrafa até a primeira urina do dia seguinte.

DIA DA COLETA: final de semana. Sugestão: começar no sábado pegando a $2^{\circ}$ urina do dia e todas as outras até a primeira do domingo, ou, começar no domingo pegando a $2^{\circ}$ urina do dia e terminar com a $1^{\circ}$ urina da segunda. 


\section{APÊNDICE IV \\ ORIENTAÇÕES SOBRE COMO PREENCHER O REGISTRO ALIMENTAR}

Este texto irá esclarecer algumas das suas dúvidas sobre como preencher o registro alimentar de 3 dias.

1- A primeira coisa muito importante é o dia de preencher. É fundamental que você escolha dois dias da semana alternados (de segunda a sexta) que representem sua dieta habitual. Por exemplo, se você for num barzinho na quarta-feira de última hora, é melhor escolher outro dia. No final de semana sei que é mais difícil fazer sempre a mesma coisa, mas se você costuma almoçar na casa da avó aos domingos, seria interessante escolher este dia. Anote o DIA DA SEMANA na parte superior da folha;

2- Procure anotar o HORÁRIO certo em que você realiza suas refeições;

3- Anote na coluna REFEIÇÃO se é café da manhã, almoço, lanche, etc...

4- Anote a marca dos alimentos industrializados olhando a embalagem do produto;

5- Fique atento também para o tipo de preparação. Por exemplo, não anote apenas "um pedaço de bife" e sim "1/2 bife médio frito". Sei que é mais chato fazer assim, mas é importante que eu saiba o tipo de preparação porque as calorias mudam muito de uma pra outra;

6- O mais difícil é estimar o tamanho das porções para colocar na coluna de MEDIDAS CASEIRAS, mas abaixo há um quadro com as medidas caseiras para ajudar. A ideia é você anotar assim: "2 colheres de sopa rasa de farofa pronta" e não apenas "2 colheres de farofa". Eu preciso saber qual o tipo de colher porque a quantidade de alimento varia muito de uma colher de sopa para uma colher de servir. Isso serve também para os copos e xícaras. 
7- Se você tiver muita dificuldade em estimar as medidas caseiras, pode anotar o peso direto. Por exemplo, "1 caixinha de toddynho" pode virar " $200 \mathrm{ml}$ de toddynho". Sem problemas.

8- Nas saladas e verduras vai ser mais difícil anotar com exatidão as quantidades. Eu entendo perfeitamente, mesmo porque a nutrição não é uma ciência exata. Normalmente a gente mistura tudo pra ficar gostoso. Nesse caso, anote as quantidades de todos os ingredientes da salada, e também se é refogada ou crua.

9- Não se esqueça de anotar as guloseimas, como balas, chicletes, pirulitos, etc...

10- Não desista! São apenas 3 dias!

Quadro de Medidas Caseiras

\begin{tabular}{|l|l|}
\hline COLHERES & COPOS E XÍCARAS \\
\hline café rasa & americano cheio \\
\hline café cheia & americano normal \\
\hline chá rasa & requeijão cheio \\
\hline chá cheia & requeijão normal \\
\hline sobremesa rasa & café cheia \\
\hline sobremesa cheia & café normal \\
\hline sopa rasa & chá cheia \\
\hline sopa cheia & chá normal \\
\hline arroz ou servir rasa & caneca cheia \\
\hline arroz ou servir cheia & caneca normal \\
\hline ESCUMADEIRAS e CONCHAS & PRATOS \\
\hline pequena rasa & pires de café raso \\
\hline pequena cheia & pires de café cheio \\
\hline média rasa & pires de chá raso \\
\hline
\end{tabular}




\begin{tabular}{|l|l|}
\hline média cheia & pires de chá cheio \\
\hline grande rasa & sobremesa raso \\
\hline grande cheia & sobremesa cheio \\
\hline & prato raso \\
\hline & prato fundo \\
\hline & tijelinha para sobremesa \\
\hline
\end{tabular}


Medidas Caseiras
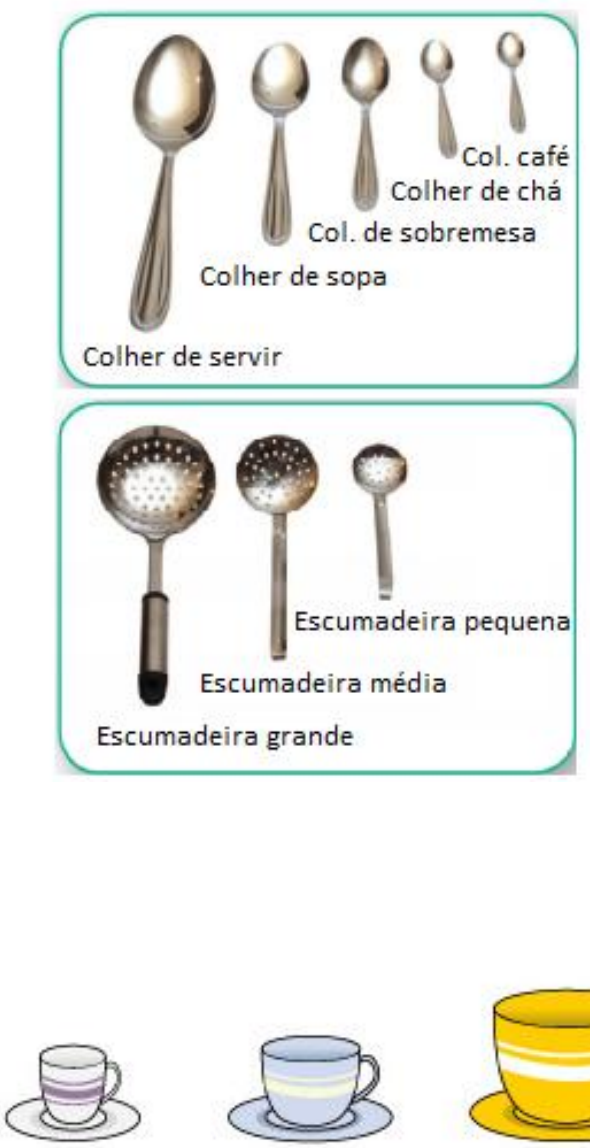

café

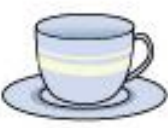

chá
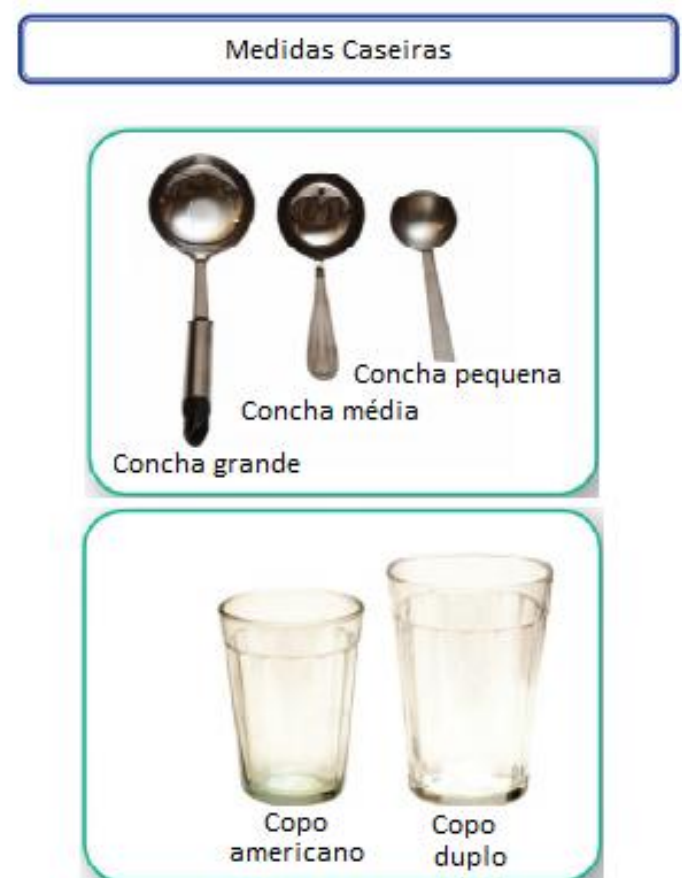


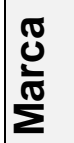

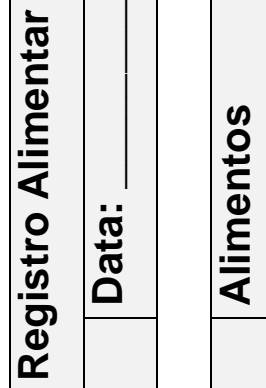

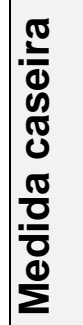

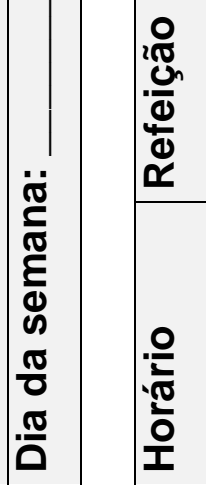


ANEXOS 


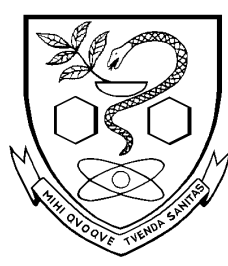

UNIVERSIDADE DE SÃO PAULO

Faculdade de Ciências Farmacêuticas

Secretaria de Pós -Graduação

\section{Informaçães para os Membros de Bancas J ulgadoras de Mestrado/ Doutorado}

1. O candidato fará uma apresentação oral do seu trabalho, com duração máxima de trinta minutos.

2. Os membros da banca farão a argüição oral. Cada examinador disporá, no máximo, detrinta minutos para argüir o candidato, exclusivamente sobre o tema do trabalho apresentado, e o candidato disporá de trinta minutos para sua resposta.

2.1 Com a devida anuência das partes (examinador e candidato), é facultada a argüição na forma de diálogo em até sessenta minutos por examinador.

3. A sessão de defesa será aberta ao público.

4. Terminada a argüição por todos os membros da banca, a mesma se reunirá reservadamente e expressará na ata (relatóio de defesa) a aprovação ou reprovação do candidato, baseando-se no trabalho escrito e na argüição.

4.1 Caso algum membro da banca reprove o candidato, a Comissão J ulgadora deverá emitir um parecer a ser escrito em campo exclusivamente indicado na ata.

4.2 Será considerado aprovado o aluno que obtiver aprovação por unanimidade ou pela maioria da banca.

5. Dúvidas poderão ser esclarecidas junto à Secretaria de PósGraduação: pgfarma@usp.br, (11) 30913621.

São Paulo, 23 de maio de 2014.

Prof. Dr. Adalberto Pessoa Junior

Presidente da CPG/FCF/USP 


\section{PROJETO DE PESQUISA}

Título: Estado nutricional relativo ao selênio e a influência do polimorfismo pro198leu na atividade da enzima glutationa peroxidase em uma população saudável da cidade de Teresina/PI.

Área Temática:

Pesquisador: Silvia Maria Franciscato Cozzolino

Versão: 2

Instituição: Faculdade de Ciências Farmacêuticas da

CAAE: 03935412.1 .0000 .0067

Universidade de São Paulo

\section{PARECER CONSUBSTANCIADO DO CEP}

Número do Parecer: 69561

Data da Relatoria: 31/07/2012

\section{Apresentação do Projeto:}

O selênio (Se), mineral traço essencial na biologia humana, tem sua essencialidade ligada principalmente a sua participação no processo de defesa antioxidante, atuando como selenoproteínas. A concentração de selênio nos alimentos depende do conteúdo do mineral no solo o que pode influenciar as concentrações sanguíneas dos indivíduos, explicando as diferenças no status do mineral em diferentes países. A glutationa peroxidase (GPx), enzima que possui selênio em sua estrutura, faz parte do sistema enzimático antioxidante e apresenta como isoforma intracelular citosólica mais abundante a GPx1. A determinação da atividade da GPx é uma forma de avaliação do status de Se, mas sua funcionalidade pode ser alterada de acordo com a concentração do mineral no organismo ou pela presença de polimorfismos genéticos que alteram sua estrutura. Em estudos de avaliação de Se é importante ainda que seja considerado o grau de estresse oxidativo que os indivíduos podem estar submetidos, visto que as propriedades antioxidantes do Se são exercidas por meio das selenoproteínas, as quais estão sujeitas a variações genéticas. Somado esses fatos a inexistência de uma faixa de referência nacional para o status de Se, que dificulta o diagnóstico de deficiência do mineral em estudos populacionais brasileiros, este estudo se propõe a avaliar o estado nutricional relativo ao Se em indivíduos saudáveis do município de Teresina/Piauí, levando em consideração fatores que possam influenciar o status do mineral como o polimorfismo genético da GPx1 e o estresse oxidativo.

\section{Objetivo da Pesquisa:}

Pretende-se avaliar o status do mineral selênio em indivíduos saudáveis do município de Teresina, estado do Piauí.

\section{Avaliação dos Riscos e Benefícios:}

Trata-se de um estudo observacional, no qual os participantes serão submetidos a uma avaliação antropométrica onde serão pesados e medidos. Também serão submetidos a uma avaliação de bioimpedância elétrica para avaliação da gordura corporal. Serão coletados $20 \mathrm{~mL}$ de sangue venoso e a urina de 24 horas. Além disso, deverão anotar em um diário tudo o que comeu durante três dias aleatórios de uma semana. A investigação apresenta risco mínimo. Os participantes conhecerão o seu estado nutricional de selênio, a possível alteração no DNA das enzimas dependentes de selênio e o seu estado de estresse oxidativo. Terão uma avaliação nutricional e orientações sobre a dieta e receberão um relatório dos resultados ao fim da pesquisa.

\section{Comentários e Considerações sobre a Pesquisa:}

Não é um estudo multicêntrico. Não haverá envio de material biológico para o exterior, nem está previsto o armazenamento das amostras de sangue coletadas visando formação de banco de material biológico. $O$ processo de recrutamento e seleção dos participantes foi descrito. 
As exigências foram atendidas.

\section{Recomendações:}

Todas as recomendações foram atendidas. O projeto encontra-se em condições de ser aprovado.

Conclusões ou Pendências e Lista de Inadequações:

O protocolo pode ser aprovado.

\section{Situação do Parecer:}

Aprovado

Necessita Apreciação da CONEP:

Não

Considerações Finais a critério do CEP:

O CEP/FCF aprovou o presente projeto em reunião de 31 de julho de 2012.

Na data de emissao desse parecer estava pendente (1) parecer de instituições coparticipantes.

SAO PAULO, 08 de Agosto de 2012

Assinado por:

Mariza Landgraf 


\section{FACULDADE DE CIÊNCIAS FARMACÊUTICAS DA UNIVERSIDADE DE SÃO}

\section{PARECER CONSUBSTANCIADO DO CEP}

\section{DADOS DO PROJETO DE PESQUISA}

Título da Pesquisa: Estado nutricional relativo ao selênio e a influência do polimorfismo pro198leu na atividade da enzima glutationa peroxidase em uma população saudável da cidade de Teresina/PI.

Pesquisador: Silvia Maria Franciscato Cozzolino

\section{Área Temática:}

Versão: 3

CAAE: 03935412.1 .0000 .0067

Instituição Proponente: Faculdade de Ciências Farmacêuticas da Universidade de São Paulo

\section{DADOS DO PARECER}

Número do Parecer: 158.233

Data da Relatoria: $26 / 11 / 2012$

\section{Apresentação do Projeto:}

O selênio ( $\mathrm{Se}$ ) é um mineral traço essencial na biologia humana. Participa no processo de defesa antioxidante atuando como selenoproteínas. A concentração de selênio nos alimentos depende do conteúdo do mineral no solo o que pode influenciar as concentrações sanguíneas dos indivíduos, explicando as diferenças no status do mineral em diferentes países. A glutationa peroxidase (GPx), enzima que possui selênio em sua estrutura, faz parte do sistema enzimático antioxidante e apresenta como isoforma intracelular citosólica mais abundante a GPx1. A determinação da atividade da GPx é uma forma de avaliação do status de Se, mas sua funcionalidade pode ser alterada de acordo com a concentração do mineral no organismo ou pela presença de polimorfismos genéticos que alteram sua estrutura. Em estudos de avaliação de Se é importante que sejam considerados o grau de estresse oxidativo que os indivíduos podem estar submetidos, visto que as propriedades antioxidantes do Se são exercidas por meio das selenoproteínas, as quais estão sujeitas a variações genéticas. A inexistência de uma faixa de referência nacional para o status de Se dificulta o diagnóstico de deficiência do mineral em estudos populacionais brasileiros.

\section{Objetivo da Pesquisa:}

Avaliar o estado nutricional relativo ao selênio e a influência do polimorfismo pro198leu na atividade da enzima glutationa peroxidase em uma população saudável da cidade de Teresina/PI.

Endereço: Av.Profo Lineu Prestes, № 580 - Bloco 17 -

Bairro: superior - Butantã

CEP: $05.508-900$

UF: SP

Município: SAO PAULO

Telefone: (11)3091-3785

Fax: (11)3091-3677

E-mail: cepfcf@usp.br 


\section{FACULDADE DE CIÊNCIAS FARMACÊUTICAS DA UNIVERSIDADE DE SÃO}

\section{Avaliação dos Riscos e Benefícios:}

Está prevista a participação de 300 indivíduos saudáveis selecionados na Universidade Federal do Piauí (UFPI), entre alunos, funcionários e visitantes. Os participantes serão submetidos a uma coleta de $20 \mathrm{~mL}$ de sangue em jejum. A urina deverá ser coletada durante 24 horas para determinação de Se, Zn, Cu nos compartimentos biológicos, marcadores de estresse oxidativo e de polimorfismos das enzimas antioxidantes. Será realizada avaliação antropométrica na qual serão pesados e medidos, e também serão submetidos a uma avaliação de bioimpedância elétrica para aferição da gordura corporal. Uma avaliação dietética (três registros alimentares) será realizada para obtenção de informações sobre o consumo alimentar de Se, Zn, Cu, ¿-tocoferol e macronutrientes. O risco é mínimo e os participantes conhecerão o seu estado nutricional de selênio, a possível alteração no DNA das enzimas dependentes de selênio e o seu estado de estresse oxidativo. Terão uma avaliação nutricional e orientações sobre a dieta e receberão um relatório dos resultados ao final da pesquisa.

\section{Comentários e Considerações sobre a Pesquisa:}

Não é um estudo multicêntrico. Não haverá envio de material biológico para o exterior. Está previsto o armazenamento das amostras visando formação de banco de material biológico.

Considerações sobre os Termos de apresentação obrigatória:

O projeto foi alterado e o TCLE foi reelaborado. As exigências éticas foram atendidas.

\section{Recomendações:}

Nenhuma recomendação se faz necessária.

Conclusões ou Pendências e Lista de Inadequações:

O projeto encontra-se em condições de ser aprovado.

Situação do Parecer:

Aprovado

\section{Necessita Apreciação da CONEP:}

Não

\section{Considerações Finais a critério do CEP:}

O CEP/FCF em reunião de 26/11/12 aprovou o adendo referente ao presente estudo.

Endereço: Av.Profo Lineu Prestes, № 580 - Bloco 17 -

$\begin{array}{ll}\text { Bairro: } & \text { superior - Butantã } \\ \text { UF: SP } & \text { Município: SAO PAULO }\end{array}$

Telefone: (11)3091-3785 Fax: (11)3091-3677_E-mail: cepfcf@usp.br 


\section{FACULDADE DE CIÊNCIAS \\ FARMACÊUTICAS DA UNIVERSIDADE DE SÃO}

SAO PAULO, 29 de Novembro de 2012

Assinador por:

Cristina Helena dos Reis Serra

(Coordenador)

Endereço: Av.Profo Lineu Prestes, 끈 580 - Bloco 17 -

Bairro: superior - Butantã

CEP: $05.508-900$

UF: SP

Município: SAO PAULO

Telefone: (11)3091-3785

Fax: (11)3091-3677

E-mail: cepfcf@usp.br 


\section{MINISTÉRIO DA EDUCAÇÃO UNIVERSIDADE FEDERAL DO PIAUÍ \\ Pró-Reitoria de Pesquisa e Pós-Graduação \\ COMITÊ DE ÉTICA EM PESQUISA- CEP}

Ofício $N^{\circ}$ 06/2012 - CEP/UFPI

Teresina, 01 de Agosto de 2012.

DO: Comitê de Ética em Pesquisa da UFPI

AO: Comitê de Ética em Pesquisa da USP

Senhor Coordenador,

Tendo em vista que o estudo intitulado: " Estado nutricional relativo ao selênio e a influência do polimorfismo pro198leu na atividade da enzima glutationa peroxidase em uma população saudável da cidade de Teresina/PI.", foi analisado e aprovado pelo Comitê de Ética em Pesquisa da USP, e a aluna, assim como a pesquisadora responsável, não possuem vinculo com a Universidade Federal do Piauí, informo que não há necessidade de apreciação do referido projeto por este Comitê.

Atenciosamente,

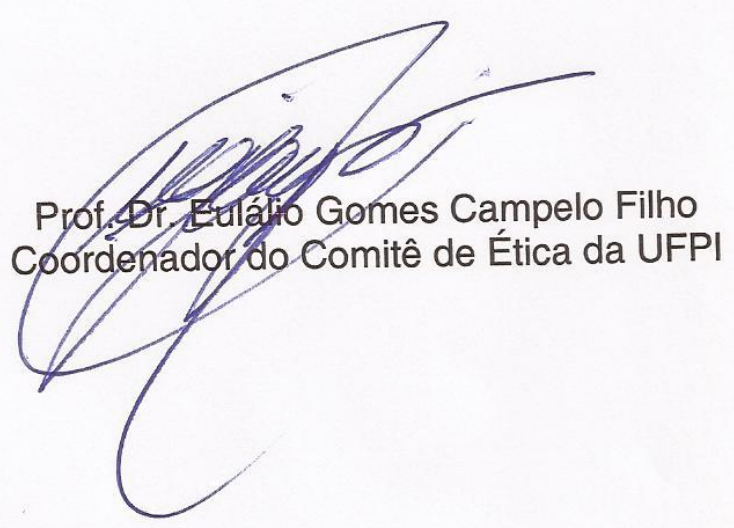




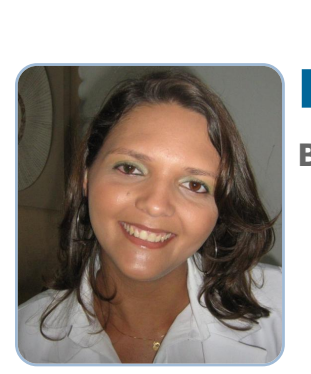

\section{ANEXO V Kaluce Gonçalves de Sousa Almondes}

Bolsista de Doutorado do CNPq

Endereço para acessar este CV: http://lattes.cnpq.br/6889770722928265

Última atualização do currículo em 05/05/2014

Doutoranda em Ciências dos Alimentos pela Faculdade de Ciências Farmacêuticas da USP. Mestre em Ciências dos Alimentos pela mesma Faculdade. Atua principalmente nos seguintes temas: estado nutricional relativo ao selênio, estresse oxidativo e polimorfismo da enzima glutationa peroxidase I. Possui experiência na avaliação do estado nutricional relativo ao zinco e cobre em populações. (Texto informado pelo autor)

\section{Identificação}

\begin{tabular}{ll}
\hline Nome & Kaluce Gonçalves de Sousa Almondes \\
Nome em citações bibliográficas & ALMONDES, K. G. S. ;ALMONDES, KALUCE GONÇALVES DE SOUSA;DE SOUSA \\
& ALMONDES, KALUCE GONÇALVES
\end{tabular}

\section{Endereço}

\section{Formação acadêmica/titulação}

2012 Doutorado em andamento em Ciências dos Alimentos (Conceito CAPES 7).
Universidade de São Paulo, USP, Brasil.
Título: Estado nutricional relativo ao selênio e sua relação com o polimorfismo
pro198leu da enzima GPx1 em uma população saudável da cidade de
Teresina/PI,
Orientador: (9) Silvia Maria Franciscato Cozzolino.
Bolsista do(a): Conselho Nacional de Desenvolvimento Científico e Tecnológico,
CNPq, Brasil.
Mestrado em Ciências dos Alimentos (Conceito CAPES 7).
Universidade de São Paulo, USP, Brasil.
Título: ESTADO NUTRICIONAL RELATIVO AO SELÊNIO EM PACIENTES NA FASE
DE PÓS-TRATAMENTO DA LEUCEMIA LINFÓIDE AGUDA E SUA RELAÇÃO COM
O ESTRESSE OXIDATIVO,Ano de Obtenção: 2011.
Orientador: (9) Profa. Dra. Silvia Maria Franciscato Cozzolino.
Bolsista do(a): Fundação de Amparo à Pesquisa do Estado de São Paulo,
FAPESP, Brasil.
Graduação em Nutrição.
Universidade Federal do Piauí, UFPI, Brasil.

\section{Formação Complementar}

$2013-2013$

$2013-2013$

$2013-2013$
Princípios de Biologia Molecular. (Carga horária: 16h).

Life Tecnologies.

A importância de primers bem desenhados para a PCR. (Carga horária: 8h). Life Tecnologies.

Fundamentos da PCR Quantitativa em tempo real. (Carga horária: 20h). Life Tecnologies. 
$2013-2013$

$2013-2013$

$2013-2013$

$2012-2012$

2011 - 2011

$2008-2008$

$2008-2008$

$2005-2008$

$2006-2006$

2006 - 2006

$2006-2006$

$2005-2005$

$2005-2005$

$1999-2001$
Life Tecnologies.

Quantificação da Expressão Gênica. (Carga horária: 16h).

Life Tecnologies.

Curso de bioestatística. (Carga horária: 7h).

Faculdade de Ciências Farmacêuticas-USP.

Métodos Estatísticos Multivariados. (Carga horária: 16h).

Universidade de São Paulo, USP, Brasil.

MINI-CURSO ESTATÍSTICA APLICADA A NUTRIÇÃO. (Carga horária: 27h).

Sociedade Brasileira de Alimentação e Nutrição.

Bioestatística. (Carga horária: 12h).

Universidade de São Paulo, USP, Brasil.

Extensão universitária em Monitoria da Disciplina Nutrição Experimental. (Carga horária: 192h).

Universidade Federal do Piauí, UFPI, Brasil.

Pacote Estatístico STATA. (Carga horária: 20h).

Universidade de São Paulo, USP, Brasil.

Extensão Continuada em Língua Inglesa. (Carga horária: 270h).

Universidade Federal do Piauí, UFPI, Brasil.

Extensão universitária em Monitoria da Disciplina Nutrição Experimental. (Carga horária: 192h).

Universidade Federal do Piauí, UFPI, Brasil.

Sustentabilidade dos Projetos de Cooperação. (Carga horária: 56h).

Università degli Studi di Padova.

Estágio Extracurricular no Lar da Criança. (Carga horária: 320h).

Secretaria de Ação Social e Cidadania.

Extensão universitária em Monitoria da Disciplina Fisiologia Para Nutrição.

(Carga horária: 192h).

Universidade Federal do Piauí, UFPI, Brasil.

Curso Sobre Pesquisa Científica. (Carga horária: 12h).

Associação Brasileira de Enfermagem.

Curso de Habilitação Profissional para Magistério. (Carga horária: 3330h).

Colegio Eden.

\section{Atuação Profissional}

Universidade de São Paulo, USP, Brasil.

Vínculo institucional

2012 - Atual

Vínculo institucional

2009 - 2011
Vínculo: Bolsista - doutorado, Enquadramento Funcional: aluno, Regime: Dedicação exclusiva.

Vínculo: Boslsista mestrado, Enquadramento Funcional: aluno, Regime: Dedicação exclusiva.

Universidade Federal do Piauí, UFPI, Brasil.

Vínculo institucional

$2003-2008$

Vínculo: aluno, Enquadramento Funcional: aluno, Regime: Dedicação exclusiva.

\section{Projetos de pesquisa}


$2009-2011$

$2008-2008$

$2007-2008$

$2007-2008$
Integrantes: Kaluce Gonçalves de Sousa Almondes - Coordenador.

Estado Nutricional relativo ao selênio e sua relação com estresse oxidativo de pacientes no pós-tratamento da leucemia linfóide aguda

Situação: Concluído; Natureza: Pesquisa.

Alunos envolvidos: Mestrado acadêmico: (1) .

Integrantes: Kaluce Gonçalves de Sousa Almondes - Integrante / Silvia Maria Franciscato Cozzolino - Coordenador.

Financiador(es): Fundação de Amparo à Pesquisa do Estado de São Paulo Bolsa / Fundação de Amparo à Pesquisa do Estado de São Paulo - Auxílio financeiro.

Monitoração de Propaganda e Publiciade de Produtos Sujeitos à Vigilância Sanitária Fase III

Descrição: Este projeto visava a monitoração de propaganda de alimentos, medicamentos e produtos para a saúde, no intuito de verificar se a mesma está de acordo com as legislações vigentes. .

Situação: Concluído; Natureza: Pesquisa.

Alunos envolvidos: Graduação: (5) / Mestrado acadêmico: (0) / Mestrado profissional: (1) .

Integrantes: Kaluce Gonçalves de Sousa Almondes - Coordenador / Heila D. S. P. Aguiar - Integrante / Maria S. C. Ferreira - Integrante / Tatiane Leocádio Temóteo - Integrante / Camila Calado Lima - Integrante / Júlio César Dias Castro - Integrante.

Financiador(es): Agência Nacional de Vigilância Sanitária - Cooperação / Organização das Nações Unidas para a Educação, Ciência e Cultura - Auxílio financeiro.

Diagnóstico de Desnutrição Energético Protéica e da Deficiência de Micronutrientes em Escolares da Rede Pública de Ensino do Município de Teresina-PI

Descrição: Neste projeto realizou-se um questionário de freqüência de consumo alimentar, teste para diagnóstico de anemia (método da cianometahemoglobina) e avaliação antropométrica, maturação sexual e hábitos saudáveis. .

Situação: Concluído; Natureza: Pesquisa.

Alunos envolvidos: Graduação: (1) / Mestrado profissional: (4) / Doutorado: (3)

Integrantes: Kaluce Gonçalves de Sousa Almondes - Integrante / Apolônia Maria Tavares Nogueira - Integrante / Geânia de Sousa Paes Lima - Integrante / Clélia de Moura Fé Campos - Integrante / Maria Rosália Ribeiro Brandim Integrante / Regilda Saraiva dos Reis Moreira Araújo - Integrante / Alexsandra Hermelina Carvalho - Integrante / Cecília M. R. G. Carvalho - Integrante / Nadir N. Nogueira - Coordenador / Dilina N. Marreiro - Integrante.

Financiador(es): Conselho Nacional de Desenvolvimento Científico e Tecnológico - Auxílio financeiro.

Número de produções $C, T \& A: 1$

Determinação do estado nutricional relativo ao zinco e da atividade da enzima superóxido dismutase em pacientes portadores de doença inflamatória intestinal

Descrição: Este projeto visava avaliar o estado nutricional relativo ao zinco de pacientes com doença inflamatória intestinal, bem como a atividade da enzima superóxido dismutase. Além disso, ainda foi avaliado o consumo alimentar e adequação de energia, macronutrientes e zinco, segundo as DRI's (2001), e os índices antropométricos como IMC, PCT, CB e CMB..

Situação: Concluído; Natureza: Pesquisa.

Alunos envolvidos: Graduação: (1) / Doutorado: (4) .

Integrantes: Kaluce Gonçalves de Sousa Almondes - Integrante / Semiramis Jamil Hadad do Monte - Integrante / José Miguel Luz Parente - Integrante / Nadir N. Nogueira - Coordenador / Dilina N. Marreiro - Integrante. 

Tecnológico - Bolsa.

Tecnologia de hortas para a melhoria da segurança alimentar em distritos selecionados de Teresina no Estado do Piauí (Brasil)

Descrição: Neste projeto foram desenvolvidas atividades na áres de alimentação e nutrição para as famílias da comunidade Socopo, Teresina-PI. Situação: Em andamento; Natureza: Pesquisa.

Alunos envolvidos: Graduação: (5) / Especialização: (0) / Mestrado acadêmico: (0) / Mestrado profissional: (2) / Doutorado: (2).

Integrantes: Kaluce Gonçalves de Sousa Almondes - Integrante / Marize Melo dos Santos - Coordenador / Isabel Caroline S de Sousa - Integrante / Ivonete Moura Campelo - Integrante / Nayana Valéria Veras - Integrante / Clélia de Moura Fé Campos - Integrante / Maria Alice Paulino Mota de Alencar Integrante / Lívia Oliveira da Silva - Integrante / Rayssa Oliveira Amorim de Sá - Integrante.

Financiador(es): Universidade Federal do Piauí - Cooperação / Fundação Cultural e de Fomento a Pesquisa, Ensino e Extensão - Cooperação / Fundação Padre Antônio Dante Civiero - Cooperação / Prefeitura Municipal de Teresina Cooperação / Universidade de Padova - Auxílio financeiro.

Primeiro Monitoramento Oficial da Norma Brasileira de Comercialização de Alimentos para Lactentes e Crianças de Primeira Infância, Mamadeira, Bico e Chupeta - NBCAL

Descrição: O objetivo geral do projeto foi avaliar a adequação da promoção comercial dos alimentos para lactentes e crianças na primeira infância, bicos, mamadeiras e chupetas, realizadas nas mais diversas mídias e expostas em diversos locais. .

Situação: Concluído; Natureza: Pesquisa.

Alunos envolvidos: Graduação: (3) / Especialização: (0) / Mestrado acadêmico: (1) / Mestrado profissional: (1) / Doutorado: (0).

Integrantes: Kaluce Gonçalves de Sousa Almondes - Integrante / Maria do Socorro Cordeiro Ferreira - Coordenador / Heila Dias de Sousa Pinho Aguiar Integrante / José de Sousa Lima Neto - Integrante / Thissiane Marla Alves Cavalcante - Integrante.

Financiador(es): Agência Nacional de Vigilância Sanitária - Auxílio financeiro / Ministério da Saúde - Auxílio financeiro.

Número de produções $C, T \& A: 1$

Monitoramento de Propaganda de Produtos Sujeitos à Vigilência Sanitária Fase II

Descrição: Este projeto visava a monitoração de propaganda de alimentos, medicamentos e produtos para a saúde, no intuito de verificar se a mesma está de acordo com as legislações vigentes. .

Situação: Concluído; Natureza: Pesquisa.

Alunos envolvidos: Graduação: (1) / Especialização: (4) / Mestrado acadêmico: (1) / Mestrado profissional: (1) / Doutorado: (1).

Integrantes: Kaluce Gonçalves de Sousa Almondes - Integrante / Maria do Socorro Cordeiro Ferreira - Coordenador / Heila Dias de Sousa Pinho Aguiar Integrante / José de Sousa Lima Neto - Integrante / Thissiane Marla Alves Cavalcante - Integrante / Marcela Rosado Drumond - Integrante / Naiguel Castelo Branco Silva - Integrante / Alline Vieira dos Santos Costa - Integrante / Lidianne Mayra Lopes Campêlo - Integrante / Nadir N. Nogueira - Integrante. Financiador(es): Agência Nacional de Vigilância Sanitária - Auxílio financeiro / Ministério da Saúde - Auxílio financeiro.

Assistência Domiciliar na Perspectiva da Qualidade da Saúde e Nutrição das Famílias da Vila do Avião do Programa de Saúde da Família do Município de Teresina-PI

Descrição: O objetivo geral deste projeto foi desenvolver um Programa de Educação Nutricional para as Famílias atendidas pelo Programa Saúde da Família da Vila do Avião de Teresina, com base na situação de saúde e nutrição identificadas. .

Situação: Concluído; Natureza: Pesquisa. 
(0) / Mestrado profissional: (2) / Doutorado: (2) .

Integrantes: Kaluce Gonçalves de Sousa Almondes - Integrante / Shirlane de Sousa Rodrigues - Integrante / Marize Melo dos Santos - Coordenador / Cecília Maria Conçalves Resende - Integrante / Apolônia Maria Tavares Nogueira Integrante / Geânia de Sousa Paes Lima - Integrante / Nayara Batista de Araújo - Integrante / Heila Dias de Sousa Pinho Aguiar - Integrante / Patrícia Leão - Integrante / Linard e Silva Martins - Integrante / Isabel Caroline S de Sousa - Integrante / Nayara Valéria Veras - Integrante.

Financiador(es): Conselho Nacional de Desenvolvimento Científico e

Tecnológico - Cooperação / Fundação de Amparo à Pesquisa do Estado do Piauí - Auxílio financeiro / Ministério da Saúde - Cooperação / Universidade Federal do Piauí - Cooperação.

\title{
Revisor de periódico
}

\section{Áreas de atuação}

\section{Produções}

\author{
Produção bibliográfica
}

\section{Artigos completos publicados em periódicos}

Ordenar por

Ordem Cronológica

1. ALMONDES, KALUCE GONÇALVES DE SOUSA ; OLIVEIRA, TIAGO FRANCO DE ; SIVIERO-MIACHON, ADRIANA APARECIDA ; LEE, MARIA LÚCIA DE MARTINO ; Rondó, Patrícia Helen de Carvalho ; LOUREIRO, ANA PAULA DE MELO ; SPINOLA-CASTRO, ÂNGELA MARIA ; Cozzolino, Silvia Maria Franciscato. Selenium inadequacy is not associated with oxidative stress in child and adolescent acute lymphocytic leukemia survivors. Nutrition (Burbank, Los Angeles County, Calif.) JCR, v. 30, p. 563-568, 2014.

\section{Citações: scopus 2}

2. BRITO, J. A. ; MARREIRO, Dilina Do Nascimento ; MOITA NETO, J. M. ; SILVA, D. M. C. E. ; ALMONDES, K. G. S. ; VALADARES NETO, J. D. ; NOGUEIRA, Nadir Do Nascimento. Enzyme activity of superoxide dismutase and zincemia in women with preeclampsia. Nutrición Hospitalaria JCR, v. 28, p. 486-490, 2013.

3. $\quad$ Ferro, FIÃ via Ennes Dourado ; Sousa Lima, Vanessa Batista ; Soares, Nina Rosa Mello ; ALMONDES, K. G. S. ; Pires, Liliane Viana ; Cozzolino, Silvia Maria Franciscato ; Nascimento Marreiro, Dilina . Parameters of Metabolic Syndrome and Its Relationship with Zincemia and Activities of Superoxide Dismutase and Glutathione Peroxidase in Obese Women. Biological Trace Element Research JCR, v. 143, p. 787-793, 2011.

Citações: WEB OF SCIENCE $* 4$ | SCOPUS 4

4. $\hat{\text { Al }}$ ALMONDES, K. G. S. ; Leal, Greisse Viero da Silva ; Cozzolino, Silvia Maria Franciscato ; Philippi, Sonia Tucunduva ; Rondó, Patrícia Helen de Carvalho . O papel das selenoproteínas no câncer. Revista da Associação Médica Brasileira (1992. Impresso) JCR, v. 56, p. 484-488, 2010.

Citações: WEB OF SCIENCE $=7$ | ScLLL 1 | SCOPUS 10

5. ALMONDES, KALUCE GONÇALVES DE SOUSA ; SIVIERO-MIACHON, ADRIANA APARECIDA ; SPINOLA- 
CASTRO, ÂNGELA MARIA ; PIMENTEL, JOSÉ ALEXANDRE COELHO ; BAROFALDI, RAFAEL BUENO ; Pires, Liliane Viana ; Cozzolino, Silvia Maria Franciscato. Selenium Nutritional Status and GPx Activity ofAcute Limphoblastic Leukemia PostTreatedPatients. Free Radical Biology \& Medicine JCR, v. 49, p. S219, 2010.

\section{Capítulos de livros publicados}

1. Almondes, K. G. S. ; ROCHA, A. V. ; COZZOLinO, S. M. F. . Vitamina E. In: Silvia Maria Franciscato Cozzolino; Cristiane Cominetti. (Org.). Bases bioquímicas e fisiológicas da nutrição - nas diferentes fases da vida, na saúde e na doença. 1ed.São Paulo: Manole, 2013, v. 1, p. 440-448.

2. ALMONDES, K. G. S. ; COZzolino, S. M. F. . Ácido Pantotênico. In: Silvia Maria Franciscato Cozzolino; Cristiane Cominetti. (Org. ). Bases bioquímicas e fisiológicas da nutrição - nas diferentes fases da vida, na saúde e na doença. 1ed.São Paulo: Manole, 2013, v. 1, p. 546-557.

3. CARDOSO, B. R. ; ALMONDES, K. G. S. ; COZZOLINO, S. M. F. . Alimentação do idoso. In: Silvia Maria Franciscato Cozzolino; Cristiane Cominetti. (Org.). Bases bioquímicas e fisiológicas da nutrição - nas diferentes fases da vida, na saúde e na doença. 1ed.São Paulo: Manole, 2013, v. 1, p. 779-808.

4. ALMONDES, K. G. S. ; COZZOLINO, S. M. F. . Micronutrientes e leucemia linfóide aguda. In: Silvia Maria Franciscato Cozzolino. (Org.). Biodisponibilidade de Nutrientes. 4ed.São Paulo: Manole, 2011, v. 1, p. 1159-1172.

\section{Resumos expandidos publicados em anais de congressos}

1. ALMONDES, K. G. S. ; SILVA, D. M. C. E. ; CARDOSO, D. E. L. ; MARREIRO, D. N. ; NOGUEIRA, N. N. . DETERMINAÇÃO DO ESTADO NUTRICIONAL RELATIVO AO ZINCO E DA ATIVIDADE DA ENZIMA SUPERÓXIDO DISMUTASE EM PACIENTES PORTADORES DE DOENÇA INFLAMATÓRIA INTESTINAL. In: XVII Seminário de Iniciação Científica da UFPI, 2008, Teresina. XVII Seminário de Iniciação Científica da UFPI. Teresina: UFPI, 2008.

2. ALMONDES, K. G. S. ; AGUIAR, H. D. S. P. ; OLIVEIRA, L. S. ; FERREIRA, C. O. ; NOGUEIRA, N. N. ; MARREIRO, D N . Consumo de Alimentos Fonte e Fortificados com Ácido Fólico por Gestantes Atendidas em Maternidade Pública. In: XV SEMINÁRIO DE INICIAÇÃO CIENTÍFICA DA UFPI, 2006, Teresina. XVI Seminário de Iniciação Científica da Ufpi, 2006.

3. ALMONDES, K. G. S. ; LIMA NETO, J. S. ; AGUiAR, H. D. S. P. ; CAVAlCANTE, T. M. A. ; FERREIRA, M. S. C. . Monitoramento da Norma Brasileira de Comercialização de Alimentos para Lactentes e Crianças de Primeira Infância, Bicos , Chupetas e Mamdeiras em Diversos Estabelecimentos de Teresina-PI.. In: I JORNADA DE INICIAÇÃO CIENTÍFICA e I AMOSTRA DE PESQUISA DA PÓS-GRADUAÇÃO DA NOVAFAPI, 2006, Teresina/PI. I JORNADA DE INICIAÇÃO CIENTÍFICA E I AMOSTRA DE PESQUISA DA PÓS-GRADUAÇÃO DA NOVAFAPI, 2006.

\section{Resumos publicados em anais de congressos}

1. ALMONDES, KALUCE GONÇALVES DE SOUSA ; Cozzolino, Silvia Maria Franciscato ; NOGUEIRA, Nadir Do Nascimento ; MARREIRO, Dilina Do Nascimento . Perfil Nutricional, socioeconômico e estilo de vida de estudantes universitários. In: Congresso Nacional da Sociedade Brasileira de Alimentação e Nutrição, 2013, Foz do Iguaçu. Nutrire $12^{\circ}$ Congresso Nacional da SBAN. São Paulo: Nutrire, 2013. v. 38. p. 1-475.

2. ALMONDES, K. G. S. ; NOGUEIRA, Nadir Do Nascimento ; MARREIRO, D. N. ; COZZOLINO, S. M. F. . Índice de massa corpórea e sua relação com perfil lipídico em adultos jovens. In: Congresso Nacional da Sociedade Brasileira de Alimentação e Nutrição, 2013, Foz do Iguaçu. Nutrire $12^{\circ}$ Congresso Nacional da SBAN. São Paulo: Nutrire, 2013. v. 38. p. $1-475$.

3. ALMONDES, K. G. S. ; PIRES, L. V. ; BANDEIRA, V. S. ; HASHIMOTO, L. ; ALENCAR, L. L. ; BIUDE, G. ; CALLOU, K. R. A. ; PIMENTEL, J. A. C. ; BUENO, R. B. ; COZZOLINO, S. M. F. . AVALIAÇÃO DO ESTADO NUTRICIONAL RELATIVO AO SELÊNIO, DE ENZIMAS ANTIOXIDANTES E DO DANO AO DNA EM PACIENTES NO PÓS-TRATAMENTO DA LEUCEMIA LINFÓIDE AGUDA. In: ENCONTRO SBAN: NUTRIÇÃO CLÍNICA, 2012, NATAL. ENCONTRO SBAN: NUTRIÇÃO CLÍNICA - NUTRIRE - SUPLEMENTO 37. SÃO PAULO: Nutrire: revista da Sociedade Brasileira de Alimentação e Nutrição, 2012. p. $1-80$.

4. AlMONDES, K. G. S. ; MiACHON, A. A. S. ; CASTRO, A. M. S. ; LEE, M. L. M. ; PIMENTEL, J. A. C. ; COZZOLINO, 
S. M. F. . Avaliação do estado nutricional relativo ao selênio e sua relação com o estresse oxidativo em pacientes no pós-tratamento da leucemia linfóide aguda. In: XIV Congresso Brasileiro de Nutrologia, 2010, São Paulo. XIV Congresso Brasileiro de Nutrologia, 2010.

5. NOGUEIRA, N. N. ; MATIAS, J P ; BRANDIM, M. R. R. ; MELO, M. T. ; MARREIRO, D. N. ; ALMONDES, K. G. S. ; NOGUEIRA, A. M. T. . PERFIL DE CRESCIMENTO E COMPOSIÇÃO CORPORAL DE ESCOLARES DA REDE PÚBLICA MUNICIPAL DE ENSINO. TERESINA-PI. In: Congresso Nacional da Sociedade Brasileira de Alimentação e Nutrição, 2009, São Paulo. Nutrire (São Paulo). São Paulo: Nutrire, 2009. v. 34. p. 1-508.

6. NOGUEIRA, N. N. ; ALMONDES, K. G. S. ; MARREIRO, D. N. ; FONTES, A. L. ; CARDOSO, B V S ; RODRIGUES, G P ; SOUSA, A F ; MAIA, C. S. C. ; PARENTE, J. M. L. ; COZZOLINO, S. M. F. . ESTADO NUTRICIONAL RELATIVO AO ZINCO E DA ATIVIDADE DA ENZIMA SUPERÓXIDO DISMUTASE EM PACIENTES COM DOENÇA INFLAMATÓRIA INTESTINAL. In: $10^{\circ}$ Congresso Nacional da Sociedade Brasileira de Alimentação e Nutrição, 2009, São Paulo. Nutrire (São Paulo). São Paulo: Nutrire, 2009. v. 34. p. 1-508.

7. MARREIRO, D. N. ; VERAS, C. M. T. ; PIRES, L. V. ; SOUSA, M. S. B. ; NOGUEIRA, N. N. ; PIMENTEL, J. A. C. ; BUENO, R. B. ; ALMONDES, K. G. S. ; COZZOLINO, S. M. F. . CONCENTRAÇÕES PLASMÁTICAS E ERITROCITÁRIAS DE ZINCO EM MULHERES COM CÂNCER DE MAMA. In: $10^{\circ}$ Congresso Nacional da Sociedade Brasileira de Alimentação e Nutrição, 2009, São Paulo. Nutrire (São Paulo). São Paulo: Nutrire, 2009. v. 34. p. 1-508.

8. 1 BRANDIM, M. R. R. ; NOGUEIRA, N. N. ; ALMONDES, K. G. S. ; NOGUEIRA, A. M. T. ; MARREIRO, D N ; LIMA, G. S. P. ; CARVALHO, A. H. ; CAMPOS, C. M. F. ; REIS, N. S. ; CAVALCANTE, C. A. S. C. ; ABREU, C. R. ; FERNANDES, S. H. G. ; REIS, E. N. ; MACHADO, L. M. B. . Avaliação Antropométrica de Adolescentes Matriculados em Escolas Públicas de Teresina-Pi. In: III Congresso Internacional de Alimentação do Escolar para América Latina, 2007, Recife. III Congresso Internacional de Alimentação do Escolar para América Latina. Recife, 2007.

9. NOGUEIRA, N. N. ; ALMONDES, K. G. S. ; MOREIRA-ARAÚJO, R. S. R. ; NOGUEIRA, A. M. T. ; CARVALHO, C M R G ; MARREIRO, D N ; BRANDIM, M. R. R. ; LIMA, G. S. P. ; CARVALHO, A. H. ; CAMPOS, C. M. F. ; OLIVEIRA, M. C. G. ; BESERRA, M. L. S. ; REIS, E. N. ; MACHADO, L. M. B. . Prevalência de anemia em escolares da rede pública estadual e municipal de Teresina-Piauí. In: $9^{\circ}$ Congresso Nacional da Sociedade Brasileira de Alimentação e Nutrição - SBAN, 2007, São Paulo. $9^{\circ}$ Congresso Nacional da Sociedade Brasileira de Alimentação e Nutrição - SBAN. São Paulo, 2007.

10. ALMONDES, K. G. S. ; REIS, E. N. ; VIANA, C. S. ; SILVA, C. P. ; ARAUJO, M. A. M. ; MOREIRA-ARAÚJO, R. S. R. . Formulação de torta doce a base de arroz, soja e goiaba para portadores de doença celíaca. In: 70 Simpósio Latino Americano de Ciências de Alimentos - Ciência e Tecnologia de Alimentos em Benefício a Sociedade: Ligando a Agricultura à Saúde, 2007, Campinas - SP. 70 Simpósio Latino Americano de Ciências de Alimentos - Ciência e Tecnologia de Alimentos em Benefício a Sociedade: Ligando a Agricultura à Saúde, 2007.

11. ALMONDES, K. G. S. ; CARDOSO, B V S ; AGUIAR, H. D. S. P. ; OLIVEIRA, L. S. ; FERREIRA, C. O. ; NOGUEIRA, N. N. . CONSUMO DE ALIMENTOS FORTIFICADOS COM ÁCIDO FÓLICO POR GESTANTES ATENDIDAS EM MATERNIDADE PÚBLICA. In: VII CONGRESSO NORTE-NORDESTE DE NUTRIÇÃO PARENTERAL E ENTERAL, VII CONGRESSO NORTE NORDESTE DE NUTRIÇÃO CLÍNICA, I SIMPÓSIO DE NUTRIÇÃO EM PEDIATRIA, I SIMPÓSIO DE NUTRIÇÃO ESPORTIVA, 2006, NATAL/RN. PROGRAMAÇÃO OFICIAL: VII CONGRESSO NORTE-NORDESTE DE NUTRIÇÃO PARENTERAL E ENTERAL, VII CONGRESSO NORTE NORDESTE DE NUTRIÇÃO CLÍNICA, I SIMPÓSIO DE NUTRIÇÃO EM PEDIATRIA, I SIMPÓSIO DE NUTRIÇÃO ESPORTIVA. 12 a 14 DE OUTUBRO DE 2006., 2006. p. 01-60.

\section{Apresentações de Trabalho}

1. AlMONDES, K. G. S. ; PIRES, L. V. ; CALlOU, K. R. A. ; PIMENTEL, J. A. C. ; BUENO, R. B. ; BANDEIRA, V. S. ; BIUDE, G. ; COZZOLINO, S. M. F. . AVALAÇÃO DO ESTADO NUTRICIONAL RELATIVO AO SELÊNIO, DE ENZIMAS ANTIOXIDANTES E DO DANO AO DNA EM PACIENTES NO PÓS-TRATAMENTO DA LEUCEMIA LINFÓIDE AGUDA. 2012. (Apresentação de Trabalho/Conferência ou palestra).

2. Vanessa Batista de Sousa Lima ; FERRO, F. E. D. ; SOARES, N. R. M. ; ALMONDES, K. G. S. ; COZZOLINO, S. M. F. ; NOGUEIRA, N. N. ; MARREIRO, D. N. . COMPONENTES DA SÍNDROME METABÓLICA E SUA RELAÇÃO COM A ZINCEMIA E A ATIVIDADE DAS ENZIMAS SUPERÓXIDO DISMUTASE E GLUTATIONA PEROXIDASE EM MULHERES OBESAS. 2011. (Apresentação de Trabalho/Congresso).

3. SILVA, D. M. C. E. ; BRITO, J. A. ; Neta, E. A. S. ; ALMONDES, K. G. S. ; OLIVEIRA, F. E ; MATIAS, J. P. ; MARREIRO, D. N. ; NOGUEIRA, N. N. . INFLAMAÇÃO E ZINCO PLASMÁTICO EM GESTANTES COM PRÉ-ECLÂMPSIA. 2011. (Apresentação de Trabalho/Congresso). 
4. RODRIGUES, Gilmara Pereira ; CALDAS, D. R. C. ; SILVA, K. G. ; ALMONDES, K. G. S. ; PIMENTEL, J. A. C. ; MOITA NETO, J. M. ; CARVALHO, C. M. R. G. ; MARREIRO, D. N. ; NOGUEIRA, N. N. . ZINCO E COBRE PLASMÁTICO E SUA RELAÇÃO COM A FUNÇÃO COGNITIVA NA DOENÇA DE ALZHEIMER. 2011. (Apresentação de Trabalho/Congresso).

5. ALMONDES, K. G. S. ; CASTRO, A. M. S. ; MIACHON, A. A. S. ; LEE, M. L. M. ; PIMENTEL, J. A. C. ; PIRES, L. V. ; BUENO, R. B. ; CALLOU, K. R. A. ; COZZOLINO, S. M. F. . TEOR DE SELÊNIO PLASMÁTICO E ERITROCITÁRIO E SUA CORRELAÇÃO COM A ENZIMA GPX EM PACIENTES NO PÓS-TRATAMENTO DA LEUCEMIA LINFÓIDE AGUDA. 2011. (Apresentação de Trabalho/Congresso).

6. Vanessa Batista de Sousa Lima ; SILVA, M. M. ; CAVALCANTE, N. A. A. ; SILVA, D. M. C. E. ; ALMONDES, K. G. S. ; MEDEIROS, L. G. O. ; COZZOLINO, S. M. F. ; NOGUEIRA, N. N. ; MARREIRO, D. N. . PARÂMETROS BIOQUÍMICOS RELATIVOS AO ZINCO EM JOGADORES DE FUTEBOL. 2011. (Apresentação de Trabalho/Congresso).

7. ALMONDES, K. G. S. ; MIACHON, A. A. S. ; CASTRO, A. M. S. ; LEE, M. L. M. ; PIMENTEL, J. A. C. ; COZZOLINO, S. M. F. . Avaliação do estado nutricional relativo ao selênio e sua relação com o estresse oxidativo em pacientes no pós-tratamento da leucemia linfóide aguda. 2010. (Apresentação de Trabalho/Congresso).

8. NOGUEIRA, N. N. ; MATIAS, J P ; BRANDIM, M. R. R. ; MELO, M. T. ; MARREIRO, D. N. ; ALMONDES, K. G. S. ; NOGUEIRA, A. M. T. . PERFIL DE CRESCIMENTO E COMPOSIÇÃO CORPORAL DE ESCOLARES DA REDE PÚBLICA MUNICIPAL DE ENSINO. TERESINA-PI. 2009. (Apresentação de Trabalho/Congresso).

9. NOGUEIRA, N. N. ; ALMONDES, K. G. S. ; MARREIRO, D. N. ; FONTES, A. L. ; CARDOSO, B V S ; RODRIGUES, G P ; SOUSA, A F ; MAIA, C. S. C. ; PARENTE, J. M. L. ; COZZOLINO, S. M. F. . ESTADO NUTRICIONAL RELATIVO AO ZINCO E DA ATIVIDADE DA ENZIMA SUPERÓXIDO DISMUTASE EM PACIENTES COM DOENÇA INFLAMATÓRIA INTESTINAL. 2009. (Apresentação de Trabalho/Congresso).

10. MARREIRO, D. N. ; VERAS, C. M. T. ; PIRES, L. V. ; SOUSA, M. S. B. ; NOGUEIRA, N. N. ; PIMENTEL, J. A. C. ; BUENO, R. B. ; ALMONDES, K. G. S. ; COZZOLINO, S. M. F. . CONCENTRAÇÕES PLASMÁTICAS E ERITROCITÁRIAS DE ZINCO EM MULHERES COM CÂNCER DE MAMA. 2009. (Apresentação de Trabalho/Congresso).

11. ALMONDES, K. G. S. ; AGUIAR, H. D. S. P. ; TEMOTEO, T. L. ; CASTRO, J. C. D. ; LIMA, C. C. ; FERREIRA, L. L. B. ; RODRIGUES, M. P. S. L. ; AMORIM, L. S. . Monitorando a Saúde. 2008. (Apresentação de Trabalho/Outra).

12. ALMONDES, K. G. S. ; SILVA, D. M. C. E. ; CARDOSO, D. E. L. ; MARREIRO, D. N. ; NOGUEIRA, N. N. . DETERMINAÇÃO DO ESTADO NUTRICIONAL RELATIVO AO ZINCO E DA ATIVIDADE DA ENZIMA SUPERÓXIDO DISMUTASE EM PACIENTES PORTADORES DE DOENÇA INFLAMATÓRIA INTESTINAL. 2008. (Apresentação de Trabalho/Seminário).

13. A BRANDIM, M. R. R. ; NOGUEIRA, N N ; ALMONDES, K. G. S. ; NOGUEIRA, A. M. T. ; MARREIRO, D N ; LIMA, G. S. P. ; CARVALHO, A. H. ; CAMPOS, C. M. F. ; MOREIRA-ARAÚJO, R. S. R. ; REIS, E. N. ; CAVALCANTE, C. A. S. C. ; ABREU, C. R. ; FERNANDES, S. H. G. ; REIS, N. S. ; MACHADO, L. M. B. . Avaliação Antropométrica de Adolescentes Matriculados em Escolas Públicas de Teresina-Pi. 2007. (Apresentação de Trabalho/Congresso).

14. NOGUEIRA, N. N. ; ALMONDES, K. G. S. ; MOREIRA-ARAÚJO, R. S. R. ; NOGUEIRA, A. M. T. ; CARVALHO, C M R G ; MARREIRO, D N ; BRANDIM, M. R. R. ; LIMA, G. S. P. ; CARVALHO, A. H. ; CAMPOS, C. M. F. ; MEDEIROS, G. S. ; OLIVEIRA, M. C. G. ; BESERRA, M. L. S. ; REIS, E. N. ; MACHADO, L. M. B. . Prevalência de anemia em escolares da rede pública estadual e municipal de Teresina-Piauí. 2007. (Apresentação de Trabalho/Congresso).

15. AGUiAR, H. D. S. P. ; ALMONDES, K. G. S. ; NOGUEIRA, A. M. T. ; CARVALHO, C M R G ; LIMA, G. S. P. ; TELES, J. B. M. ; SANTOS, M. M. . Consumo Alimentar e Hábitos Sociais de Estudantes de Escolas Públicas Estaduais Localizadas em Teresina-PI. 2007. (Apresentação de Trabalho/Congresso).

16. ALMONDES, K. G. S. ; REIS, E. N. ; VIANA, C. S. ; SILVA, C. P. ; ARAUJO, M. A. M. ; MOREIRA-ARAÚJO, R. S. R. . Formulação de torta doce a base de arroz, soja e goiaba para portadores de doença celíaca. 2007. (Apresentação de Trabalho/Congresso).

17. RODRIGUES, G P ; CARDOSO, B V S ; ALMONDES, K. G. S. ; MARREIRO, D N ; COSTA, I F O ; LEAL, F. L. T. ; SOUSA, A F ; MARTINS, L M ; NOGUEIRA, N N ; CARVALHO, C M R G . Comparação entre a Bioimpedância e o Somatório de Dobras Cutâneas como Métodos de Avaliação da Composição Corporal em Judocas Adolescentes. 2006. 
18. CARDOSO, B V S ; SOARES, F M ; ALMONDES, K. G. S. ; RODRIGUES, G P ; COSTA, I F O ; MARREIRO, D N ; CARVALHO, C M R G ; ROCHA, V S ; NOGUEIRA, N N ; MATIAS, J P . CONCENTRAÇÃO DE ZINCO PLASMÁTICO E CONSUMO ALIMENTAR EM PORTADORES E NÃO-PORTADORES DE CATARATA SENIL. 2006. (Apresentação de Trabalho/Congresso).

19. CARDOSO, B V S ; RODRIGUES, G P ; COSTA, I F O ; MARREIRO, D N ; NOGUEIRA, N. N. ; CARVALHO, C M R G ; ALMONDES, K. G. S. . PERFIL DE MORBIDADE E AVALIAÇÃO DO RISCO PARA O DESENVOLVIMENTO DE DOENÇAS METABÓLICAS E CARDIOVASCULARES EM IDOSOS RESIDENTES EM INSTITUIÇÕES GERIÁTRICAS. 2006. (Apresentação de Trabalho/Congresso).

20. ALMONDES, K. G. S. ; AGUIAR, H. D. S. P. ; CARDOSO, B V S ; OLIVEIRA, L. S. ; FERREIRA, C. O. ; NOGUEIRA, N N . CONSUMO DE ALIMENTOS FORTIFICADOS COM ÁCIDO FÓLICO POR GESTANTES ATENDIDAS EM MATERNIDADE PÚBLICA. 2006. (Apresentação de Trabalho/Congresso).

21. ALMONDES, K. G. S. ; AGUIAR, H. D. S. P. ; FERREIRA, C. O. ; NOGUEIRA, N N ; MARREIRO, D N . Consumo de Alimentos Fonte e Fortificados com Ácido Fólico por Gestantes Atendidas em Maternidade Pública. 2006. (Apresentação de Trabalho/Seminário).

22. ALMONDES, K. G. S. ; LIMA NETO, J. S. ; AGUIAR, H. D. S. P. ; CAVAlCANTE, T. M. A. ; FERREIRA, M. S. C. . Monitoramento da Norma Brasileira de Comercialização de Alimentos para Lactentes e Crianças de Primeira Infância, Bicos , Chupetas e Mamdeiras em Diversos Estabelecimentos de Teresina-PI. 2006. (Apresentação de Trabalho/Conferência ou palestra).

\section{Eventos}

\section{Participação em eventos, congressos, exposições e feiras}

1. $12^{\circ}$ Congresso Nacional da Sociedade Brasileira de Alimentação e Nutrição. Perfil Nutricional , socioeconômico e estilo de vida de estudantes universitários. 2013. (Congresso).

2. XVI Congresso Brasileiro de Nutrogia, XVII Simpósio de Obesidade e Síndrome Metabólica. 2012. (Congresso).

3. ENCONTRO SBAN: NUTRIÇÃO CĹNICA.AVALIAÇÃO DO ESTADO NUTRICIONAL RELATIVO AO SELÊNIO, DE ENZIMAS ANTIOXIDANTES E DO DANO AO DNA EM PACIENTES NO PÓS-TRATAMENTO DA LEUCEMIA LINFÓIDE AGUDA. 2012. (Encontro).

4. $11^{\circ}$ Congresso Nacional da Sociedade Brasileira de Alimentação e Nutrição - SBAN. TEOR DE SELÊNIO PLASMÁTICO E ERITROCITÁRIO E SUA CORRELAÇÃO COM A ENZIMA GPX EM PACIENTES NO PÓS-TRATAMENTO DA LEUCEMIA LINFÓIDE AGUDA. 2011. (Congresso).

5. XV Congresso Brasileiro de Obesidade e Síndrome Metabólica; XVI Simpósio de Obesidade e Síndrome Metabólica; IX Annual Meeting International Colleges for Advancements of Medical Nutrition; VII Fórum de Direito Humano de Alimentação Adequada. 2011. (Congresso).

6. XIV Congresso Brasileiro de Nutrologia. Avaliação do estado nutricional relativo ao selênio e sua relação com o estresse oxidativo em pacientes no pós-tratamento da leucemia linfóide aguda. 2010. (Congresso).

7. II Simpósio Internacional Unilever. 2010. (Simpósio).

8. IV Jornada de Atualização em Nutrição Pediátrica. 2010. (Outra).

9. $10^{\circ}$ Congresso Nacional da Sociedade Brasileira de Alimentação e Nutrição - Dos Genes à Coletividade. 2009. (Congresso).

10. VII Congresso Paulista de Nutrição Clínica; VI Congresso Paulista de Nutrição Humana; I Congresso Paulista de 
Nutrição Esportiva. 2009. (Congresso).

11. Perspectivas em Nutrição na Era Pós-Genoma. 2009. (Simpósio).

12. Pipetas - Informações e Cuidados Gerais. 2009. (Outra).

13. Workshop latino-americano; Ações e oportunidades na área de fortificação de alimentos. 2009. (Outra).

14. I Congresso Materno-Infantil e Adolescente. 2008. (Congresso).

15. Workshop: O Melhor Remédio é a Informação. Monitorando a Saúde. 2008. (Outra).

16. 90 Congresso Nacional da Sociedade Brasileira de Alimentação e Nutrição - SBAN. 2007. (Congresso).

17. IV Simpósio Piauiense de Saúde e Nutrição. 2007. (Simpósio).

18. III Conferência Estadual de Segurança Alimentar e Nutricional. 2007. (Encontro).

19. Reunião de Apresentação dos Resultados do $1^{0}$ Monitoramento Oficial da Norma Brasileira de Comercialização de Alimentos para Lactentes e Crianças na Primeira Infância, Mamadeira, Bicos e Chupetas - NBCAL. 2007. (Encontro).

20. VII Congresso Norte-Nordeste de nutrição Parenteral e Enteral, VII Congresso Norte-Nordeste de Nutrição Clínica, I Simpósio de Nutrição em Pediatria e I Simpósio de Nutrição Esportiva.. 2006. (Congresso).

21. $3^{\circ}$ Seminário de Iniciação à Pesquisa Científica. 2006. (Seminário).

22. I Jornada de Iniciação Científica e I Mostra de Pesquisa da Pós-Graduação. 2006. (Oficina).

23. I Jornada de Iniciação Científica I Mostra de Pesquisa da Pós-Graduação. Monitoramento da Norma Brasileira de Comercialização de Alimentos para Lactentes e Crianças de Primeira Infância, Bicos , Chupetas e Mamdeiras em Diversos Estabelecimentos de Teresina-PI. 2006. (Outra).

24. III Simpósio Piauiense de Saúde, Alimentação e Nutrição. 2005. (Simpósio).

25. Workshop de Nutrição. 2005. (Outra).

26. Ação Global. 2005. (Outra).

27. Seminário: Saúde em Pauta - A Interdisciplinaridade em Busca do Equilíbrio Nutricional. 2004. (Seminário).

\section{Organização de eventos, congressos, exposições e feiras}

1. ALMONDES, K. G. S. ; AGUIAR, H. D. S. P. ; DRUMOND, Marcela Rosado ; TEMOTEO, T. L. ; LIMA, C. C. ; CASTRO, J. C. D. ; FERREIRA, M. S. C. . Workshop: O melhor remédio é a informação. 2008. (Outro). 
Fanus - Sistema Administrativo da Pós-Graduação

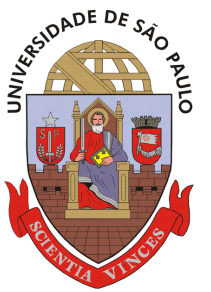

\author{
Universidade de São Paulo \\ Faculdade de Ciências Farmacêuticas \\ Documento sem validade oficial
}

FICHA DO ALUNO

9132 - 6369527/2 - Kaluce Gonçalves de Sousa Almondes

$\begin{array}{ll}\text { Email: } & \text { kaluce@usp.br } \\ \text { Data de Nascimento: } & 18 / 12 / 1984 \\ \text { Cédula de Identidade: } & \text { RG - 2.211.665 - PI } \\ \text { Local de Nascimento: } & \text { Estado do Piauí } \\ \text { Nacionalidade: } & \text { Brasileira } \\ \text { Graduação: } & \text { Nutricionista - Universidade Federal do Piauí - Piauí - Brasil - } 2008 \\ \text { Mestrado: } & \text { Mestre em Ciências - Área: Nutrição Experimental - Faculdade de Ciências } \\ & \text { Farmacêuticas - Universidade de São Paulo - São Paulo - Brasil - } 2011\end{array}$

\section{Curso:}

Programa:

Área:

Data de Matrícula:

Início da Contagem de Prazo:

Data Limite para o Depósito:

Orientador:

Orientador:

Proficiência em Línguas:

Data de Aprovação no Exame de Qualificação:

Data do Depósito do Trabalho:

Título do Trabalho:

Data Máxima para Aprovação da

Banca:

Data de Aprovação da Banca:

Data Máxima para Defesa:

Data da Defesa:

Resultado da Defesa:

Histórico de Ocorrências:

\section{Doutorado}

Ciência dos Alimentos

Nutrição Experimental

26/03/2012

26/03/2012

$28 / 03 / 2016$

Prof(a). Dr(a). Thomas Prates Ong - 26/03/2012 até 04/09/2012. Email: tong@usp.br

Prof(a). Dr(a). Silvia Maria Francis cato Cozzolino - 05/09/2012 até o presente.Email:smfcozzo@usp.br

Inglês, Aprovado em 26/03/2012

Aprovado em 21/05/2014

Aluno matriculado no Regimento da Pós-Graduação USP (Resolução nº 5473 em vigor de 18/09/2008 até 19/04/2013).

Última ocorrência: Matrícula de Acompanhamento em 05/02/2015

Impresso em: 30/04/2015 18:06:51 


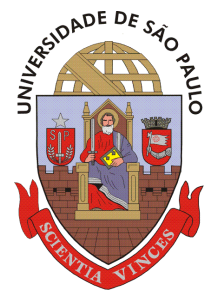

\section{Universidade de São Paulo \\ Faculdade de Ciências Farmacêuticas \\ Documento sem validade oficial}

FICHA DO ALUNO

\section{2 - 6369527/2 - Kaluce Gonçalves de Sousa Almondes}

\begin{tabular}{|c|c|c|c|c|c|c|c|c|c|}
\hline Sigla & Nome da Disciplina & Início & Término & $\begin{array}{l}\text { Carga } \\
\text { Horária }\end{array}$ & Cred. & Ereq. & Conc. & Exc. & Situação \\
\hline $\begin{array}{l}\text { FBA5712- } \\
5 / 4\end{array}$ & Fisiologia da Nutrição I & $16 / 04 / 2012$ & $27 / 05 / 2012$ & 90 & 6 & 100 & $A$ & $\mathrm{~N}$ & Concluída \\
\hline $\begin{array}{c}\text { HEP5762- } \\
5 / 2\end{array}$ & $\begin{array}{l}\text { Estatística não Paramétrica (Faculdade } \\
\text { de Saúde Pública - Universidade de } \\
\text { São Paulo) }\end{array}$ & $22 / 05 / 2012$ & 03/07/2012 & 60 & 4 & 100 & A & $\mathrm{N}$ & Concluída \\
\hline $\begin{array}{c}\mathrm{NHA} 5705- \\
2 / 4\end{array}$ & $\begin{array}{l}\text { Fundamentos da Biologia Molecular } \\
\text { Aplicados à Nutrição Humana (Curso } \\
\text { Interunidades: Nutrição Humana } \\
\text { Aplicada - Universidade de São Paulo) }\end{array}$ & $28 / 05 / 2012$ & 01/07/2012 & 60 & 4 & 90 & A & $\mathrm{N}$ & Concluída \\
\hline $\begin{array}{c}\text { HEP5743- } \\
6 / 2\end{array}$ & $\begin{array}{l}\text { Modelos de Regressão Aplicados em } \\
\text { Epidemiologia I (Faculdade de Saúde } \\
\text { Pública - Universidade de São Paulo) }\end{array}$ & $14 / 08 / 2012$ & $18 / 09 / 2012$ & 60 & 4 & 100 & $A$ & $\mathrm{~N}$ & Concluída \\
\hline $\begin{array}{c}\text { FBA } 5751- \\
1 / 1\end{array}$ & $\begin{array}{l}\text { Minerais em Nutrição: Distribuição } \\
\text { Compartimental e Mecanismos de } \\
\text { Regulação de sua Homeostase }\end{array}$ & $11 / 09 / 2012$ & $01 / 10 / 2012$ & 30 & 2 & 100 & A & $\mathrm{N}$ & Concluída \\
\hline $\begin{array}{c}\text { HEP5763- } \\
4 / 2\end{array}$ & $\begin{array}{l}\text { Modelos de Regressão Aplicados em } \\
\text { Epidemiologia II (Faculdade de Saúde } \\
\text { Pública - Universidade de São Paulo) }\end{array}$ & $25 / 09 / 2012$ & $06 / 11 / 2012$ & 60 & 4 & 100 & A & $\mathrm{N}$ & Concluída \\
\hline $\begin{array}{c}\text { HEP5764- } \\
4 / 2\end{array}$ & $\begin{array}{l}\text { Modelos de Regressão Aplicados em } \\
\text { Epidemiologia III (Faculdade de Saúde } \\
\text { Pública - Universidade de São Paulo) }\end{array}$ & 06/11/2012 & $11 / 12 / 2012$ & 60 & 4 & 100 & A & $\mathrm{N}$ & Concluída \\
\hline $\begin{array}{c}\text { HNT5768- } \\
1 / 1\end{array}$ & $\begin{array}{l}\text { Modelos Lineares Generalizados } \\
\text { (Faculdade de Saúde Pública - } \\
\text { Universidade de São Paulo) }\end{array}$ & $27 / 09 / 2013$ & $31 / 10 / 2013$ & 30 & 2 & 100 & A & $\mathrm{N}$ & Concluída \\
\hline
\end{tabular}

\begin{tabular}{|l|c|c|c|}
\hline \hline & \multicolumn{2}{|c|}{ Créditos mínimos exigidos } & Créditos obtidos \\
\hline & Para exame de qualificação & Para depósito de tese & \\
\hline Disciplinas: & 0 & 20 & 30 \\
\hline Estágios: & 0 & 20 & 30 \\
\hline Total: & 0 & 20 \\
\hline
\end{tabular}

Créditos Atribuídos à Tese: 167

\section{Conceito a partir de 02/01/1997:}

A - Excelente, com direito a crédito; B - Bom, com direito a crédito; C - Regular, com direito a crédito; $\mathrm{R}$ - Reprovado; $\mathrm{T}$ - Transferência.

Um(1) crédito equivale a 15 horas de atividade programada.

Última ocorrência: Matrícula de Acompanhamento em 05/02/2015

Impresso em: 30/04/2015 18:06:51 